\title{
SPATIAL AND TEMPORAL VARIABILITY OF DISSOLVED ALUMINUM AND \\ MANGANESE IN SURFACE WATERS OF THE NORTHERN GULF OF ALASKA
}

By

Anna R. Y. Kandel

A Thesis Submitted in Partial Fulfillment of the Requirements

for the Degree of

Master of Science

in

Oceanography

University of Alaska Fairbanks

December 2020

Dr. Ana Aguilar-Islas, Committee Chair

Dr. Seth Danielson, Committee Member

Dr. Gwenn Hennon, Committee Member

Dr. Russ Hopcroft, Chair

Department of Oceanography

Dr. S. Bradley Moran, Dean

College of Fisheries and Ocean Sciences

Dr. Richard Collins

Director of the Graduate School 


\begin{abstract}
The Northern Gulf of Alaska (NGA) shelf is a productive high-latitude environment where nutrient dynamics are greatly impacted by the seasonal variability in freshwater input and water column mixing. Iron is a key nutrient on the NGA shelf that directly modulates primary production, but inputs are difficult to quantify due to high biological uptake and control exerted by Fe-binding organic ligands. Other lithogenic elements such as aluminum and manganese have the same sources as iron (rivers and sediment) and similar abiotic removal via particle scavenging, but exhibit quasi-conservative behavior in seawater allowing for their use as tracers of these sources. Thus, Al and Mn distributions can help provide insight into iron inputs and the relative importance of various mechanisms influencing nutrient dynamics in the NGA.

The data are derived from spring, summer, and fall NGA LTER (long term ecological research) cruises from 2018 and 2019 that included a focused five-day Copper River plume study, several surface transects from Kayak Island to Kodiak Island, and vertical profiles at several locations sparsely distributed throughout the shelf. We find that seasonal patterns in the surface concentrations of $\mathrm{dMn}$ and $\mathrm{dAl}$ mirrored annual glacial melt cycles, with the lowest values observed in spring and higher values in summer and fall. Spatial patterns were also apparent as both metals tended to be lower offshore than inshore, and were also lower overall (by 1-2 orders of magnitude) on transects further from the outflow of the Copper River, a major source of freshwater to the NGA. Extremely high concentrations in the Copper River plume ( $\leq 1395 \mathrm{nM} \mathrm{dAl}, \leq 128 \mathrm{nM} \mathrm{dMn})$ and strong correlations with salinity $(\mathrm{p}<0.0001)$ highlight their quasi-conservative nature, and their usefulness as tracers of freshwater input, which helps inform iron inputs from this source. Enhanced $\mathrm{dAl}$ and $\mathrm{dMn}$ concentrations within nepheloid layers in subsurface waters indicate regions where a sedimentary source of iron is likely to be important. Residence times for $\mathrm{dAl}$ and dMn in surface waters over the NGA shelf were estimated to be 31 days (dAl) and 42 days ( $\mathrm{dMn}$ ) on average based on summer and fall data from both years.
\end{abstract}




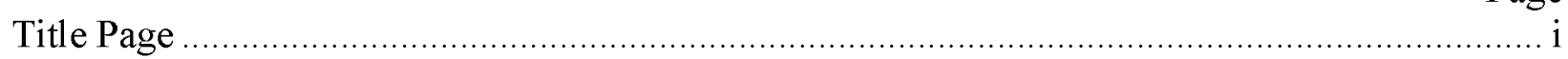

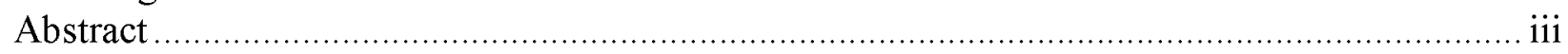

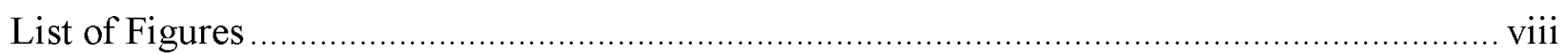

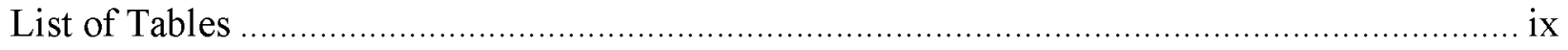

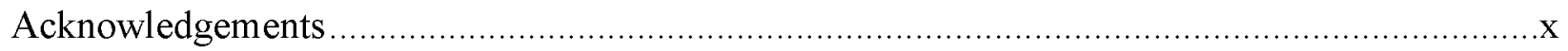

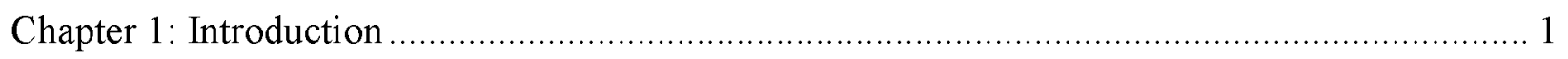

1.1 Contribution of this study to the NGA Long-Term Ecological Research Site ................. 1

1.2 Dissolved aluminum in the oceans ................................................................. 1

1.3 Dissolved manganese in the oceans .................................................................. 4

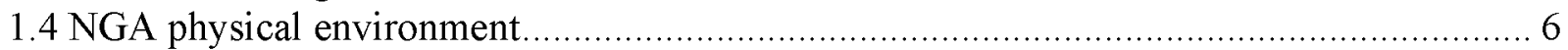

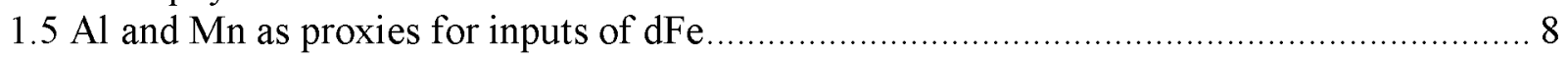

Chapter 2: Spatial and temporal variability of dissolved aluminum and manganese in surface waters of the northern Gulf of Alaska .......................................................................... 9

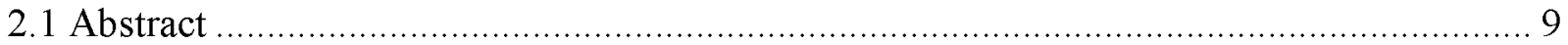

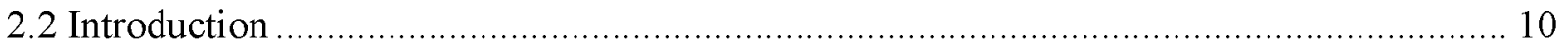

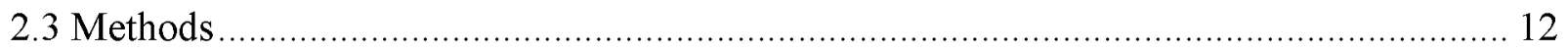

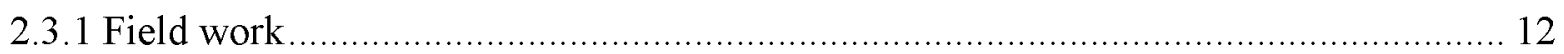

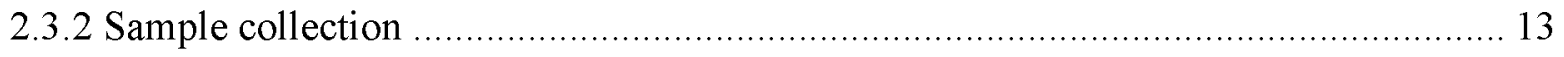

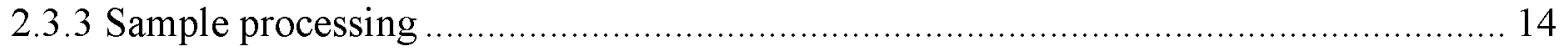

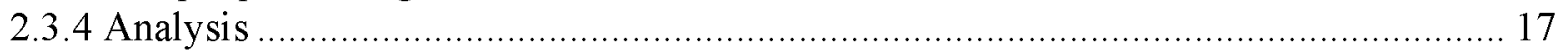

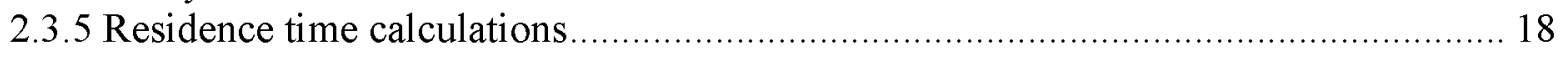

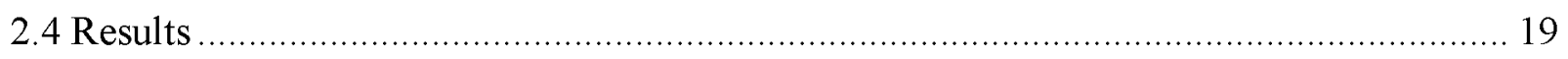

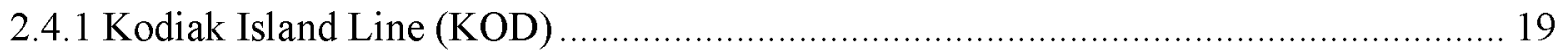

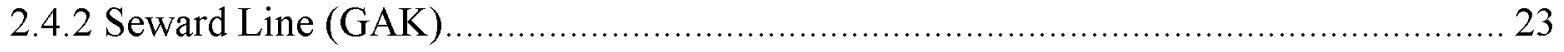

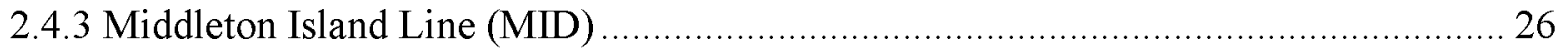

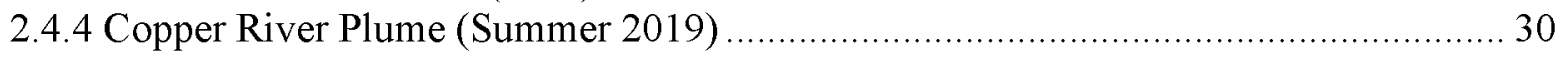

2.4.5 Residence Times.......................................................................................... 34

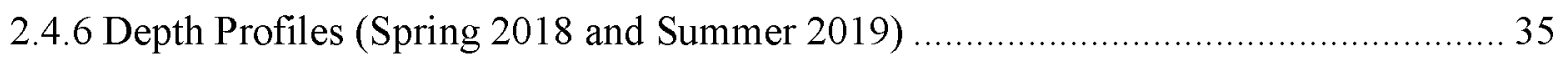

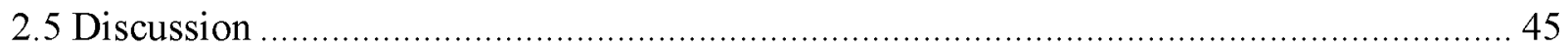

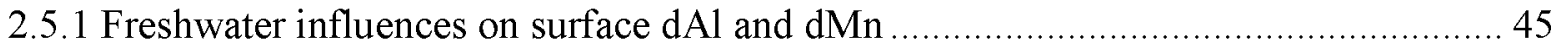

2.5.2 The influence of bathymetric features on $\mathrm{dAl}$ and $\mathrm{dMn} \ldots \ldots \ldots \ldots \ldots \ldots \ldots \ldots \ldots \ldots \ldots . \ldots \ldots$

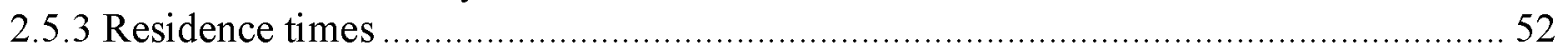

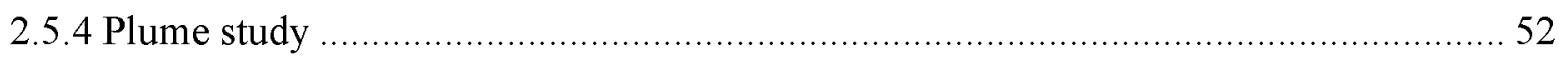

2.5.5 Dissolved $\mathrm{Al}$ and $\mathrm{Mn}$ as tracer of the $\mathrm{dFe}$ input into the NGA ............................. 56

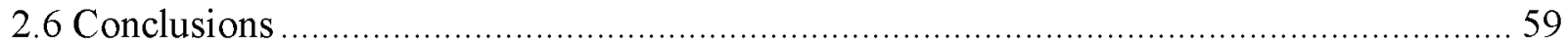

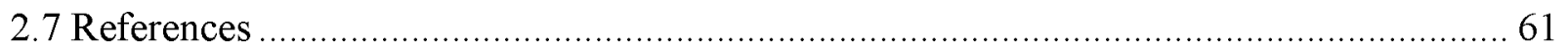

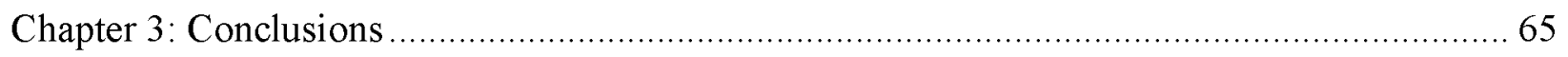

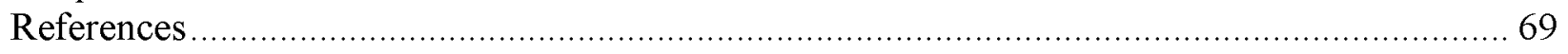




\section{List of Figures}

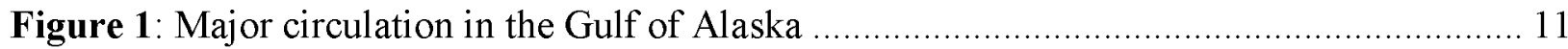

Figure 2: Offline system for preconcentrating $\mathrm{dAl}$ and $\mathrm{dMn}$ in seawater samples................. 16

Figure 3: Map of sampling sites in the Northern Gulf of Alaska ........................................... 19

Figure 4: a) Surface temperatures and b) surface salinity values along the KOD Line............. 20

Figure 5: a) dAl and b) dMn vs. latitude along the KOD Line ......................................... 21

Figure 6: a) dAl and b) dMn vs. salinity along the KOD Line ...................................... 21

Figure 7: Map with surface dMn values along the KOD Line (fall 2018) .............................. 22

Figure 8: Map with surface dMn values along the KOD Line (spring 2019) ....................... 23

Figure 9: a) Surface temperatures and b) surface salinity values along the Seward Line .......... 24

Figure 10: a) dAl and b) dMn vs. latitude along the Seward Line....................................... 24

Figure 11: Map with surface dMn values along the Seward Line (spring 2019) ................... 25

Figure 12: a) dAl and b) dMn vs. salinity along the Seward Line ....................................... 26

Figure 13: a) Surface temperatures and b) surface salinity values along the MID Line............ 27

Figure 14: a) dAl and b) dMn vs. latitude along the MID Line in the Northern Gulf of Alaska. 28

Figure 15: Maps with surface dMn values along the MID Line (summer 2019 and fall 2019) .. 28

Figure 16: a) dAl and b) dMn vs. salinity along the MID Line .......................................... 29

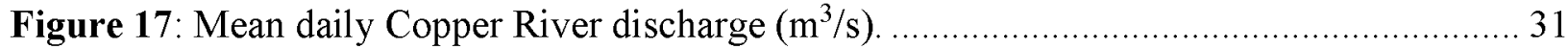

Figure 18: a) Surface temperature and b) surface salinity (both from underway data) during the 2019 plume study in the Northern Gulf of Alaska............................................ 31

Figure 19: Maps of surface a) dAl and b) dMn for the 2019 plume study ............................. 32

Figure 20: dAl vs. salinity for the Copper River plume study (summer 2019) ..................... 33

Figure 21: dMn vs. salinity for the Copper River plume study (summer 2019)..................... 34

Figure 22: a) Temperature, b) salinity, and c) transmissivity for KOD5 ............................... 36

Figure 23: dAl and dMn profiles for KOD5 ......................................................... 36

Figure 24: a) Temperature, b) salinity, and c) transmissivity at GAK 1 ................................. 37

Figure 25: dAl and dMn profiles for GAK1 .......................................................... 38

Figure 26: a) Temperature, b) salinity, and c) transmissivity at GAK5 from CTD casts in the Northern Gulf of Alaska on 5/3/18 and 7/13/19 .............................................. 39

Figure 27: $\mathrm{dAl}$ and dMn profiles for GAK5 .................................................................... 39

Figure 28: a) Temperature, b) salinity, and c) transmissivity at MID2 from CTD casts in the Northern Gulf of Alaska on 4/26/18 and 7/1/19.................................................. 40

Figure 29: $\mathrm{dAl}$ and dMn profiles for MID2 ............................................................ 41

Figure 30: a) Temperature, b) salinity, and c) transmissivity at MID5 .............................. 42

Figure 31: dAl and dMn profiles for MID5 .............................................................. 42

Figure 32: a) Temperature, b) salinity, and c) transmissivity at PWS2 ............................. 44

Figure 33: dAl and dMn profiles for PWS2 .......................................................... 44

Figure 34: dMn vs. dAl along the KOD Line ............................................................ 48

Figure 35: dMn vs. dAl along the Seward Line .............................................................. 48

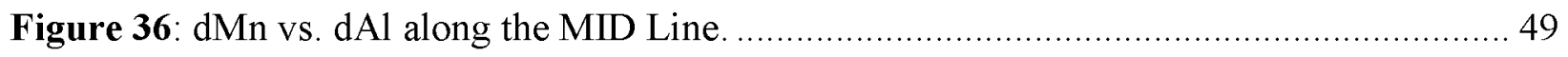

Figure 37: Major bathymetric features along the Northern Gulf of Alaska shelf..................... 50 
Figure 38: dAl vs. salinity in GOA freshwater plumes ................................................... 53

Figure 39: dMn vs. dAl for the Copper River plume study ................................................. 54

Figure 40: Satellite image of the Copper River plume in the Northern Gulf of Alaska taken on $6 / 29 / 19$ overlaid with surface dAl values ....................................................... 56

Figure 41: dFe vs. a) dAl and b) dMn in the Copper River plume study ............................. 58

Figure 42: $\mathrm{dFe} / \mathrm{dMn}$ ratio plotted as a function of $\mathrm{dMn}$ for the Copper River plume study....... 59

Figure 43: Schematic describing how to interpret data plotted as dMn vs. dFe/dMn .............. 59

Figure 44: Diagram illustrating processes affecting $\mathrm{dAl}, \mathrm{dMn}$, and $\mathrm{dFe}$ distributions throughout the water column.

\section{List of Tables}

Table 1: Cruise vessels, dates, and IDs

Page

Table 2: Figures of merit for both methods of sample processing

Table 3: Dissolved Mn values obtained for CASS-6 and NASS-7 reference materials

Table 4: Residence times calculated for $\mathrm{dAl}$ and $\mathrm{dMn}$ 


\section{Acknowledgements}

First and foremost I would like to thank my advisor, Dr. Ana Aguilar-Islas, for her guidance and support throughout the past two years, and especially during the writing process for always being thorough and challenging me to hold myself to a higher standard of work. I have learned a lot from her, both at sea and on land. I would like to thank my committee members, Drs. Gwenn Hennon and Seth Danielson for their continued support and thoughtful feedback throughout the whole process. Thank you as well to Mette Kaufman, who helped me with the ICP-MS almost every time I analyzed samples, and whose general presence made long hours a windowless lab far more bearable. I would like to thank my lab mates in the Aguilar-Islas lab, Emily Ortega and Channing Bolt (and Jasper), for both work-related and personal support. On a similar note I would also like to thank all the friends and colleagues I have met through the NGA LTER cruises, in particular, Hana Busse (my personal R coder), Rachel Potter (computer wizard), Kira Monell (sass master), and Kerri Fredrickson (the best program manager/cowboy out there). I would also like to thank the captains and crews of the R/V Sikuliaq and M/V Tiglax, for help conducting research at sea and generally putting up with us. I would like to acknowledge funding from University of Alaska Fairbanks (College of Fisheries and Ocean Sciences and College of Natural Science and Mathematics) as well as the NGA LTER grant (National Science Foundation award 1656070), and finally I would like to thank my family and all my nonoceanography friends for their continued love and emotional support. 
Chapter 1: Introduction

1.1 Contribution of this study to the NGA Long-Term Ecological Research Site

The Northern Gulf of Alaska (NGA) was established as one of NSF's LTER (long term ecological research) sites in fall 2017, with the overarching goal of investigating the resilience of the NGA ecosystem to environmental disturbances (Hopcroft et al. 2016). The project's initial core hypotheses are centered around nutrient supply and primary and secondary production. Gaining insight into nutrient cycling, including the important micronutrient dissolved iron (dFe), in the NGA contributes to the investigations of these core hypotheses. Here we use dissolved aluminum ( $\mathrm{dAl})$ and manganese $(\mathrm{dMn})$ as quasi-conservative tracers of riverine Fe input to gain insight into input variability of this major source of dFe in the NGA, as previous work has established the viability of both $\mathrm{dAl}$ and $\mathrm{dMn}$ as tracers of freshwater inputs in other shelf areas (Ren et al. 2006, Aguilar-Islas and Bruland 2006). Further, the wide range of concentrations exhibited by both $\mathrm{dAl}$ and $\mathrm{dMn}$ as a result of the NGA being a highly complex environment exemplifies the extreme variability experienced by this ecosystem, with $\mathrm{dAl}$ and $\mathrm{dMn}$ concentrations ranging over 4 orders of magnitude. This is the second study reporting $\mathrm{dAl}$ values in this region and the first to investigate temporal variability, both seasonal and interannual. This is the first study reporting dMn values in the NGA.

\subsection{Dissolved aluminum in the oceans}

Aluminum is a lithogenic element that constitutes on average $8.23 \%$ of the Earth's crust by weight (Taylor 1964, Wedepohl 1995) making it the third most abundant element in the crust, but in seawater it is only present in the dissolved phase at nanomolar concentrations. In surface seawater, dissolved aluminum (dAl) mainly exists as $\mathrm{Al}(\mathrm{OH})_{4}{ }^{-}$due to the slightly basic $\mathrm{pH}$, with the other species $\mathrm{Al}(\mathrm{OH})_{2}{ }^{+}$and $\mathrm{Al}(\mathrm{OH})_{3}$ present in smaller fractions (Byrne et al. 1988). Dominant sources of $\mathrm{Al}$ to surface waters are riverine input and aeolian dust deposition (e.g., Hydes 1979, Orians and Bruland 1986). It has been shown, however, that abiotic estuarine removal processes keep fluvial $\mathrm{dAl}$ inputs confined to nearshore areas (e.g. Hydes and Liss 1977) and that after dissolution, aeolian input is the primary source of $\mathrm{dAl}$ in open ocean surface waters (Maring and Duce 1987, Orians and Bruland 1986). The subtropical Atlantic Ocean off the western coast of Africa, an area that receives high dust input from the Sahara Desert (14 $\mathrm{g} \mathrm{m}^{2}$ 
$\mathrm{yr}^{-1}$ reported by Jahn, et al. 1996), has exhibited surface dAl values as high as $86 \mathrm{nM}$ (Measures and Brown 1996). In low dust areas such as the northern Pacific, dAl in offshore waters is generally on the order of $1 \mathrm{nM}$ or less (Orians and Bruland 1985). Higher dAl concentrations have been observed in nearshore regions impacted by river input, such as the temperate river plumes of the Columbia River plume (maximum of $40 \mathrm{nM}$, Brown and Bruland 2009) and the Yangtze River plume (maximum of $60 \mathrm{nM}$, Ren et al. 2006). Exceedingly high dAl values have been observed in glacial river plumes, such as the Copper River Plume (maximum of $600 \mathrm{nM}$, Brown et al. 2010), and the Alsek River plume (maximum 1200 nM, Brown et al. 2010).

The residence time of $\mathrm{dAl}$ in surface waters is relatively short, ranging from days in coastal waters highly impacted by glacial river input (Brown et al. 2010) to 4 years in offshore waters of the North Pacific where dust input is minimal (Orians and Bruland 1986). Passive adsorption onto particles is a major sink of dAl in surface waters (Moore and Millward 1984). Particle flux as measured by ${ }^{234} \mathrm{Th}$ has been shown to scale linearly with primary production (Coale and Bruland 1985) leading to increased scavenging and lower $\mathrm{dAl}$ residence times in surface waters in areas or seasons with high productivity. Due to the high particle reactivity of $\mathrm{dAl}$, it often exhibits a scavenged-type profile throughout the water column. This entails, due to external inputs, higher concentrations at the surface that decrease to a minimum at intermediate depths due to particle scavenging, and then an increase at depth often due to reduction of suspended particles via remineralization and/or re-dissolution from particles resuspended from bottom sediments (Boyle et al. 1977). For dAl specifically, particle adsorption is reversible and laboratory experiments have shown that it is pressure-dependent (Moore and Millward 1984). Thus, while particles remove $\mathrm{dAl}$ from the upper water column, desorption under high pressure may also be partially responsible for the increase in dAl observed at depth. In coastal, shelf, and slope regions, tidal currents may also generate barotropic flows and internal waves that enhance vertical mixing (Nash and Mourn 2005). Vertical mixing contributes to increased dAl throughout the water column, mixing high $\mathrm{dAl}$ values to the interior either from the bottom or from the surface depending on the mixing and the water column hydrographic structure.

In addition to passive adsorption onto sinking particles, $\mathrm{dAl}$ can also be removed from surface waters via incorporation into diatom frustules. X-ray spectroscopy has suggested that aluminum is incorporated into the frustule structure during biosynthesis rather than contaminating the frustule after formation (Gehlen et al. 2002). Aluminum uptake by diatoms 
also has implications for the use of sedimentary biogenic silica as a proxy for environmental conditions, as the inclusion of aluminum in the frustules can potentially decrease the solubility of silica at the bottom water-sediment interface (Gehlen et al. 2002). It has also been suggested that a secondary (post-mortem) aluminum uptake process occurs when the diatoms die and settle to the seafloor, where aluminum is present in clay minerals. Incubations of freshly harvested diatom frustules indicated that some number of reactive sites exists on the surface of each frustule and ultimately determines a maximum amount of $\mathrm{Al}$ that can be taken up (Koning et al. 2007). Thus, the effect of primary productivity on $\mathrm{dAl}$ distributions can be indirect, by interactions with diatom frustules.

In general, the uptake of aluminum by diatoms contributes to coupling of the $\mathrm{Al}$ and $\mathrm{Si}$ cycles in seawater. In addition to removing dAl from surface waters, nearly all ( $\sim 97 \%)$ biogenic silica produced in the surface layer is dissolved as it falls through the water column, so the fraction that actually reaches the seafloor can be quite low (Ren et al. 2013). It has been suggested that when the frustules dissolve, the release of both $\mathrm{Si}$ and $\mathrm{Al}$ partially links the cycling of the two elements (Middag et al. 2009). In the open ocean, this process could act as an additional source of $\mathrm{dAl}$ throughout the subsurface water column. The crustal aluminosilicate materials, however, that enter surface waters as dust particles exhibit Al:Si ratios around 1:3 (Taylor 1964) as compared to ratios on the order of 1:400 (Gehlen et al. 2002) in biogenic silica. Thus, the presence of solubilized crustal material, either due to local sources or advection can increase the Al:Si ratio in suspended particles within the water column. Silicon itself constitutes an average of about $28 \%$ of the continental crust by weight (Taylor 1964, Wedepohl 1995), but unlike $\mathrm{Al}$ its main source to the ocean is rivers as $\mathrm{Si}$ does not experience estuarine/coastal removal processes (DeMaster 2001) resulting in $\mathrm{dAl}: \mathrm{H}_{4} \mathrm{SiO}_{4}$ ratios in river plumes ranging from 1:30 in glacial rivers (calculated from data presented in Brown et al. 2010) to 1:5000 in temperate rivers (calculated from data presented in Brown and Bruland 2009). Thus, the relationship between $\mathrm{dAl}$ and $\mathrm{H}_{4} \mathrm{SiO}_{4}$ in coastal waters impacted by rivers appears to vary depending on rock weathering mechanisms (e.g., chemical vs. physical). However, in the open ocean diatoms are the key linkage between the two cycles, and a relationship between $\mathrm{Al}$ and $\mathrm{Si}$ is likely to be stronger in areas with high diatom activity and low surface input of both elements (Middag et al. 2009). 


\subsection{Dissolved manganese in the oceans}

Manganese is the twelfth most abundant element in the Earth's crust with an average concentration of about $716 \mathrm{ppm}$ (Wedepohl 1995), but similar to aluminum, dissolved manganese $(\mathrm{dMn})$ is present in the ocean in nanomolar and subnanomolar concentrations. In seawater the naturally occurring forms of manganese are insoluble $\mathrm{Mn}(\mathrm{III})$ and $\mathrm{Mn}(\mathrm{IV})$ oxides, while $\mathrm{dMn}$ is comprised of soluble Mn(II) ions as well as $\mathrm{Mn}$ (III) bound by organic ligands (Mn(III)-L). Also referred to as reactive soluble $\mathrm{Mn}, \mathrm{Mn}(\mathrm{III})-\mathrm{L}$ can act as both an oxidizing and reducing agent in Mn cycling. In the northwest Atlantic Ocean Mn(III)-L has been observed to account for up to $45 \%$ of total $\mathrm{dMn}$, and this percentage tended to be higher in mid and deep waters than at the surface (Jones et al. 2020). In some ways the behavior of $\mathrm{dMn}$ throughout the water column mirrors that of $\mathrm{dAl}$. Similar to $\mathrm{dAl}, \mathrm{dMn}$ can also be scavenged from surface waters by sinking particles, such that $\mathrm{dMn}$ concentrations typically decrease quickly below the surface layer. In shelf regions the loss of $\mathrm{dMn}$ by particle scavenging may be partially balanced by input from continental sediments and horizontal advection (Landing and Bruland 1980, Martin and Knauer 1984). Additionally, vertical dMn profiles tend to exhibit surface maxima due to external inputs from rivers and dust as well as photoreduction of manganese oxides (Sunda and Huntsman 1988), and deep maxima due to hydrothermal inputs and sediment resuspension (Landing and Bruland 1980). Unlike aluminum, however, throughout the water column manganese undergoes redox reactions that affect its partitioning between dissolved and particulate phases in the ocean. $\mathrm{Mn}(\mathrm{II})$ is thermodynamically unstable and prone to oxidation, but the kinetics of the oxidation process are slow and thus allow Mn(II) to exist in oxic waters (Sunda and Huntsman 1994). Mn(II) oxidation may be accelerated via microbial mediation, which decreases surface $\mathrm{dMn}$, but these microbes can also experience photoinhibition at high levels of sunlight, which favor a dMn surface maximum (Sunda and Huntsman 1988). In general, the oxidation of $\mathrm{dMn}$ to $\mathrm{Mn}(\mathrm{IV})$ and the sinking of the manganese oxide particles contributes to the decrease of $\mathrm{dMn}$ with depth in addition to scavenging by other types of particles.

Dissolved manganese in the surface waters of the North Pacific has been shown to vary from about 0.1-10 nM (Zheng et al. 2019, Sim and Orians 2019), while in the Atlantic Ocean surface concentrations range from $<0.1-4 \mathrm{nM}$ (Hatta, et al. 2015). Surface values of dMn have also been shown to be significantly higher in freshwater plumes and influenced by tidal mixing. For example, values as high as $230 \mathrm{nM}$ were observed within a near-field plume of the Columbia 
River (Aguilar-Islas and Bruland 2006) and this exceedingly high surface $\mathrm{dMn}$ value was observed during a spring tide, while $\mathrm{dMn}$ values closer to $60 \mathrm{nM}$ were observed in the same area during a neap tide (Aguilar-Islas and Bruland 2006). This difference was ascribed to stirring by stronger tidal currents during the spring tide that enhanced particle resuspension and the subsequent photoreduction of suspended particulate manganese.

Dissolved $\mathrm{Mn}$, similar to dissolved iron ( $\mathrm{dFe}$ ), is an essential micronutrient for phytoplankton. It is required in photosystem II and it acts as a cofactor in various enzymes. In some cases, $\mathrm{Mn}^{2+}$ ions can be used as an alternative to $\mathrm{Mg}^{2+}$ to activate certain enzymes (Raven 1990). Photosynthesis requires $\mathrm{dMn}$ for redox reactions that occur in Photosystem II between water molecules and oxidizing agents (Raven 1990). Another important biological function of $\mathrm{dMn}$ is in superoxide dismutase (SOD) that uses metal cofactors and transforms reactive oxygen species into $\mathrm{O}_{2}$ and $\mathrm{H}_{2} \mathrm{O}_{2}$ in organisms such as marine diatoms. SOD can use a variety of metals such as $\mathrm{Fe}, \mathrm{Mn}, \mathrm{Cu}, \mathrm{Zn}$, and $\mathrm{Ni}$, and some species of diatom such as Thalassiosira pseudonana have shown a preference for MnSOD (Wolfe-Simon 2006). When dFe is limiting such as in high-nutrient, low-chlorophyll (HNLC) regions, the production of reactive oxygen species increases and diatom incubation experiments have shown that $\mathrm{Mn}$ requirements can increase up to threefold (Peers and Price 2004). Thus, dMn becomes especially important in systems that are already iron-deficient (Middag 2010), and in these situations dMn and dFe together can co-limit diatom growth (Peers and Price 2004). Phytoplankton requirements for $\mathrm{dFe}$ are higher than their requirements for dMn. A 2013 study of cultured phytoplankton estimated dMn quotas ranging from about $0.2-1.3 \mathrm{mmol} \mathrm{dMn} / \mathrm{mol} \mathrm{P}$, while cellular requirements for $\mathrm{dFe}$ ranged from about 0.5 $5 \mathrm{mmol} / \mathrm{mol} \mathrm{P}$ (Twining and Baines 2013). These ranges reflect different quotas for different types of phytoplankton (e.g., diatoms vs. autotrophic picoplankton) as well as regional differences.

The distribution of $\mathrm{dMn}$ is also influenced by an additional deep source of $\mathrm{dMn}$ in areas where the sediment and the bottom water at the sediment-water interface is suboxic. Under suboxic conditions, manganese respiration occurs whereby manganese oxides are reduced to $\mathrm{Mn}$ (II), which may then diffuse or advect back into the aerobic zone and become re-oxidized (Rutgers Van Der Loeff et al. 1990). Suboxic and anoxic conditions develop more quickly in sediments in productive shelf/coastal regions where there is a higher flux of organic matter 
reaching the sediment and whose breakdown by microbes in the surface sediment requires oxygen (Rutgers Van Der Loeff et al. 1990, Middag 2010).

1.4 NGA physical environment

The Gulf of Alaska (GOA) is located in the North Pacific Ocean and is surrounded by the Alaskan coastline to the north, east, and west, while to the south it borders the high-nutrient, lowchlorophyll (HNLC) waters of the subarctic North Pacific. The Northern Gulf of Alaska (NGA) refers specifically to our study area within the Gulf. This consists of four transects that start near the coast between Cape Suckling $\left(144^{\circ} \mathrm{W}\right)$ and the eastern edge of Kodiak Island $\left(152^{\circ} \mathrm{W}\right)$ and extend past the shelf break, plus additional sites within Prince William Sound (Figure 3). The shelf extends from the coastline to a depth of 200-300 m, beyond which continental slope descends rapidly to the full basin depth of $4-5 \mathrm{~km}$. Major circulation in the GOA is driven by the Alaska Gyre in the ocean basin and the Alaska Coastal Current (ACC) over the shelf. Gyre circulation in the GOA includes the Alaska Current, which moves northward following the contour of the continental shelf break and turns southwest at the northernmost extent of the Gulf, becoming the Alaskan Stream (Royer and Emery 1987, Lagerloef 1995). The Alaskan Stream is the western boundary current (WBC) of the Alaska Gyre. The Alaskan Stream is narrower and faster than the Alaska Current, in some places traveling faster than $50 \mathrm{~cm} \mathrm{~s}^{-1}$ (Reed 1984). The North Pacific Current in the southern GOA is the southern boundary of the gyre. It moves eastward through the Pacific and when it reaches North America it splits into the Alaska Current to the north and the California Current to the south (Royer and Emery 1987, Stabeno et al. 2004).

On the inner portion of the continental shelf, the ACC is separate from gyre circulation and is driven by wind and freshwater input, with speeds up to $175 \mathrm{~cm} \mathrm{~s}^{-1}$ (Schumacher et al. 1989, Weingartner et al. 2005). It flows westward along the southern coast of the Kenai Peninsula, likely splitting around Kodiak Island. The majority of the current flows through Shelikof Strait and eventually enters the Bering Sea through Unimak Pass and Samalga Pass (Stabeno et al. 2004). As the ACC is highly influenced by freshwater input, it is also subject to the seasonal cycles of glacial melt experienced in this region. Maximum volume transport by the ACC, on the order of $4.5 \times 10^{4} \mathrm{~m}^{3} \mathrm{~s}^{-1}$, appears to occur in late autumn about 1-2 months after peak runoff, compared to an annual average of around $2.8 \times 10^{4} \mathrm{~m}^{3} \mathrm{~s}^{-1}$ (Weingartner et al. 2005). Strong winds in January and February tend to cause a second peak in ACC transport in winter (Royer 
1981). Data from multiple sources (moorings, drifters, and CTD deployments) indicate that ACC flow is less continuous to the east of the Kenai Peninsula (Stabeno et al. 2016). Although the signatures of the ACC (low salinity and strong along-shelf transport) are evident as far southeast as Kruzof Island, there is likely a break in coastal circulation between Cross Sound and Yakutat Bay, where the ACC reappears and continues onward to Kayak Island (Stabeno et al. 2016). As the coastal current rounds Kayak Island, a portion may be diverted along the continental slope while another portion flows northward onto the NGA shelf (Ahlnas et al. 1987). Disruptions in ACC flow generally result from baroclinic instabilities, bathymetric features such as canyons and island promontories, and variations in wind forcing along the GOA coast (Ahlnas et al. 1987, Weingartner et al. 2005, Williams et al. 2007, Stabeno, et al. 2016).

The seasonality observed in patterns of freshwater input to the GOA is mainly due to melt cycles of glaciers, which encompass an area of $>72,000 \mathrm{~km}^{2}$ in the GOA watershed (Beamer et al. 2016) as well as seasonal changes in precipitation (Hill et al. 2015). Glacial melt peaks in early autumn as a direct result of higher temperatures in the warm season, which is often defined as the period from May-October or June-November, and during which runoff has been shown to double compared to the rest of the year (Royer 1981). This peak also results indirectly from the warm season as precipitation both increases and changes from snow to rain, which accelerates the melting of snow and ice in the watershed (Beamer et al. 2016). Total freshwater discharge is estimated at $860 \mathrm{~km}^{3} \mathrm{yr}^{-1}$ (Neal et al. 2010, Hill et al. 2015, Beamer et al. 2016). This value is somewhat higher than previously calculated values as a result of more precipitation measurements at high altitude locations as well as greater glacial melt in recent years due to climate change (Hill et al. 2015).

The Copper River is the largest point source of freshwater to the GOA with a mean discharge of $1,625 \mathrm{~m}^{3} \mathrm{~s}^{-1}$ (Brabets 1997), making it a major source of trace elements such as aluminum, manganese, and iron to the NGA shelf. The upper Copper River is fed mainly by glacial streams, and interannual variation in its discharge may be due to outbursts of Van Cleve Lake, which is dammed by glaciers and can increase Copper River flow to $3,964-5,380 \mathrm{~m}^{3} \mathrm{~s}^{-1}$ (Brabets 1997). As of the late 1990s glaciers including Miles, Childs, and Goodwin constituted approximately $18 \%$ of the Copper River basin, contributing to seasonality in Copper River flow with peak outflow observed from June-September (Brabets 1997). 


\section{$1.5 \mathrm{Al}$ and $\mathrm{Mn}$ as proxies for inputs of $\mathrm{dFe}$}

Aluminum, manganese, and iron are lithogenic elements, originating from the Earth's crust and they exhibit high particle reactivity when dissolved in seawater. As the GOA is a low dust region, the main source of all 3 elements is freshwater input, with $\mathrm{dMn}$ and $\mathrm{dFe}$ having a potential additional source from the photoreduction of suspended particles in surface waters. The particle reactive nature of $\mathrm{dFe}$ compounded by high biological demand and control on $\mathrm{dFe}$ concentrations exerted by Fe-binding organic ligands makes it difficult to assess inputs of this essential element into coastal systems. In the GOA, assessing the relatively more conservative $\mathrm{dAl}$ and $\mathrm{dMn}$ inputs from large freshwater sources such as the Copper River may help quantify $\mathrm{dFe}$ inputs into the system. Numerous studies have used a similar approach to estimating $\mathrm{dFe}$ input into the open ocean, using dust as the main source of $\mathrm{dAl}$ and $\mathrm{dFe}$ instead of freshwater (e.g., Measures and Vink 2000, Cain 2014, Han et al. 2008). Some of these studies also include $\mathrm{dMn}$ (Jong et al. 2007) as dMn is also an essential micronutrient, but with lower cell quotas and lower particle reactivity. Quantifying $\mathrm{dFe}$ fluxes in the GOA is important because this micronutrient is thought to influence phytoplankton community composition and productivity (Strom et al. 2006). Additionally, cross-shelf exchange can provide dFe to offshore waters, which have been characterized as a high nutrient, low chlorophyll (HNLC) region where $\mathrm{dFe}$ is the limiting nutrient (e.g., Martin et al. 1991). Previous work in the GOA has shown highly elevated $\mathrm{dAl}$ values $>1,000 \mathrm{nM}$ in freshwater plumes during the peak melt season, emphasizing that glacial melt is a major source of lithogenic elements to the GOA (Brown et al. 2010). In contrast, on the same transect concentrations of leachable particulate Fe as high as $1060 \mathrm{nM}$ were observed, while dFe ranged from 0.5-3.2 nM (Lippiatt et al. 2010). There are no previous studies of $\mathrm{dMn}$ in the GOA. Due to the particle reactive nature of $\mathrm{dAl}$ and $\mathrm{dMn}$ and the importance of freshwater input as the main source of both metals, we expected to see much lower surface dAl and $\mathrm{dMn}$ values away from rivers, e.g., along the KOD Line or in offshore waters in general. Enhanced $\mathrm{dAl}$ and $\mathrm{dMn}$ signals near river outflows and the control exerted on surface distributions exerted by abiotic processes (for $\mathrm{dAl}$ in particular) make both metals good candidates for tracers of river input and dFe sources over the NGA shelf. 
Chapter 2: Spatial and temporal variability of dissolved aluminum and manganese in surface waters of the northern Gulf of Alaska ${ }^{1}$

\subsection{Abstract}

The Northern Gulf of Alaska (NGA) shelf is a productive high-latitude environment where nutrient dynamics are greatly impacted by the seasonal variability in freshwater input and water column mixing. Iron is a key nutrient on the NGA shelf that directly modulates primary production, but inputs are difficult to quantify due to high biological uptake and control exerted by Fe-binding organic ligands. Other lithogenic elements such as aluminum and manganese have the same sources as iron (rivers and sediment) and similar abiotic removal via particle scavenging, but exhibit quasi-conservative behavior in seawater allowing for their use as tracers of these sources. Thus, Al and Mn distributions can help provide insight into iron inputs and the relative importance of various mechanisms influencing nutrient dynamics in the NGA.

Sample data are derived from spring, summer, and fall NGA LTER (Long-term Ecological Research) cruises during 2018 and 2019 that included a focused five-day Copper River plume study, several surface transects from Kayak Island to Kodiak Island, and vertical profiles at several locations sparsely distributed throughout the shelf. We find that seasonal patterns in the surface concentrations of $\mathrm{dMn}$ and $\mathrm{dAl}$ mirrored annual glacial melt cycles, with the lowest values observed in spring and higher values in summer and fall. Spatial patterns were also apparent as both metals tended to be lower offshore than inshore, and were also lower overall (by 1-2 orders of magnitude) on transects further from the outflow of the Copper River, a major source of freshwater to the NGA. Extremely high concentrations in the Copper River plume ( $\leq 1395 \mathrm{nM} \mathrm{dAl}, \leq 128 \mathrm{nM} \mathrm{dMn})$ and strong correlations with salinity $(\mathrm{p}<0.0001)$ highlight their quasi-conservative nature, and their usefulness as tracers of freshwater input, which helps inform iron inputs from this source. Enhanced $\mathrm{dAl}$ and $\mathrm{dMn}$ concentrations within nepheloid layers in subsurface waters indicate regions where a sedimentary source of iron is likely to be important. Residence times for $\mathrm{dAl}$ and $\mathrm{dMn}$ in surface waters over the NGA shelf

\footnotetext{
${ }^{1}$ Kandel, Anna and Ana Aguilar-Islas. In prep. Spatial and temporal variability of dissolved aluminum and manganese in surface waters of the northern Gulf of Alaska. To be submitted for publication in Deep Sea Research II - Understanding Ecosystem Processes in the Gulf of Alaska: Vol. 3
} 
were estimated to be 31 days ( $\mathrm{dAl}$ ) and 42 days $(\mathrm{dMn})$ on average based on summer and fall data from both years.

\subsection{Introduction}

Aluminum ( $\mathrm{Al})$ and manganese $(\mathrm{Mn})$ are lithogenic elements that are respectively the third and twelfth most abundant elements in the Earth's crust (Taylor 1964, Wedepohl 1995) but in seawater their dissolved phases are only present in nanomolar $\left(10^{-9} \mathrm{~mol} / \mathrm{L}\right)$ concentrations. In surface seawater dissolved aluminum (dAl) mainly exists as $\mathrm{Al}(\mathrm{OH})_{4}{ }^{-}$due to the slightly basic $\mathrm{pH}$, with the other species $\mathrm{Al}(\mathrm{OH})_{2}{ }^{+}$and $\mathrm{Al}(\mathrm{OH})_{3}$ present in smaller fractions (Byrne et al. 1988). Dominant sources of $\mathrm{dAl}$ to surface waters are riverine input and aeolian dust deposition (e.g., Hydes 1979, Orians and Bruland 1986), however abiotic estuarine removal processes keep fluvial dAl inputs confined to nearshore areas (e.g., Hydes and Liss 1977) such that aeolian input is the primary source in the open ocean (Maring and Duce 1987, Orians and Bruland 1986). The residence time of $\mathrm{dAl}$ in surface waters is relatively short, estimated to range from $\sim 5$ weeks to 4 years depending on factors that affect its removal throughout the water column (Orians and Bruland 1986), such as passive adsorption onto particles which is a major sink of dAl in surface waters (Moore and Millward 1984). As dAl distributions are mainly controlled by external inputs and particle adsorption, it tends to exhibit scavenged-type vertical profiles with a clear surface maximum, rapid decrease below the surface due to scavenging, and often an increase below the subsurface minimum due to remineralization throughout the water column and sediment resuspension in bottom waters (Hydes 1979).

In seawater the naturally occurring forms of manganese are insoluble $\mathrm{Mn}(\mathrm{III})$ and Mn(IV) oxides, while dMn is comprised of soluble Mn(II) ions as well as Mn(III) bound by organic ligands (Mn(III)-L), which acts as both an oxidizing and reducing agent in Mn cycling (Jones et al. 2020). Similar to dAl, dMn is also particle reactive and tends to exhibit a surface maximum. This maximum, however, may also be enhanced by $\mathrm{dMn}$ produced in surface waters via photoreduction of manganese oxides into Mn(II) (Sunda and Huntsman 1988). Dissolved Mn is also similar to dissolved iron ( $\mathrm{dFe}$ ), as it is an essential micronutrient for phytoplankton used in Photosystem II although biological requirements for $\mathrm{dMn}$ are lower than for $\mathrm{dFe}$ (Twining and Baines 2013). When dFe is limiting, however, such as in high-nutrient, low-chlorophyll (HNLC) regions, cellular Mn requirements can increase up to threefold (Peers and Price 2004). The 
distribution of $\mathrm{dMn}$ is also influenced by an additional deep source of $\mathrm{dMn}$ as $\mathrm{Mn}$ respiration can occur in suboxic sediments, reducing manganese oxides to $\mathrm{Mn}$ (II) that can flux back into the water column (Rutgers Van Der Loeff et al. 1990).

The Gulf of Alaska (GOA) is surrounded by the Alaskan coastline to the north, east, and west, while to the south it borders the high-nutrient, low-chlorophyll (HNLC) waters of the subarctic North Pacific. The Northern Gulf of Alaska (NGA) refers specifically to our study area within the Gulf, consisting of three transects that start along the coast between the Copper River delta $\left(145^{\circ} \mathrm{W}\right)$ to the eastern edge of Kodiak Island $\left(152^{\circ} \mathrm{W}\right)$ and extend offshore just off the shelf, as well as various sites within Prince William Sound. Major circulation in the GOA is driven by the Alaska Gyre in the ocean basin and the Alaska Coastal Current (ACC) over the shelf (Fig. 1). Gyre circulation in the GOA includes the Alaska Current, which moves northward following the contour of the continental shelf break and turns southwest at the northernmost extent of the Gulf, becoming the Alaskan Stream (Royer and Emery 1987, Lagerloef 1995). On the inner portion of the continental shelf, the ACC is separate from gyre circulation and is driven by wind and freshwater input, with speeds up to $175 \mathrm{~cm} / \mathrm{s}$ (Schumacher et al. 1989, Weingartner et al. 2005). It flows westward along the southern coast of the Kenai Peninsula, likely splitting around Kodiak Island (Stabeno et al. 2016).

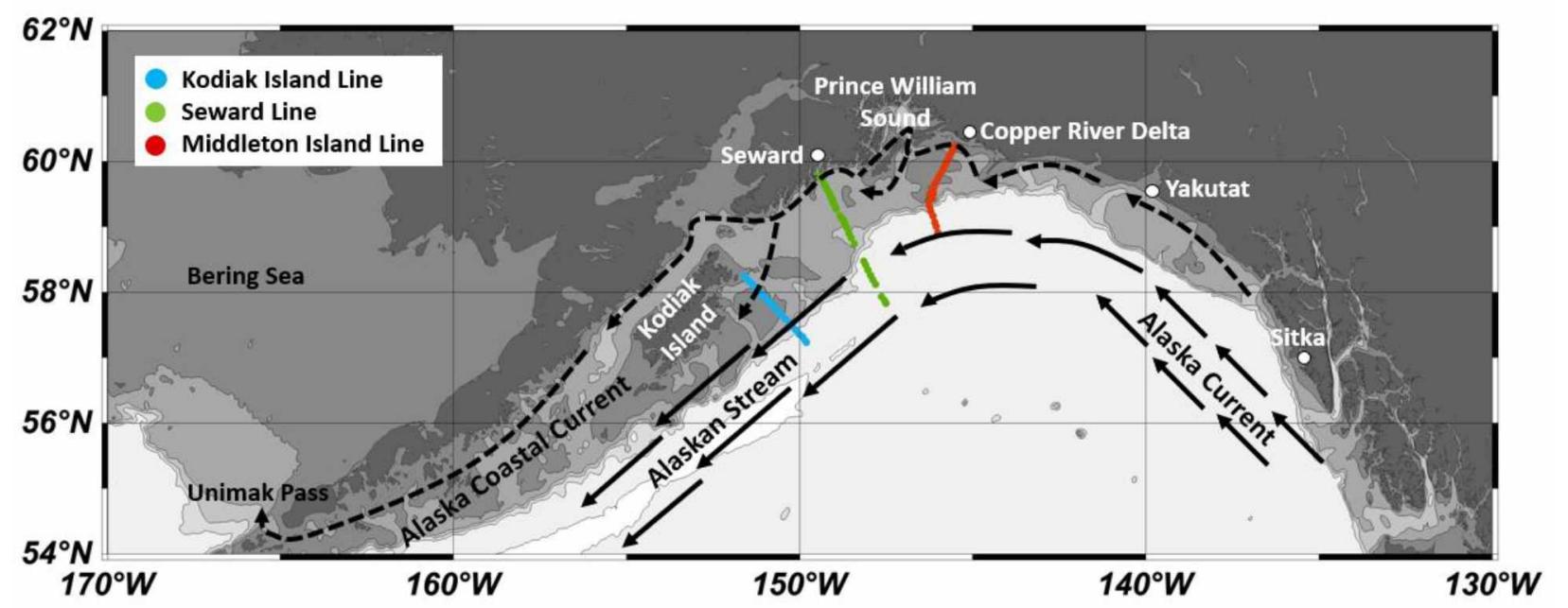

Figure 1: Major circulation in the Gulf of Alaska with bathymetry contours at $100 \mathrm{~m}, 250 \mathrm{~m}$, $500 \mathrm{~m}, 1000 \mathrm{~m}$, and $5000 \mathrm{~m}$. The Kodiak, Seward, and Middleton Lines sampled in this study are also shown.

The pressure system over the NGA shelf is dominated by the Aleutian Low for most of the year, leading to strong downwelling from fall-spring. In summer the Aleutian Low may be 
displaced by the North Pacific High leading to a relaxation of the downwelling winds and thus weak upwelling (Royer 1975). The NGA also experiences intense seasonal variability in freshwater input, mainly due to the melt cycles of glaciers which encompass an area of $>72,000$ $\mathrm{km}^{2}$ in the GOA watershed (Beamer et al. 2016) as well as seasonal changes in precipitation (Hill et al. 2015). Glacial melt peaks in early autumn as a direct result of higher temperatures in the warm season, which is often defined as the period from May-October or June-November, and during which runoff has been shown to double compared to the rest of the year (Royer 1981).

The purpose of this study was to quantify $\mathrm{dAl}$ and $\mathrm{dMn}$, which can be used as quasiconservative tracers of freshwater/terrestrial inputs (e.g., Ren et al. 2006, Aguilar-Islas and Bruland 2006). Seasonal and spatial patterns of $\mathrm{dAl}$ and $\mathrm{dMn}$ distributions in NGA surface waters can therefore help strengthen our understanding of the behavior of freshwater inputs into the system, which can also provide insight into inputs of dissolved iron (dFe). Dissolved Fe is an essential micronutrient that has the same sources as $\mathrm{dAl}$ and $\mathrm{dMn}$ and is thought to directly modulate primary production in the NGA shelf (Strom et al. 2006). Yet due to rapid biological uptake, observed $\mathrm{dFe}$ concentrations might not be indicative of how much is actually entering the system. The wide ranges of dAl (Brown et al. 2010) and dFe (Lippiatt et al. 2010, Aguilar-Islas et al. 2016) values previously observed in the NGA also highlight the variability of the NGA.

\subsection{Methods}

\subsubsection{Field work}

Seawater samples were collected during 6 cruises (spring, summer, and fall) in 2018 and 2019. Cruise dates and vessels are shown in Table 1. Cruises sampled established NGA LTER stations along the historic Seward Line, the Middleton Island Line (MID), and the Kodiak Line (KOD), as well as stations throughout western Prince William Sound (PWS). Additional transects were sampled during the summer 2019 cruise to study the Copper River plume (7/3/19$7 / 8 / 19)$. 
Table 1: Cruise vessels, dates, and IDs for all 2018 and 2019 NGA LTER cruises.

\begin{tabular}{|l|l|l|l|}
\hline Season & Vessel & Dates & Cruise ID \\
\hline Spring 2018 & $R V$ Sikuliaq & $4 / 18-5 / 5$ & SKQ201810S \\
\hline Summer 2018 & $M V$ Woldstad & $7 / 3-7 / 18$ & WOL201807 \\
\hline Fall 2018 & $M V$ Tiglax & $9 / 11-9 / 25$ & TGX201809 \\
\hline Spring 2019 & $M V$ Tiglax & $4 / 26-5 / 9$ & TGX201904 \\
\hline Summer 2019 & $R V$ Sikuliaq & $6 / 27-7 / 17$ & SKQ201915S \\
\hline Fall 2019 & $M V$ Tiglax & $9 / 11-9 / 25$ & TGX201909 \\
\hline
\end{tabular}

\subsubsection{Sample collection}

Surface sampling $(\sim 1 \mathrm{~m})$ was conducted with a towed surface pump "Fe fish" system modified from that described in Aguilar-Islas and Bruland (2006). The modified system is comprised of an air-actuated PTFE diaphragm pump (Wilden) and PFA Teflon ${ }^{\text {TM}}$-lined tubing attached to a bathythermograph. In rough conditions a secondary $20 \mathrm{~kg}$ PVC torpedo was added to keep the Fe fish below the surface and prevent "porpoising" while towing. The Fe fish was deployed from the starboard side of the vessels and towed at speeds of 6-10 knots depending on conditions, allowing for clean underway surface water sampling. On all cruises except TGX201904 (spring 2019), underway salinity data were acquired via a YSI Sonde positioned in the clean lab space inside a plastic cylinder from the overflow of the Fe fish system.

Surface samples taken for dissolved aluminum and manganese analysis were filtered inline through a $0.2 \mu \mathrm{m}$ filter cartridge (Supor Acropak 200, Pall Corporation) and collected in acid-cleaned, $100 \mathrm{~mL}$, low density polyethylene (LDPE) bottles (Bel-Art). New filter cartridges were initially rinsed in-line with at least $5 \mathrm{~L}$ seawater prior to use, and then with $0.5 \mathrm{~L}$ seawater before taking each sample. When possible, a single filter cartridge was used per sampling line by storing cartridges emptied of seawater in a plastic bag and refrigerating overnight.

Depth profiles could not be obtained from cruises on $M V$ Tiglax and $M V W$ Woldstad due to lack of required deployment equipment on those vessels. Therefore, vertical profiles were obtained only from the $R / V$ Sikuliaq (spring 2018 and summer 2019) using a trace metal clean 12-bottle rosette (TMCTD) as described in Rember et al. (2016). The rosette is a powder-coated aluminum frame fitted with a Sea-Bird Electronics 19plus profiler for conductivity, temperature, and depth (CTD) measurements, a Wet Labs EcoView fluorometer, a Wet Labs C-star transmissometer, and a Sea-Bird Electronics auto fire module (AFM) to close bottles at pre-

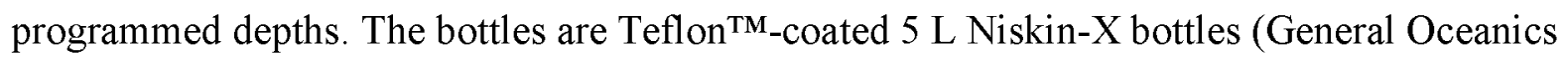




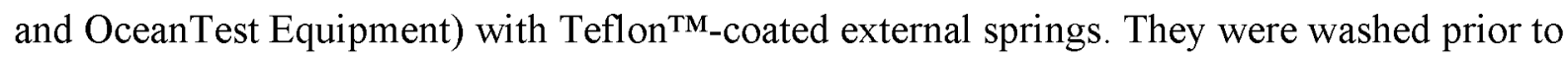
the cruises with dilute trace metal grade hydrochloric acid (TMG HCl) and ultrapure Milli-Q (MQ) water, stored with MQ water for 1 month, and then stored emptied until used. An AmSteel ${ }^{\text {TM }}$ line and a trace metal-clean block were used during deployment to prevent contamination. Following recovery, the bottles were transferred to a plastic enclosure with positive pressure, and seawater was filtered through $0.4 \mu \mathrm{m}$ polycarbonate filters (Nuclepore) mounted on Teflon filter holders (Savillex). Samples were collected in acid-cleaned $125 \mathrm{~mL}$ high-density polyethylene (HDPE) bottles. To increase filtering speed the Niskin bottles were pressurized with ultrapure nitrogen gas ( 5 psi) (the tank was kept outside of the plastic enclosure). Aluminum bar clamps were used to hold the Niskin bottles closed while the gas was on, and their metal bars were covered with electrical tape to prevent contamination.

\subsubsection{Sample processing}

Seawater samples were stored at room temperature and acidified with Optima grade concentrated $\mathrm{HCl}(2 \mathrm{~mL} \mathrm{HCl} / \mathrm{L})$ to $\sim \mathrm{pH} 1.7$ upon return to the laboratory. Due to wide ranges of $\mathrm{dAl}$ and $\mathrm{dMn}$ values, samples with high concentrations (operationally defined here as $>70 \mathrm{nM}$ $\mathrm{Al},>20 \mathrm{nM} \mathrm{Mn}$ ) were diluted prior to analysis, while samples with concentrations below those thresholds were concentrated onto a column as detailed below.

Samples with high concentrations of $\mathrm{dAl}$ and $\mathrm{dMn}$ were diluted into $15 \mathrm{~mL}$ Teflon ${ }^{\mathrm{TM}}$ tubes using $0.13 \mathrm{~mL}$ sample, $3.77 \mathrm{~mL} \mathrm{2 \%}$ Optima-grade nitric acid $\left(\mathrm{HNO}_{3}\right)$, and $0.1 \mathrm{~mL}$ indium (In) spike (40 ppb in 2\% Optima-grade HNO3). Combined aluminum and manganese standards were made in $2 \%$ Optima-grade $\mathrm{HNO}_{3}$ with concentrations of $0,5,10,20$, and $40 \mathrm{nM} \mathrm{Al}$ and 0 , 1, 3, 5, and $10 \mathrm{nM} \mathrm{Mn}$. To ensure matrix matching between standards and samples, solutions containing $0.13 \mathrm{~mL}$ low-aluminum seawater $(<5 \mathrm{nM}), 3.77 \mathrm{~mL}$ standard, and $0.1 \mathrm{~mL}$ In spike were prepared immediately prior to analysis.

Samples with low concentrations of $\mathrm{dAl}$ and $\mathrm{dMn}$ (operationally defined here as $<70 \mathrm{nM}$ $\mathrm{Al},<20 \mathrm{nM} \mathrm{Mn}$ ) were preconcentrated in an offline, flow-through system consisting of two 6port, 2-position valves (VICI) and a 12-position actuator valve (VICI) that functioned as an autosampler (Fig. 2). A column packed with NOBIAS Chelate-PA1 resin was used to concentrate trace elements and remove major salts (Sakamoto, et al. 2006) and ammonium acetate was used to modify sample $\mathrm{pH}$ prior to column loading. Samples were eluted with 10\% 
optima-grade HNO3, while Milli-Q water (MQ) was used as the column conditioner. Eluted solutions were collected into $8 \mathrm{ml}$ acid clean LDPE bottles. The ammonium acetate solution was prepared with a 10:7:33 ratio of optima-grade ammonium hydroxide, glacial acetic acid, and MQ to achieve $\mathrm{pH}$ 5.5-6 in the sample-buffer mixture, previously determined to be ideal for retention of both $\mathrm{Al}$ and Mn (Minami et al. 2015). Ratios between the sizes of pump tubing (and thus flow rates) are comparable to those used in Brown and Bruland (2008) except for the eluent tubing, for which a larger size was used (Fig 2).

Combined $\mathrm{dAl}$ and $\mathrm{dMn}$ standards were prepared in a 50/50 (by weight) solution of MQ and filtered low-aluminum seawater $(<5 \mathrm{nM} \mathrm{dAl})$ collected from offshore in the NGA during the summer 2019 cruise and acidified with optima grade $\mathrm{HCl}(2 \mathrm{~mL} \mathrm{HCl} / \mathrm{L})$. Aluminum standard concentrations were $0,1,5,10,15,25,40,55,70$, and $80 \mathrm{nM}$, and $\mathrm{Mn}$ standard concentrations were $0,0.1,0.5,1,3,5,9,12,15$, and $20 \mathrm{nM}$. Pump tubing (Fisher Scientific; ALPKEM) was replaced after four days of use, or approximately every 120 samples. Up to 10 days prior to use new tubing was filled with 10\% trace metal grade (TMG) HCl (Fisher Scientific) which was changed every couple days to ensure thorough cleaning.

All valves were controlled using VICI VCom software. The system was cleaned immediately prior to use with $0.1 \%$ optima grade $\mathrm{HCl}$. A blank equivalent to the $0 \mathrm{nM}$ std was placed in position 1 on Valve 3 and the $\mathrm{pH}$ of the sample-buffer mixture was checked using the waste line from Valve 1. If the $\mathrm{pH}$ was too low, additional optima grade $\mathrm{NH}_{4} \mathrm{OH}$ was added to the ammonium acetate solution. To condition the column with seawater the blank was then loaded and eluted for 2 min. each, and this cycle was run 5 times. 


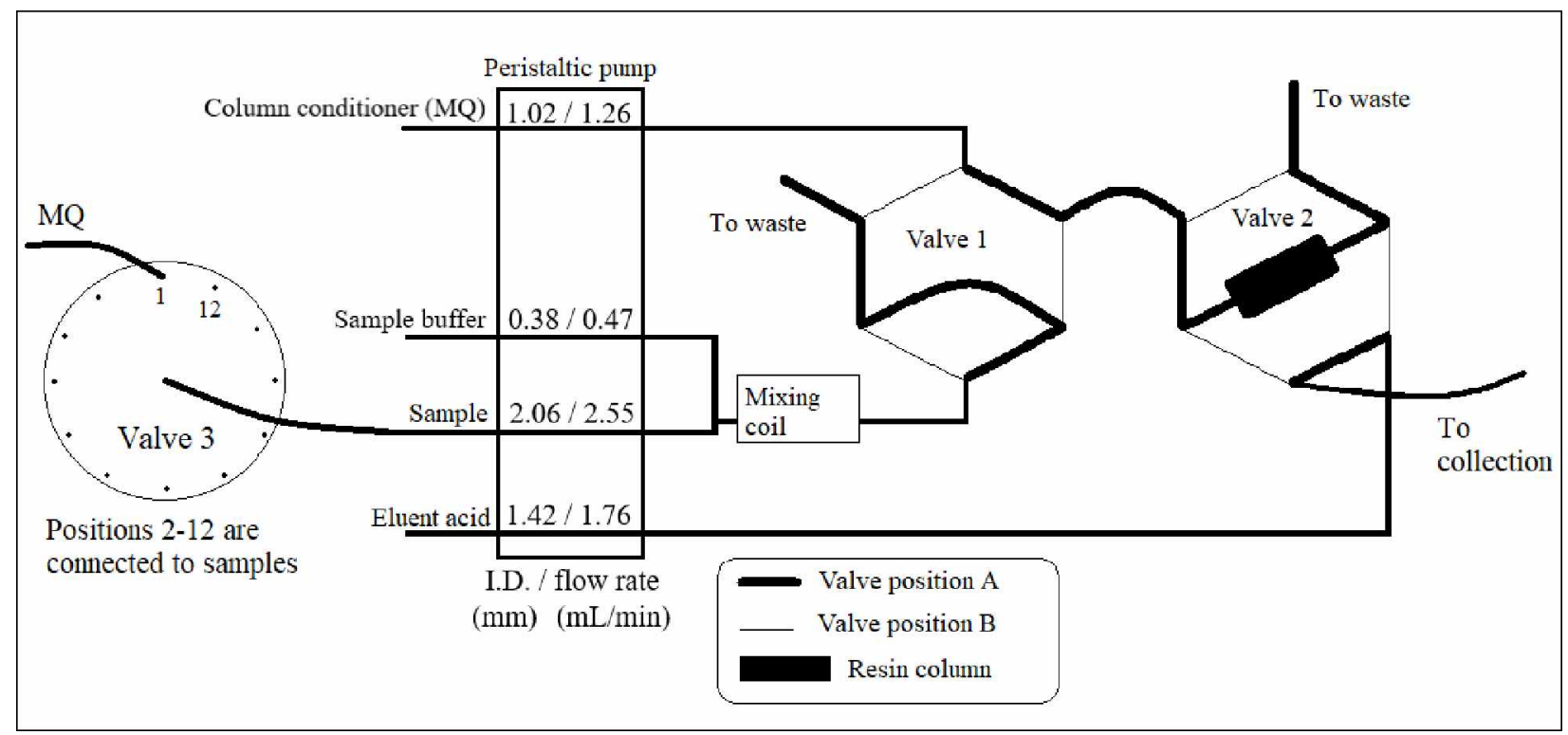

Figure 2: Offline system for preconcentrating dAl and dMn in seawater samples. Modified from Brown and Bruland 2008.

A set of 5 standards was chosen for each day based on expected dAl and dMn values of the samples, estimated either by using the dilution method first or by comparison to geographically and temporally nearby samples that had already been quantified. Standards were collected in duplicate before samples were run. Standards were run in decreasing order from highest concentration to lowest to facilitate accurate quantification of the lowest standards, as seawater helps condition the column resin. Samples were collected only once except for the sample in position 12 on Valve 3 that was always collected in duplicate.

At the beginning of each preconcentration both valves started in position $\mathrm{A}(\mathrm{A} / \mathrm{A})$ for 15 seconds to rinse the tubing and condition the column. Valve 1 then switched to position B (B/A) for 7.25 minutes to load the buffered sample onto the column. Valve 1 then switched back to position $\mathrm{A}(\mathrm{A} / \mathrm{A})$ for another 15 seconds to rinse major salts from the column. Finally, Valve 2 was switched to position $\mathrm{B}(\mathrm{A} / \mathrm{B})$ for 1.25 minutes to elute the sample off the column and the eluent was collected in $8 \mathrm{~mL}$ LDPE bottles. These bottles, however, have HDPE caps and so to prevent contamination with regard to $\mathrm{dAl}$ (Brown and Bruland 2008) samples were kept upright to prevent contact with the cap and analyzed as quickly as possible after preconcentration (ideally within 1-2 days). To prevent cross-contamination from one sample to the next, the inlet side of the sample lines (on Valve 3) were dipped in 1\% TMG HCl after each use. 
Blanks for the dilution method $(\mathrm{n}=10)$ were $3.9 \mathrm{~mL} 2 \%$ optima-grade $\mathrm{HNO}_{3}$ with $0.1 \mathrm{~mL}$ In spike. Values obtained using these blanks (Table 2) were multiplied by the dilution factor (29). Blanks for the preconcentration method ( $\mathrm{n}=7$ for $\mathrm{dAl}, \mathrm{n}=10$ for $\mathrm{dMn}$ ) were the same offshore, low-trace metal seawater used to make the standards for this method. All blank values are reported as the average \pm 1 standard deviation $(\sigma)$.

Table 2: MQ blank values, system limits of detection (LODs), precision (mean relative standard deviation (RSD)), and median RSD for both methods of sample processing. System LOD values are based on blanks and RSD values are based on samples that were run in duplicate.

\begin{tabular}{|c|c|c|c|c|}
\hline & \multicolumn{2}{|c|}{ Dilution method } & \multicolumn{2}{c|}{ Preconcentration method } \\
\hline & Al & Mn & Al & Mn \\
\hline Blanks (nM) & $30.5 \pm 12.5$ & $0.65 \pm 0.11$ & $10.7 \pm 2.6$ & $0.97 \pm 0.05$ \\
\hline $\begin{array}{c}\text { System LOD (nM) } \\
(3 \sigma)\end{array}$ & 37.6 & 0.33 & 7.8 & 0.15 \\
\hline $\begin{array}{c}\text { Sample precision } \\
\text { (mean sample RSD) }\end{array}$ & $13.5 \%$ & $10.0 \%$ & $23.8 \%$ & $4.3 \%$ \\
\hline Median sample RSD & $6.1 \%$ & $9.2 \%$ & $11.4 \%$ & $2.2 \%$ \\
\hline
\end{tabular}

\subsubsection{Analysis}

Analyses were performed at the University of Alaska Fairbanks on an Element 2 (Thermo-Finnigan) inductively coupled plasma mass spectrometer (ICP-MS) run at medium resolution. Table 2 shows figures of merit. Dilution blanks consisted of $3.9 \mathrm{~mL} 2 \% \mathrm{HNO}_{3}$ and $0.1 \mathrm{~mL}$ In spike $(\mathrm{n}=10)$, and preconcentration blanks were MQ water acidified in the same manner as the seawater samples $(2 \mathrm{~mL} \mathrm{HCl} / \mathrm{L})$ and run through the offline preconcentration system $(n=7)$. The blank values were subtracted from samples, however a blank value for dAl was not obtained for this method. The system limit of detection (LOD) was determined by $3 \sigma$ where $\sigma$ is the standard deviation of the blanks (for both metals in the dilution method, and Mn only in the preconcentration method). The precision of the method was obtained from samples that were run in duplicate. The dilution method tended to be more precise for quantifying $\mathrm{dAl}$ while the offline preconcentration method yielded lower RSD values for dMn data. 
To assess the accuracy of methods used here, certified reference materials CASS-6 $(n=3)$ and NASS-7 (North Atlantic Surface Seawater, National Research Council Canada) ( $\mathrm{n}=3$ ) were analyzed and $\mathrm{dMn}$ values were compared to their certified values provided in Yang et al. 2018 (Table 3). Dissolved Al values are not published for these materials. Based on the expected $\mathrm{dMn}$ concentrations CASS-6 (Coastal Atlantic Surface Seawater, National Research Council Canada) was processed using the dilution method and NASS-7 was processed using the preconcentration method, and the resulting $\mathrm{dMn}$ values (reported as mean \pm 1 standard deviation) were within the certified ranges.

Table 3: Dissolved Mn values obtained for CASS-6 and NASS-7 reference materials compared to the certified values (Yang et al. 2018).

\begin{tabular}{|c|c|c|}
\hline & CASS-6 & NASS-7 \\
\hline Method & Dilution & Preconcentration \\
\hline dMn Average (nM) & $38.21 \pm 0.55$ & $13.90 \pm 0.63$ \\
\hline Accepted Range (nM) & $39.68 \pm 2.18$ & $13.47 \pm 1.09$ \\
\hline
\end{tabular}

\subsubsection{Residence time calculations}

Residence times for $\mathrm{dAl}$ and $\mathrm{dMn}$ in surface waters relative to the input from the Copper River were estimated for the shelf area in the vicinity of the Copper River outflow for individual seasons with sufficient surface dissolved metal data. (Table 4). Freshwater input was estimated using USGS Copper River discharge data, averaging the daily discharge means from the 3 days immediately before and during our occupation. Linear relationships between $\mathrm{dAl}$ or $\mathrm{dMn}$ and salinity (Fig. 16) were used to extrapolate to the zero-salinity endmembers for each season (Brown et al. 2010). Shelf dimensions of $50 \mathrm{~km}$ length and $100 \mathrm{~km}$ width were chosen to encapsulate the shelf area between Hinchinbrook and Kayak Islands, as well as a mixed layer depth of $10 \mathrm{~m}$. To calculate $\mathrm{dAl}$ and $\mathrm{dMn}$ reservoirs the geometric means of surface water values between MID1-MID6, and values over the shelf from the plume study were used. 
2.4 Results

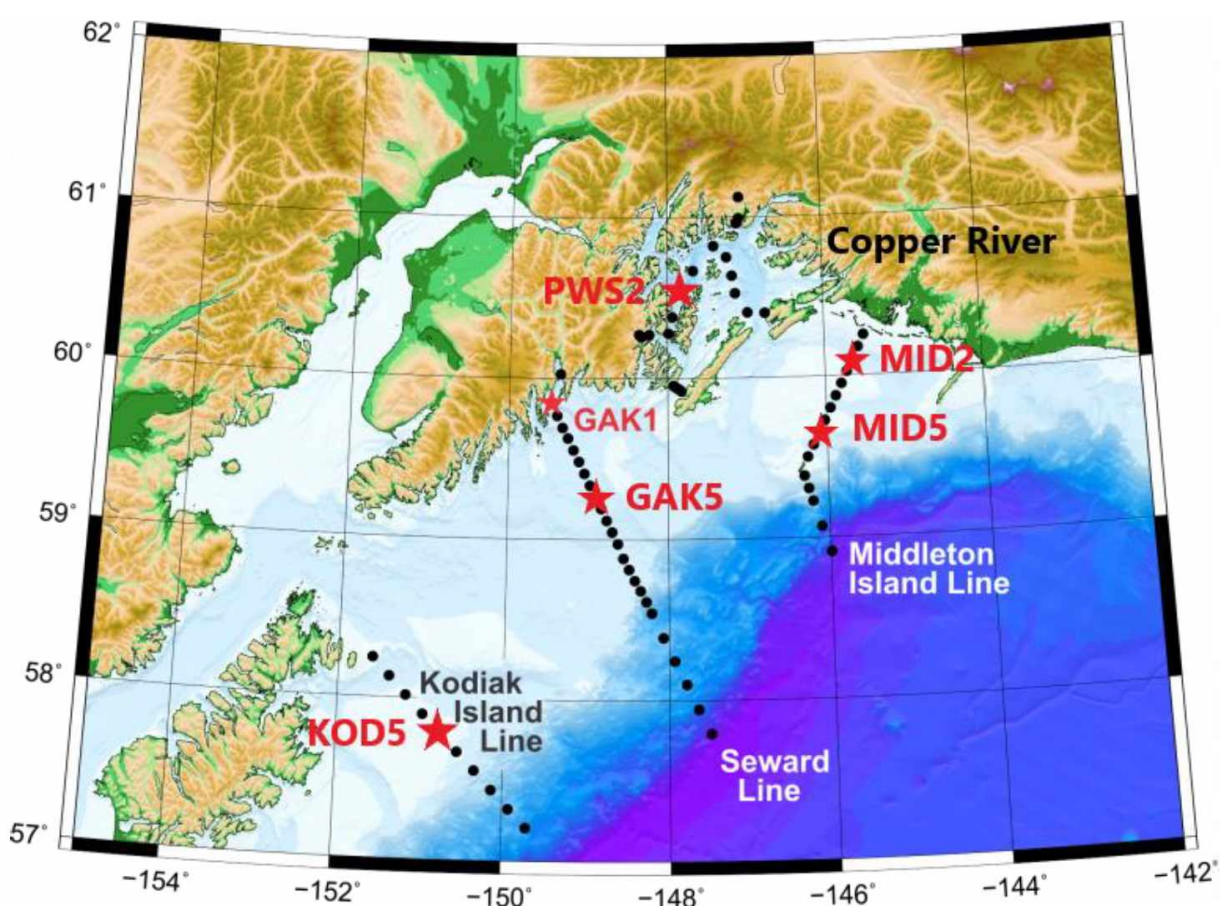

Figure 3: Map of sampling sites in the Northern Gulf of Alaska showing the KOD, GAK, and MID Lines as well as sites within Prince William Sound. Red stars indicate stations with vertical profiles of dAl and dMn. LTER cruises took place during spring, summer, and fall in 2018 and 2019, sampling every line on every cruise (weather permitting).

\subsubsection{Kodiak Island Line (KOD)}

Surface temperatures on the KOD Line increased moving offshore on all cruises (Fig. 4a), however weather prevented sampling past KOD7 $\left(57.55^{\circ} \mathrm{N}\right)$ during fall 2019 so we are unable to quantify temperature changes along offshore KOD line stations for that season.

Temperatures were seasonally lowest during spring, and at this time of year exhibited the lowest absolute temperature change between inshore and offshore stations. Spring 2019 was warmer than 2018 by approximately $1.2^{\circ} \mathrm{C}$. Both spring transects showed relatively invariant temperature from $\operatorname{KOD} 1\left(58.23^{\circ} \mathrm{N}\right)$ to $\operatorname{KOD} 5\left(57.79^{\circ} \mathrm{N}\right)$ and then an increase to KOD7 from which temperature values stabilized again. Warmer temperatures were also observed over most of the transect during summer $2019\left(2.4^{\circ} \mathrm{C}\right.$ warmer on average) compared to summer 2018 , and fall 2019 ( $\sim 0.1^{\circ} \mathrm{C}$ warmer on average) relative to fall 2018 . At the two inner shelf stations, surface temperatures were warmest during fall. 
Surface salinity values were seasonally elevated and with little cross-shelf variability during spring, and the salinity gradient from inshore to offshore was most pronounced during fall (Fig. 4b). Summer salinity values were more similar to those observed in spring - salinity values during spring ranged from about 32.2 to 32.6 , while in summer the lower limit was closer to 31.7. In the fall, at the end of peak melt season, surface salinity along the shelf (KOD1 to KOD7) ranged from $\sim 30.2$ to 31.4. This suggests that diversion of $\mathrm{ACC}$ waters to the offshore side of Kodiak Island may be more common during fall than summer, unlike the GAK and MID Lines (Sections 2.4.2 and 2.4.3), which exhibit the low-salinity ACC signature year-round.

a)

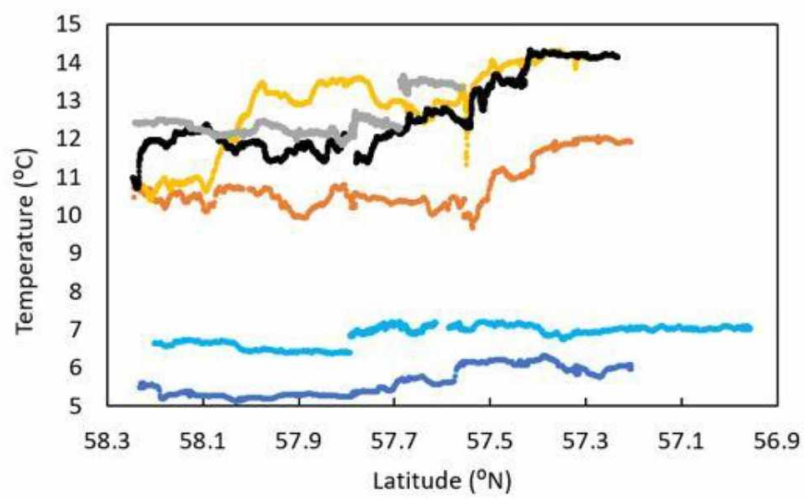

b) KOD Surface Salinity

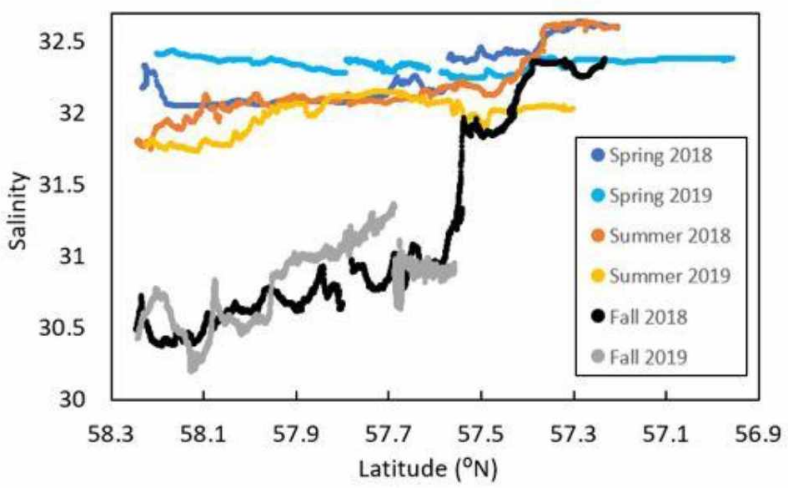

Figure 4: a) Surface temperatures and b) surface salinity values (both from underway data) recorded along the KOD Line in the Northern Gulf of Alaska during 2018 and 2019 cruises.

The highest $\mathrm{dAl}$ values on the KOD Line (as high as $47.1 \mathrm{nM}$ ) were observed during fall 2018 at inshore stations, with values generally decreasing offshore (Fig. 5a). Fall 2019 dAl values also tended to decrease from inshore to offshore, but values were lower (maximum 33.3 $\mathrm{nM}$ ) although salinity ranges were similar during both years. Summer and spring dAl values did not exhibit a distinct inshore/offshore pattern, consistent with the narrower range in salinity from KOD1 to KOD10 $\left(57.2^{\circ} \mathrm{N}\right)$ during those seasons. The three outermost samples for summer 2018 were not run due to time constraints, and in summer 2019 the KOD Line was not sampled for trace metals south of $57.8^{\circ} \mathrm{N}$. In spring 2019, dAl values were higher in the mid and outer shelf compared to the inner shelf and margin waters. The lowest dAl values were observed over the shelf during summer 2019, and over the shelf dMn was also lowest during summer 2019 and highest in fall 2018. Offshore past KOD6 the temporal dAl and dMn differences were minimal. 
Along the KOD Line the observed range of $\mathrm{dMn}$ concentrations was from $0.9 \mathrm{nM}$ offshore to a maximum of $14.4 \mathrm{nM}$ inshore (fall 2018) (Fig. 5b), while the range for dAl was broader, from $1.7 \mathrm{nM}(\sim \mathrm{KOD} 2$ during summer 2019) to $47.1 \mathrm{nM}$ (inshore fall 2018).

a) KOD Surface dAl

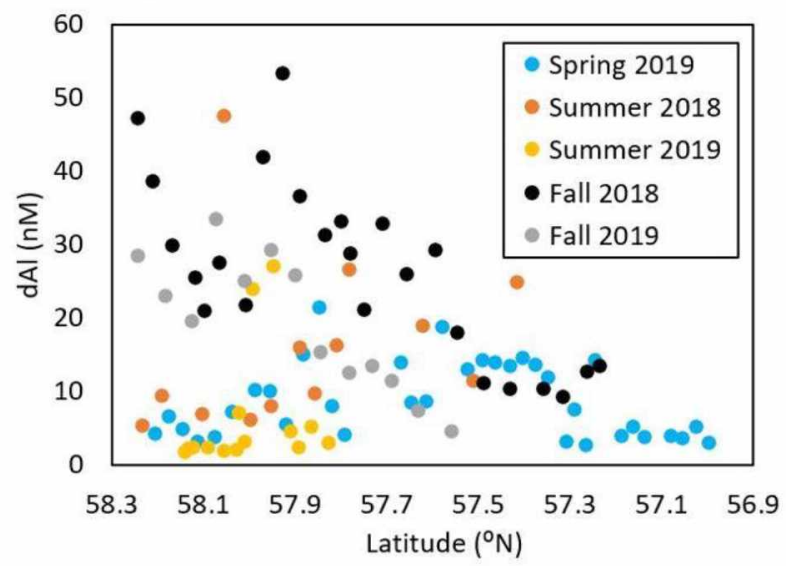

b) KOD Surface dMn

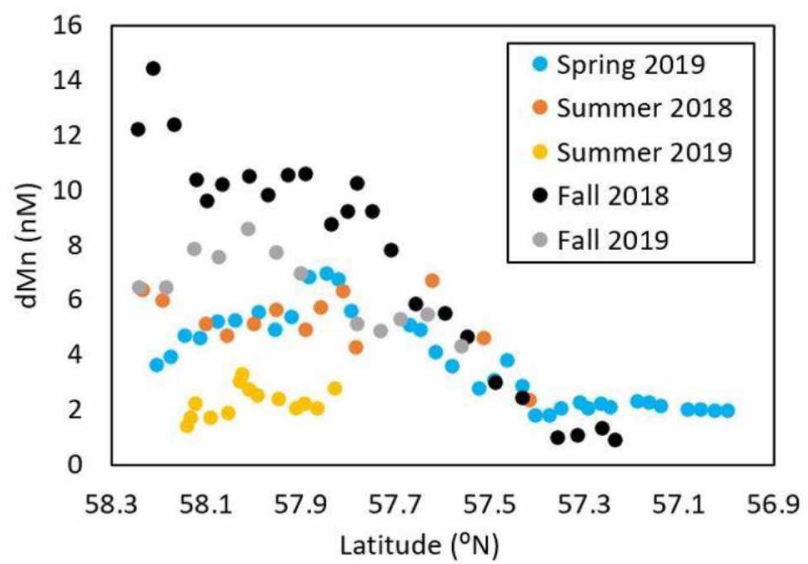

Figure 5: a) dAl and b) dMn vs. latitude along the KOD Line in the Northern Gulf of Alaska.

During fall along the KOD Line, $\mathrm{dAl}$ and $\mathrm{dMn}$ exhibited some degree of conservative mixing between fresh and saline waters (Fig. 6), and the slope in fall 2018 was roughly twice as steep as fall 2019 for both metals. During summer and spring when freshwater influence was diminished along this line, the relationship between metal concentrations and salinity lessened. Other inputs and losses likely exerted a greater influence on the distribution of $\mathrm{dAl}$ and $\mathrm{dMn}$ during these seasons. Four relationships in Fig. 6 are not statistically significant $(\alpha=0.05)$ : for dAl vs. salinity summer 2018, and summer and fall 2019, and for dMn vs. salinity summer 2019.

a)

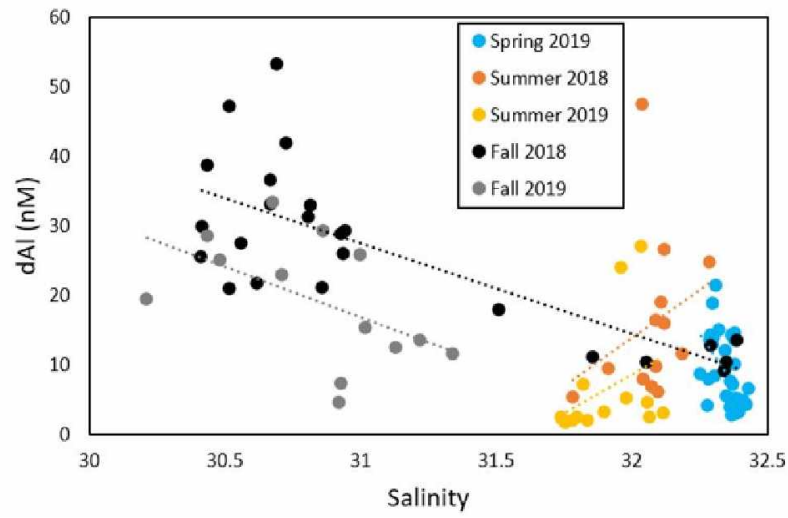

b) KOD dMn vs. Salinity

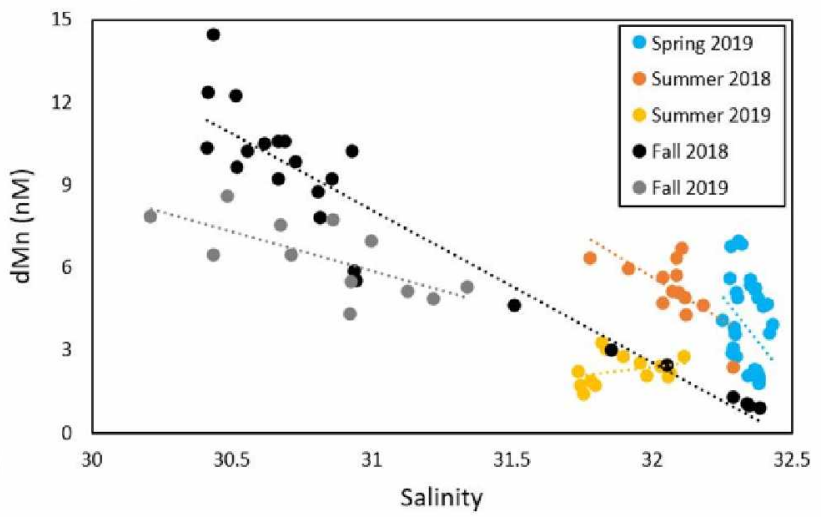

Figure 6: a) dAl and b) dMn vs. salinity along the KOD Line in the Northern Gulf of Alaska. 
In fall $2018 \mathrm{dMn}$ followed salinity trends with the highest values inshore that decreased steadily moving offshore (Fig. 7). During spring 2019, when freshwater was not impacting the shelf, the bathymetric influence on surface dMn values can be discerned in the middle of the transect over Albatross Bank (Fig. 8), where enhanced vertical mixing is observed (Cheng et al. 2012).

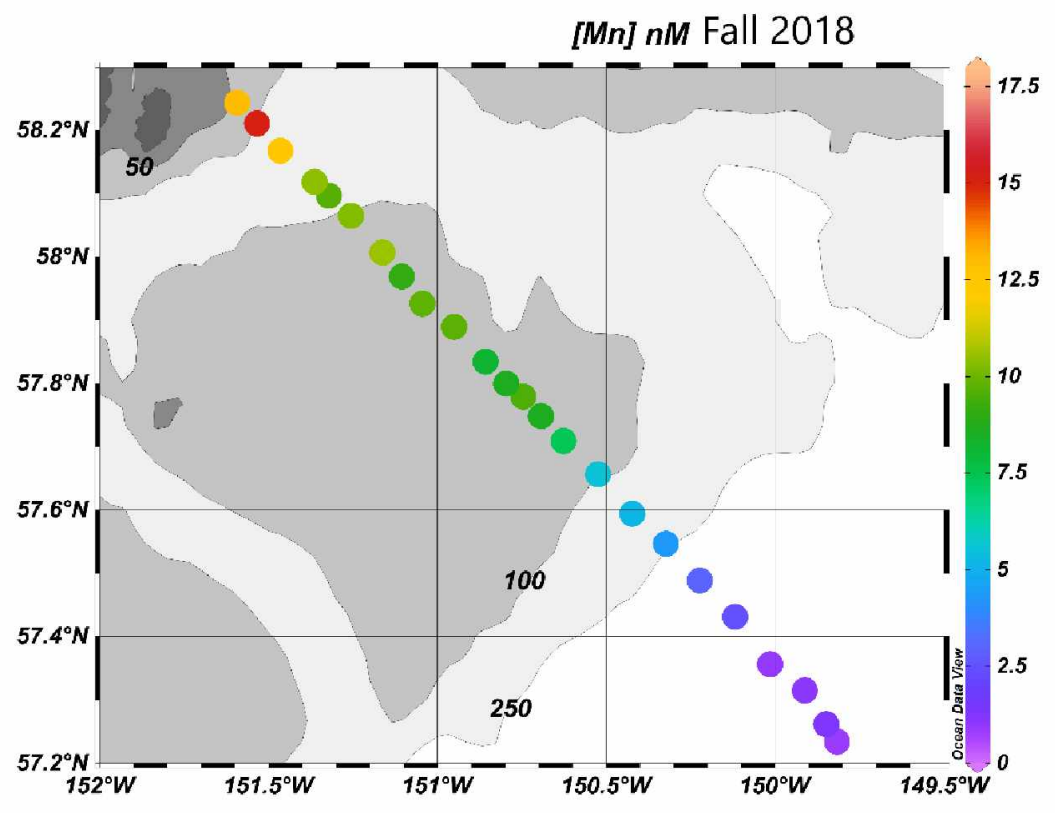

Figure 7: Map with superimposed surface dMn values along the KOD Line in the Northern Gulf of Alaska during fall 2018. Depth contours are marked in meters. 


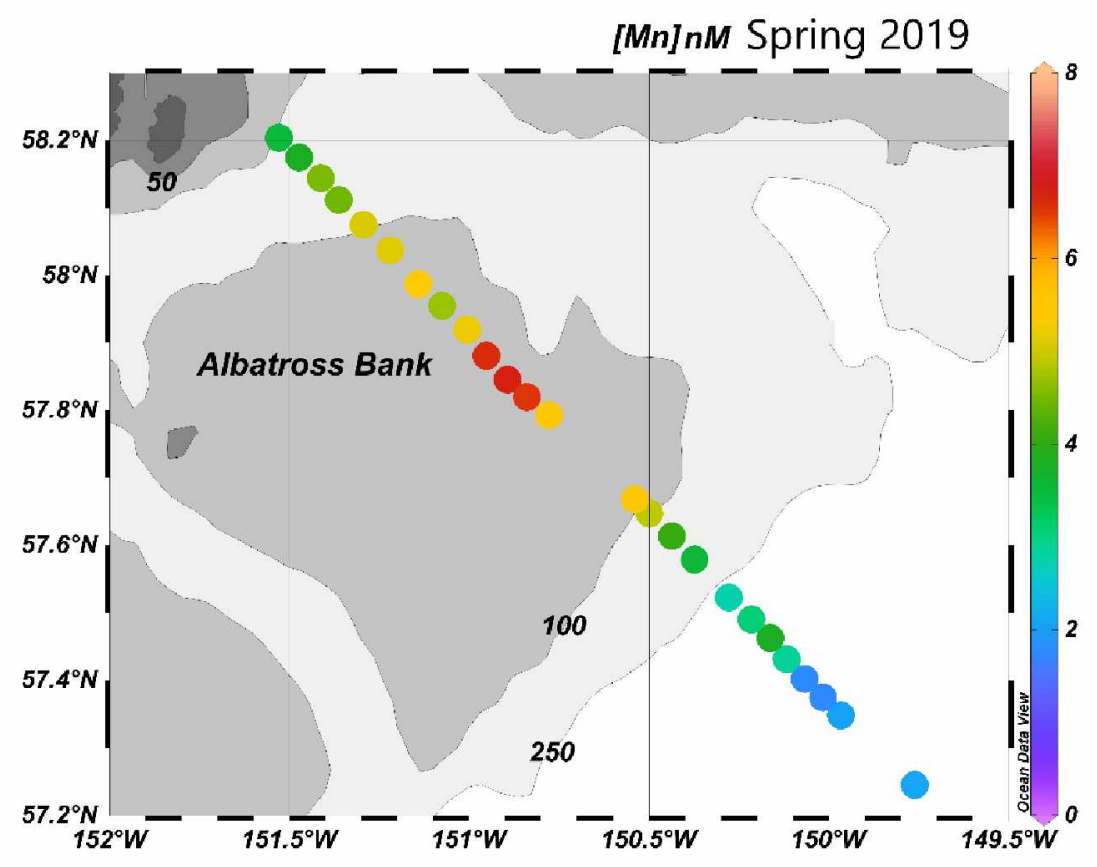

Figure 8: Map with superimposed surface dMn values along the KOD Line in the Northern Gulf of Alaska during spring 2019. Depth contours are marked in meters.

\subsubsection{Seward Line (GAK)}

Similar to the KOD Line, surface temperatures along the Seward Line showed clear differences between spring (cooler) and summer/fall as well as interannual differences in spring and summer 2019 , which were higher on average than the same seasons in 2018 by $0.43{ }^{\circ} \mathrm{C}$ and $3.76{ }^{\circ} \mathrm{C}$ respectively (Fig. 9a). Fall 2018 , however, was warmer than fall 2019 , likely as a result of enhanced mixing by storms that impacted the region during our 2019 field campaign. Inshore/offshore temperature differences were less pronounced along the Seward Line compared to the KOD Line - on all cruises the temperature difference between the furthest inshore and furthest offshore Seward Line samples was $<1{ }^{\circ} \mathrm{C}$.

Compared to the KOD Line, the Seward Line exhibited a wider range of surface salinity values, especially in summer and fall (Fig. 9b). During spring, salinity ranged only from about 31.2 to 32.6 , and by summer salinity at GAK 1 had decreased to the high 20 s and then further into the mid and low $20 \mathrm{~s}$ in the fall. The rapid decrease of surface salinity at inshore stations during summer and fall delineates the region that freshwater tends to be constrained to by coastal circulation (the ACC). Interannual salinity differences were more pronounced from GAK 1 to GAK4, with fall 2018 being fresher than fall 2019 along these shelf stations. The greater surface 
salinity in fall 2019 over the shelf supports the notion of enhanced mixing by the storms that coincided with our cruise.

a) GAK Surface Temperature

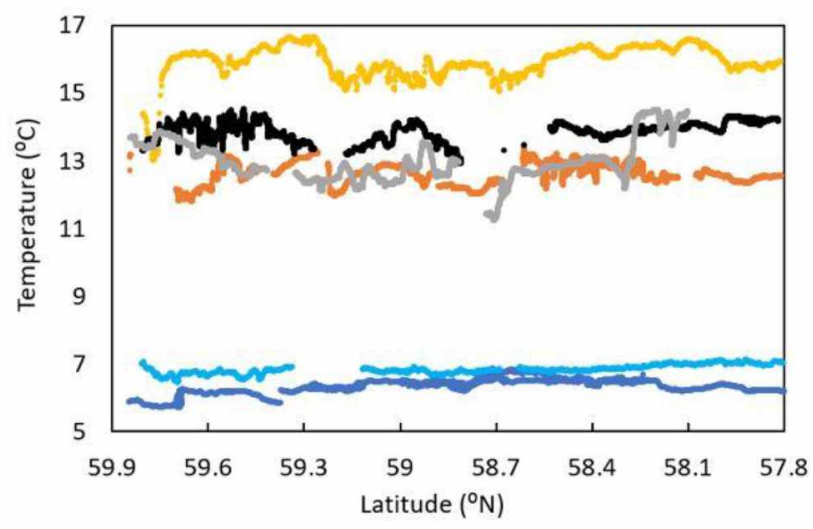

b) GAK Surface Salinity

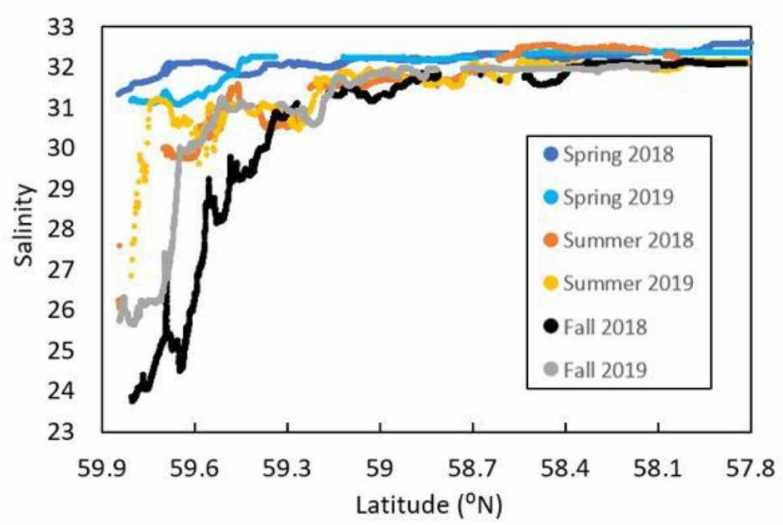

Figure 9: a) Surface temperatures and b) surface salinity values (both from underway data) recorded along the Seward Line in the Northern Gulf of Alaska on all 2018 and 2019 cruises.

Inshore/offshore gradients in $\mathrm{dAl}$ were more apparent along the Seward Line compared to the KOD Line (Fig. 10a). The strongest gradient was observed during fall 2018 with the highest value $(308.1 \mathrm{nM})$ furthest inshore followed by a decrease to about $10.8 \mathrm{nM}$ around $59.25^{\circ} \mathrm{N}$. Further south relatively similar concentrations were observed, and in all other seasons dAl in the offshore area of the Seward Line remained within the same range ( $\sim 1$ to $15 \mathrm{nM}$ ). Lower dAl concentrations in fall 2019 compared to the previous year likely resulted from the enhanced storm mixing over the shelf.
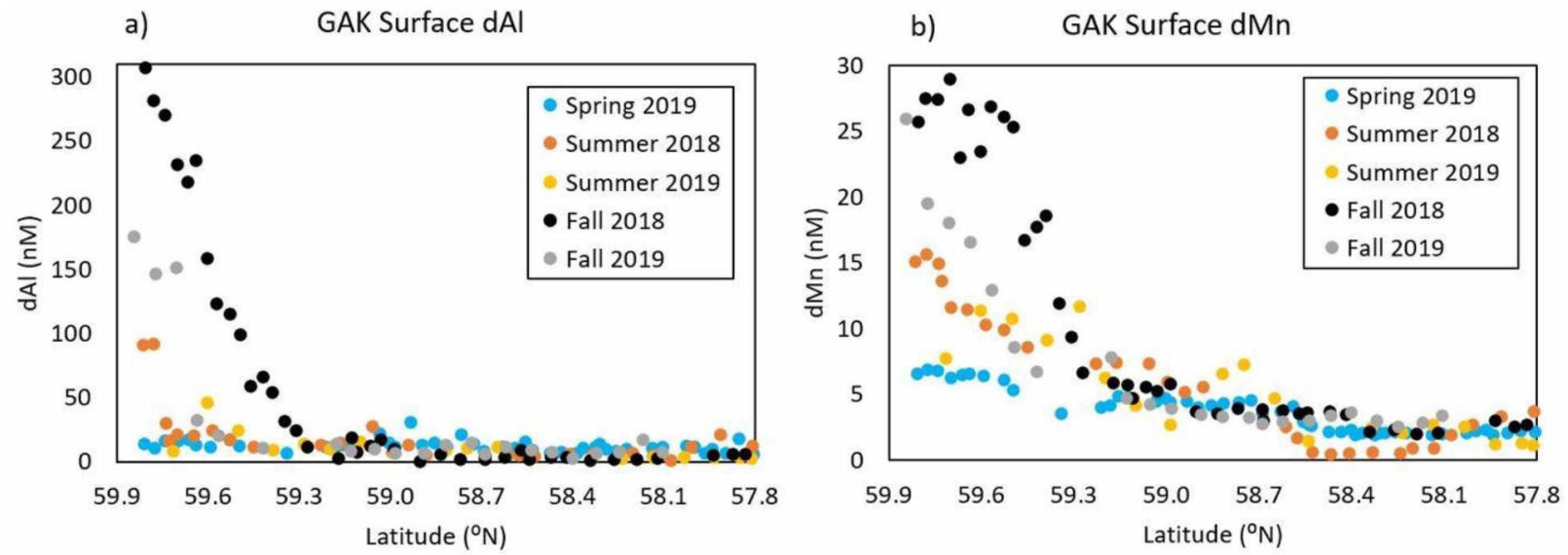

Figure 10: a) dAl and b) dMn vs. latitude along the Seward Line in the Northern Gulf of Alaska. 
Cross-shelf gradients and seasonal variability within the inshore stations were also observed for dMn (Fig. 10b). The lowest concentrations were observed in summer 2018 between $58.1^{\circ} \mathrm{N}$ and $58.6^{\circ} \mathrm{N}$, while the highest concentrations were observed inshore during fall 2018 . During all seasons $\mathrm{dMn}$ fell below $5 \mathrm{nM}$ south of $58.5^{\circ} \mathrm{N}$. The ACC, mid to outer shelf waters, and margin waters are well delineated by the distribution of $\mathrm{dMn}$ along the Seward Line. The map of surface dMn in spring 2019 (Fig. 11) also illustrates this well. In general dAl concentrations along the Seward Line were an order of magnitude higher than $\mathrm{dMn}$.

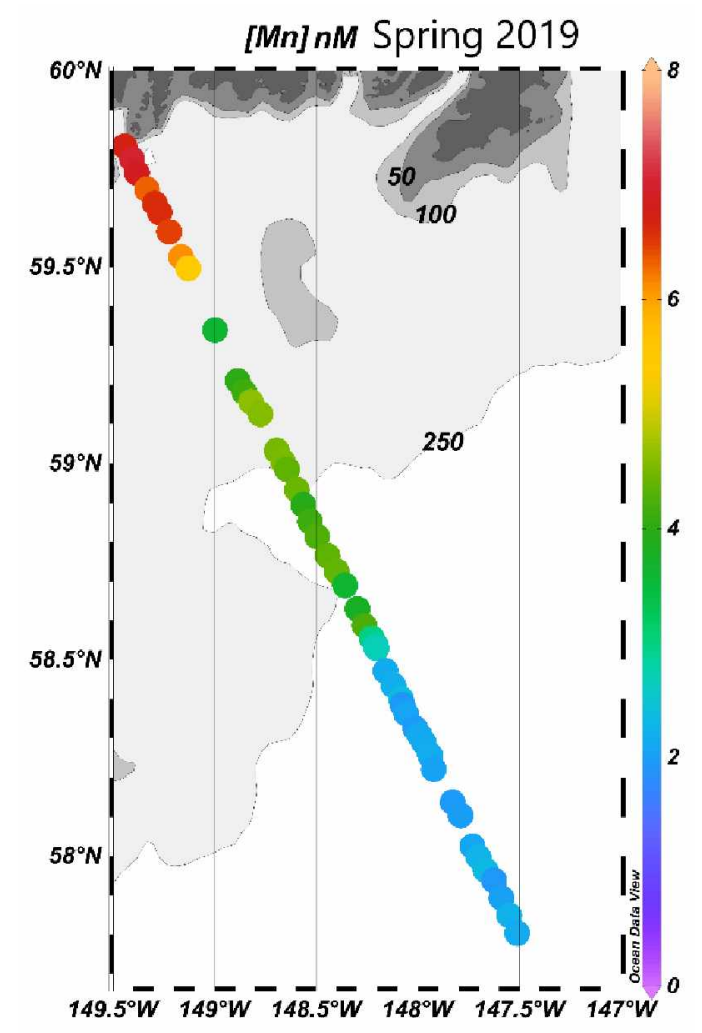

Figure 11: Map with superimposed surface dMn values along the Seward Line in the Northern Gulf of Alaska during spring 2019. Depth contours are marked in meters.

Linearity in the relationship between $\mathrm{dAl}$ and salinity increased from spring to fall along the Seward Line (Fig. 12a). In contrast dMn concentrations exhibited a high degree of linearity with salinity during all seasons, with the strongest conservative mixing line between fresh and saline water observed in summer (Fig. 12b). These plots further illustrate seasonal changes in freshwater influence along the $\mathrm{ACC}$, and its influence in surface $\mathrm{dAl}$ and $\mathrm{dMn}$, although seasonal differences between dissolved metals and salinity are not as pronounced here as on the KOD 
Line, especially for $\mathrm{dMn}$. The relationships of $\mathrm{dMn}$ and $\mathrm{dAl}$ vs. salinity were statistically significant $(\alpha=0.05)$ during all seasons, except for $\mathrm{dAl}$ vs. salinity in spring 2019 (Fig. 12).
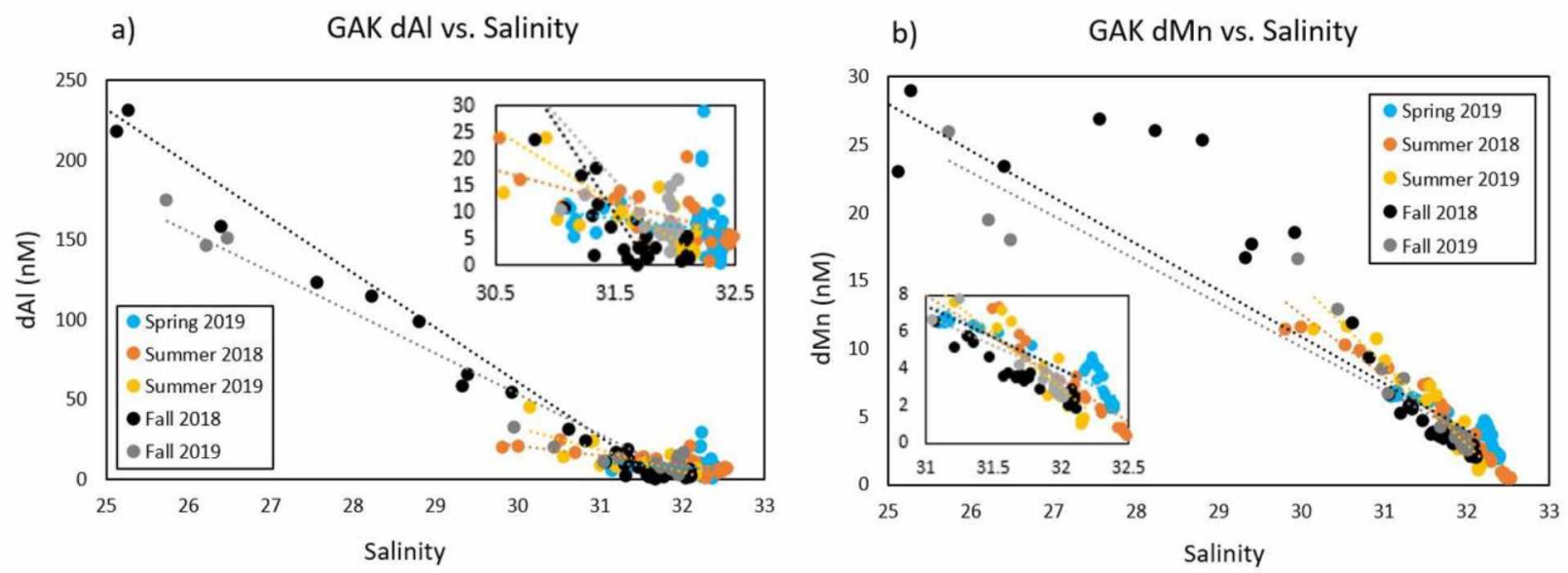

Figure 12: a) dAl and b) dMn vs. salinity along the Seward Line in the Northern Gulf of Alaska. The inserts show points (a) $\mathrm{dAl}<35 \mathrm{nM}$ and (b) $\mathrm{dMn}<8 \mathrm{nM}$ to highlight spring data.

\subsubsection{Middleton Island Line (MID)}

Spring surface temperatures on the MID Line exhibited the same pattern as GAK and KOD surface temperatures in the spring (Fig. 13a) with little variation throughout and higher values in 2019 than 2018 (average difference of $0.99^{\circ} \mathrm{C}$ ). Unlike the GAK and KOD Lines fall 2019 was warmer than fall 2018, and on both summer cruises the MID Line exhibited a significant drop in temperature reaching a minimum at MID6 (2019) or MID7 (2018) followed by an increase to MID8. Overall salinity was highest in the spring. Salinity at the inshore stations was lowest in the summer and were even lower than those observed at GAK1 (Fig. 13b) - the lowest salinity observed on the Seward Line was 23.86 during the fall 2018 cruise compared to 8.70 in the furthest inshore sample during the summer 2018 cruise. On all cruises, salinity changed most rapidly between MID1 and MID2. In summer, however, salinity increased gradually from MID2 to MID5 where it leveled out, while in fall salinity remained constant between MID2 and MID7 (2018) or MID5 (2019) where it increased again and leveled out at MID8. Even in spring, a slight decrease in salinity at MID1 is observable, with values of 30.52 and 29.50 in 2018 and 2019, respectively, which were the lowest spring salinity values observed on any of the three transects. During spring 2018, MID10 had a salinity of 32.39 compared to 32.6 at the outermost stations on the GAK and KOD lines. 
a)

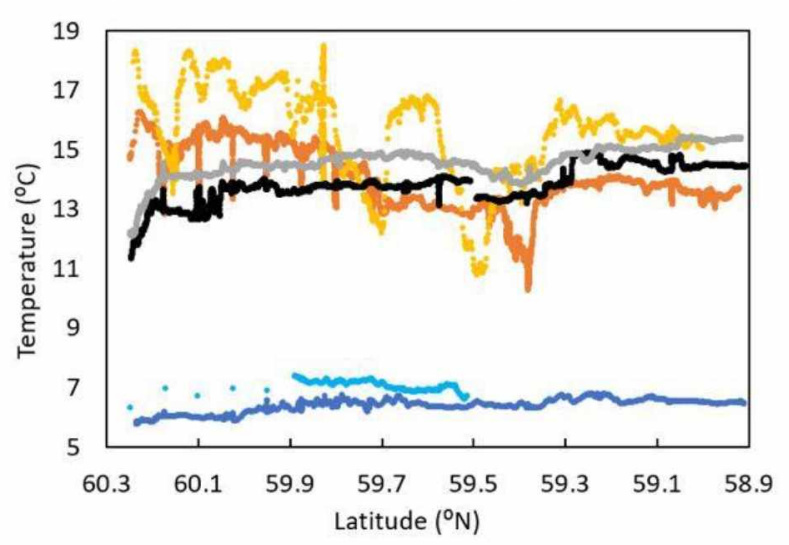

b) MID Surface Salinity

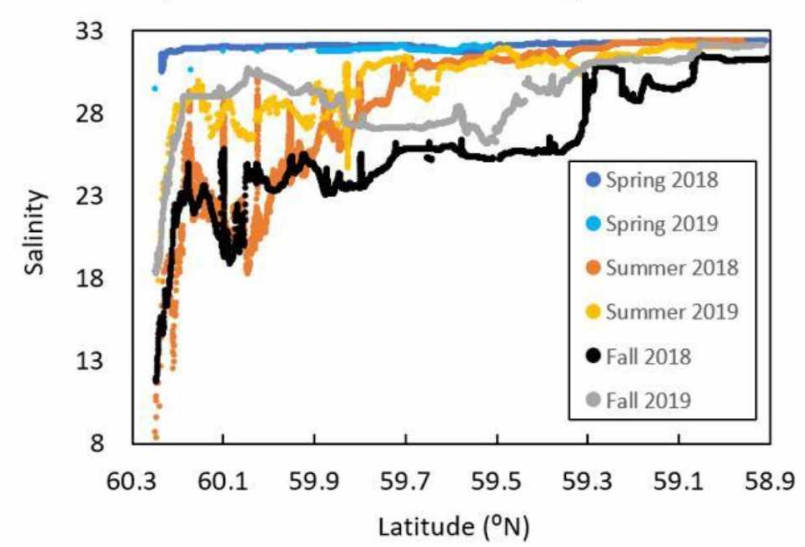

Figure 13: a) Surface temperatures and b) surface salinity values (both from underway data) recorded along the MID Line in the Northern Gulf of Alaska on all 2018 and 2019 cruises.

All transects exhibited the same general pattern of high $\mathrm{dAl}$ and $\mathrm{dMn}$ inshore decreasing moving offshore even in spring, although between the two years the highest observed values did not occur in the same season or even in the same location for $\mathrm{dAl}$ and $\mathrm{dMn}$. In 2018 the maxima for both metals occurred in the fall; the $\mathrm{dAl}$ maximum $(511.8 \mathrm{nM})$ was observed in the furthest inshore sample and the dMn maximum $(67.7 \mathrm{nM})$ was observed closer to MID2. During 2019 the maxima for both metals (1095 $\mathrm{nM} \mathrm{dAl}$ and $81.0 \mathrm{nM} \mathrm{dMn})$ were observed in the furthest inshore sample on the summer cruise (Fig. 14). The difference in $\mathrm{dAl}$ and $\mathrm{dMn}$ concentrations is similar here to that observed on the Seward Line. During summer and fall $\mathrm{dAl}$ values tended to be an order of magnitude higher than $\mathrm{dMn}$, with the exception of the maxima observed in summer 2019 where dAl reached micromolar values. During spring when both metals were lower the average $\mathrm{dAl}: \mathrm{dMn}$ ratio was 6.4. Both fall cruises also showed a slight increase in $\mathrm{dAl}$ and dMn around Middleton Island although summer 2019 did not (Fig. 15). 

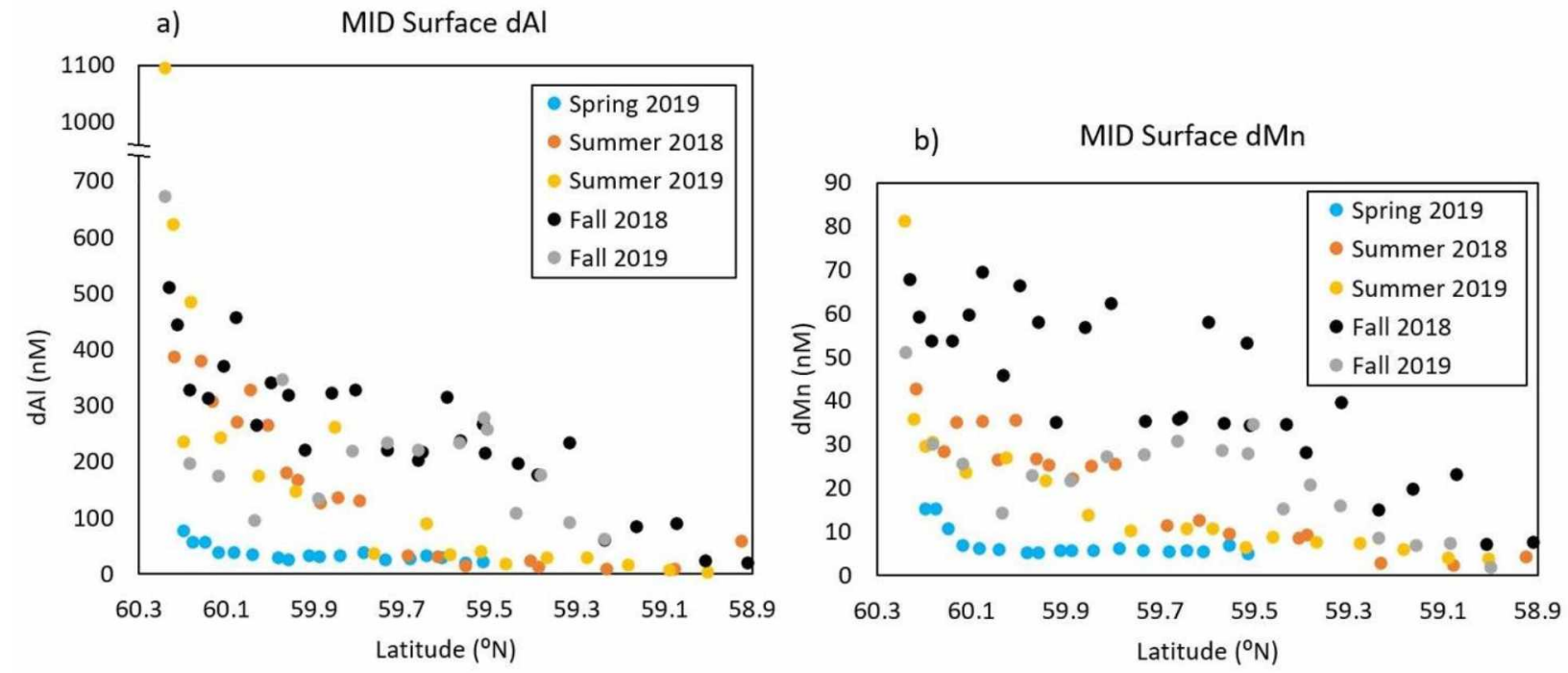

Figure 14: a) dAl and b) dMn vs. latitude along the MID Line in the Northern Gulf of Alaska.

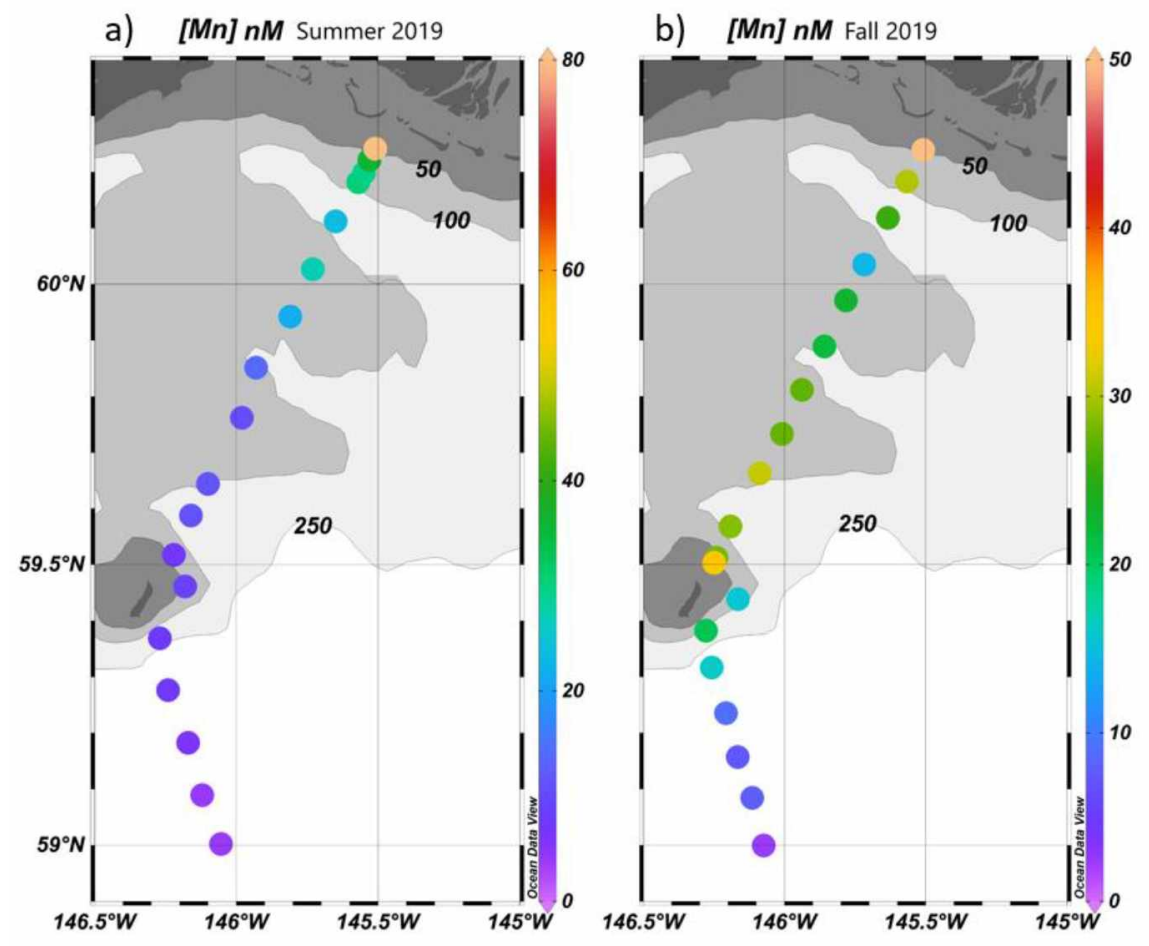

Figure 15: Maps with superimposed surface dMn values along the MID Line in the Northern Gulf of Alaska during a) summer 2019 and b) fall 2019. Depth contours are marked in meters.

Relationships of $\mathrm{dAl}$ and $\mathrm{dMn}$ with salinity were weakest in spring, however, both metals exhibited robust linear relationships with salinity during summer and fall cruises (Fig. 16), with the slopes of these lines varying seasonally and interannually. Both metals exhibited the steepest 
slope in summer 2019 and the shallowest slope in summer 2018. Changes in dAl with salinity were greater at the MID Line compared to the Seward Line and were more varied than changes of $\mathrm{dMn}$ with salinity. The relationship of $\mathrm{dAl}$ vs. salinity was significant $(\alpha=0.05)$ during all seasons (Fig. 16), while dMn vs. salinity was not significant only in spring.

a) MID dAl vs. Salinity

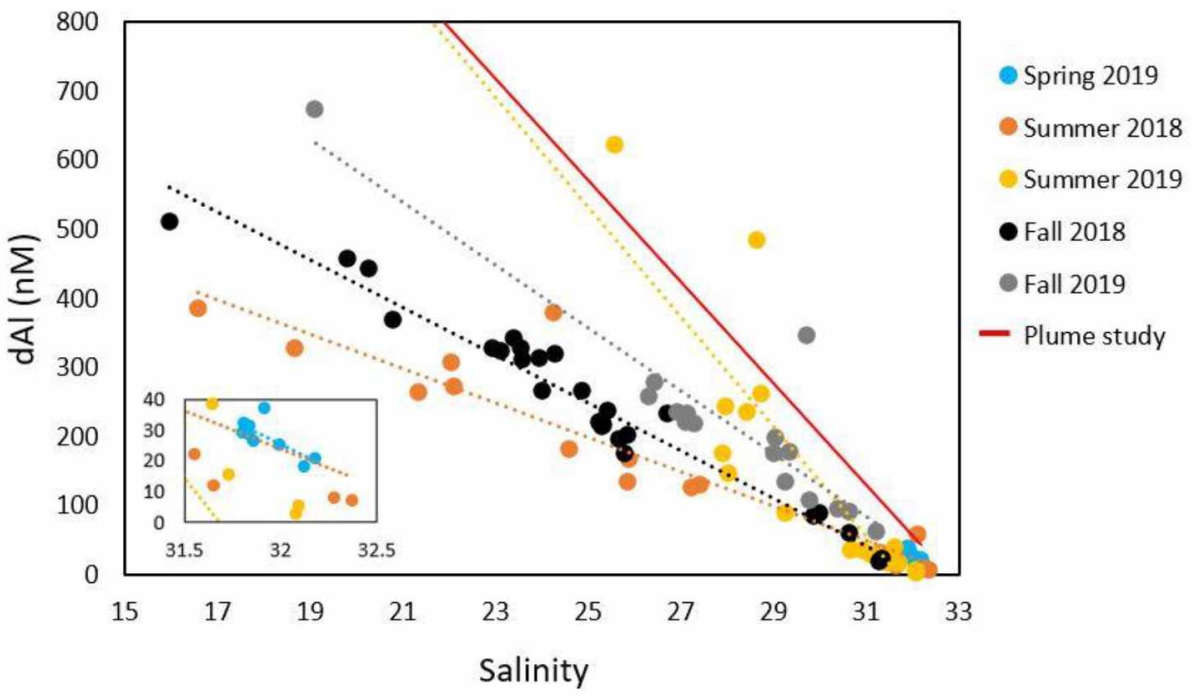

b)

MID dMn vs. Salinity

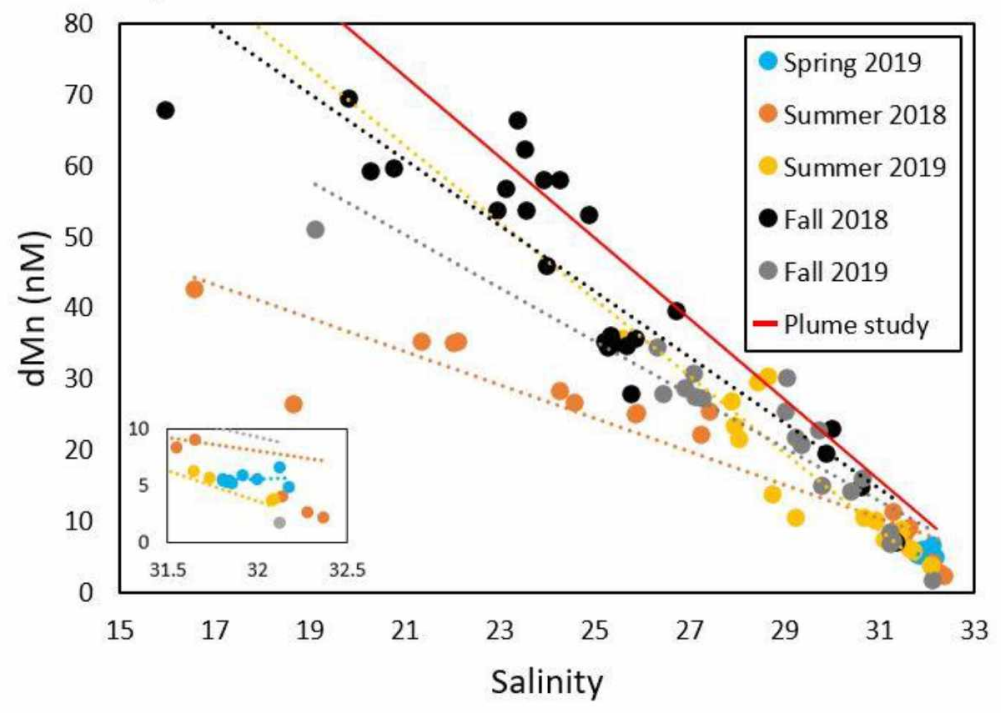

Figure 16: a) dAl and b) dMn vs. salinity along the MID Line in the Northern Gulf of Alaska. The red lines in a) and b) are trendlines from our summer 2019 Copper River plume study (data shown in Figs. 20 and 21), and inserts show samples with salinity 31.5-32.5 to highlight spring data. 


\subsubsection{Copper River Plume (Summer 2019)}

The Copper River Plume study was carried out over 5 days (7/4-7/8) during the summer 2019 cruise. It consisted of a series of transects that began at Station MID10 then moved inshore along the MID Line and sampled back and forth across the plume frontal zone between Hinchinbrook Island and Kayak Island, eventually moving southeast beyond the southern tip of Kayak Island, then turning back to the MID line and finally moving south to $\sim 58^{\circ} \mathrm{N}$. Average daily discharge for the Copper River during this 2019 plume study was high at $8,778 \mathrm{~m}^{3} / \mathrm{s}$ (USGS). The highest daily discharge value in all of 2019 was $9,798 \mathrm{~m}^{3} / \mathrm{s}$ observed on $7 / 3 / 19$, and the general peak discharge period for the year occurred from 7/2/19-7/10/19 (Fig. 17). The plume study also began during a spring tide, with a new moon on 7/2/19 and the greatest difference between high and low tides at Middleton Island occurring on 7/4/19 (NOAA tide predictions for north end of Middleton Island). The lowest temperatures $\left(10.8^{\circ} \mathrm{C}\right)$ were observed in proximity of Middleton Island while the highest temperatures $\left(18.8^{\circ} \mathrm{C}\right)$ were observed inshore in near-plume waters (Fig. 18a). As expected, the lowest surface salinity (10.79) was observed just southwest of the Copper River delta, while the highest (32.25) was sampled in offshore waters at the end of the transect (Fig. 18b). Salinity and temperature demonstrate the inherent patchiness of surface shelf waters in the NGA. For example, a patch of warmer and fresher water off the southern tip of Kayak Island is apparent on two separate legs of the transect, and a section of the southern transect east of the MID Line exhibited fresher and warmer water than the MID Line at the same latitudes. 


\section{Copper River Discharge}

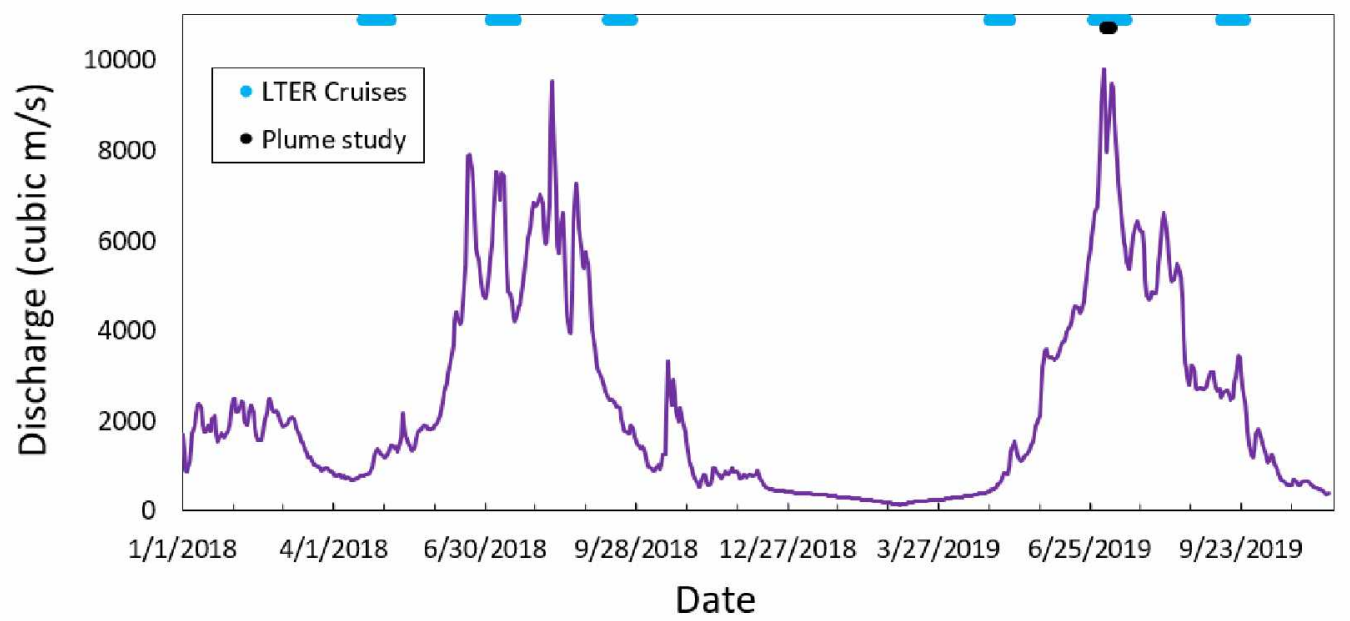

Figure 17: Mean daily Copper River discharge $\left(\mathrm{m}^{3} / \mathrm{s}\right)$ measured by USGS at Million Dollar Bridge. Blue markers indicate the dates of 2018 and 2019 cruises and the black marker indicates the dates of the summer 2019 plume study.
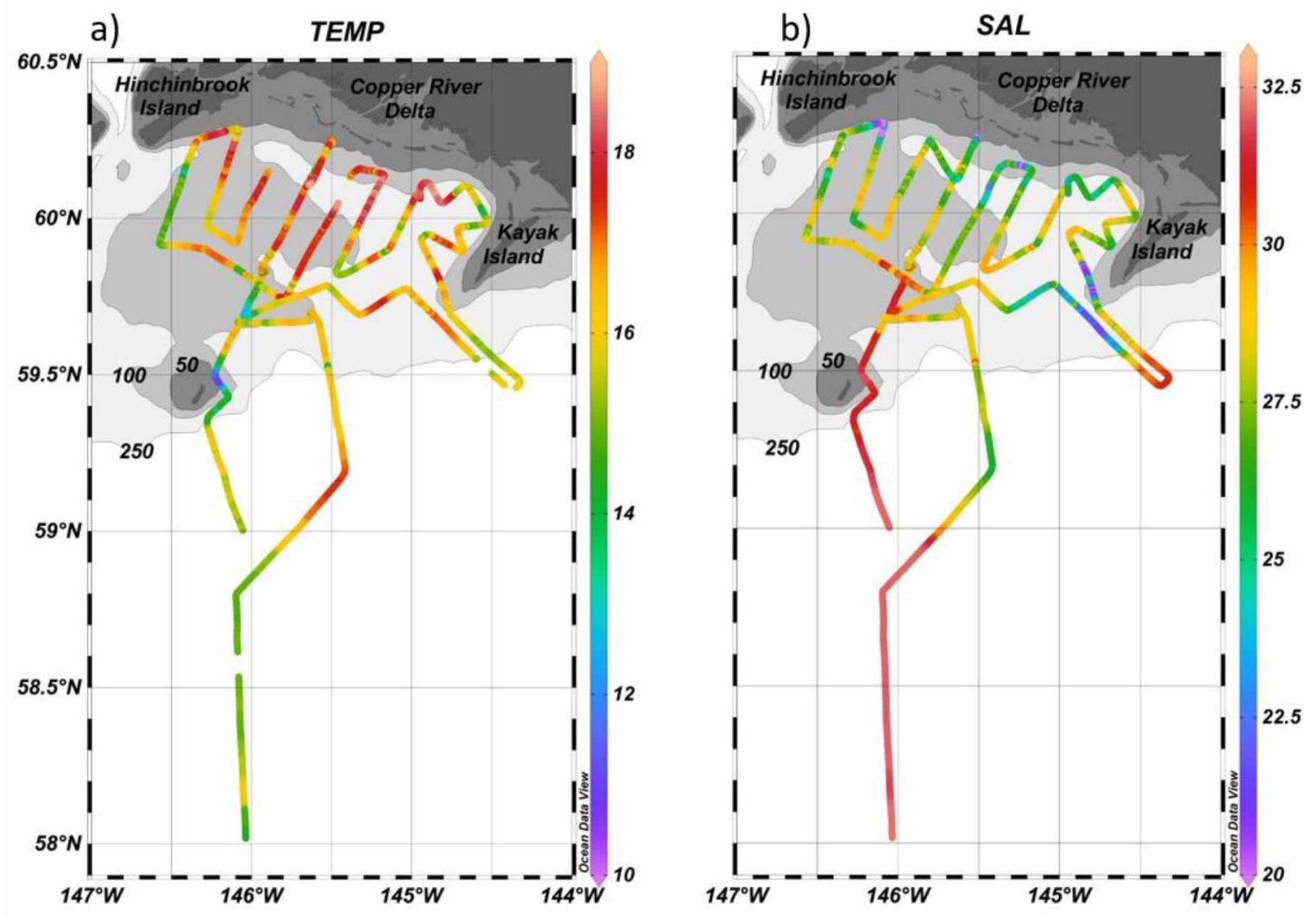

Figure 18: a) Surface temperature $\left({ }^{\circ} \mathrm{C}\right)$ and b) surface salinity (both from underway data) during the 2019 plume study in the Northern Gulf of Alaska. Depth contours are marked in meters. 
A concentration gradient from inshore to offshore was apparent for $\mathrm{dAl}$ and $\mathrm{dMn}$. Dissolved Al values exceeded 1,000 $\mathrm{nM}$ at the inshore areas near the Copper River mouth and just off the west coast of Kayak Island (Fig. 19a). In general dAl varied inversely with surface salinity as expected given high input of dAl by glacial rivers (Fig. 20a). However, the highest observed surface dAl value was $1395 \mathrm{nM}$ coincided with an intermediate salinity of 25.98 at a point off the west coast of Kayak Island in water $138.9 \mathrm{~m}$ deep, suggesting potential additional inputs. The range of concentrations for $\mathrm{dMn}$ along the transects was lower than $\mathrm{dAl}$ by an order of magnitude, with a maximum observed value of $128.0 \mathrm{nM}$ in near plume waters and decreasing to $<1 \mathrm{nM}$ in offshore waters (Fig. 19b). The maximum observed dMn value was not coincident with the dAl maximum, but occurred at the sampling location closest to the mouth of the Copper River at a salinity value of 19.90 .
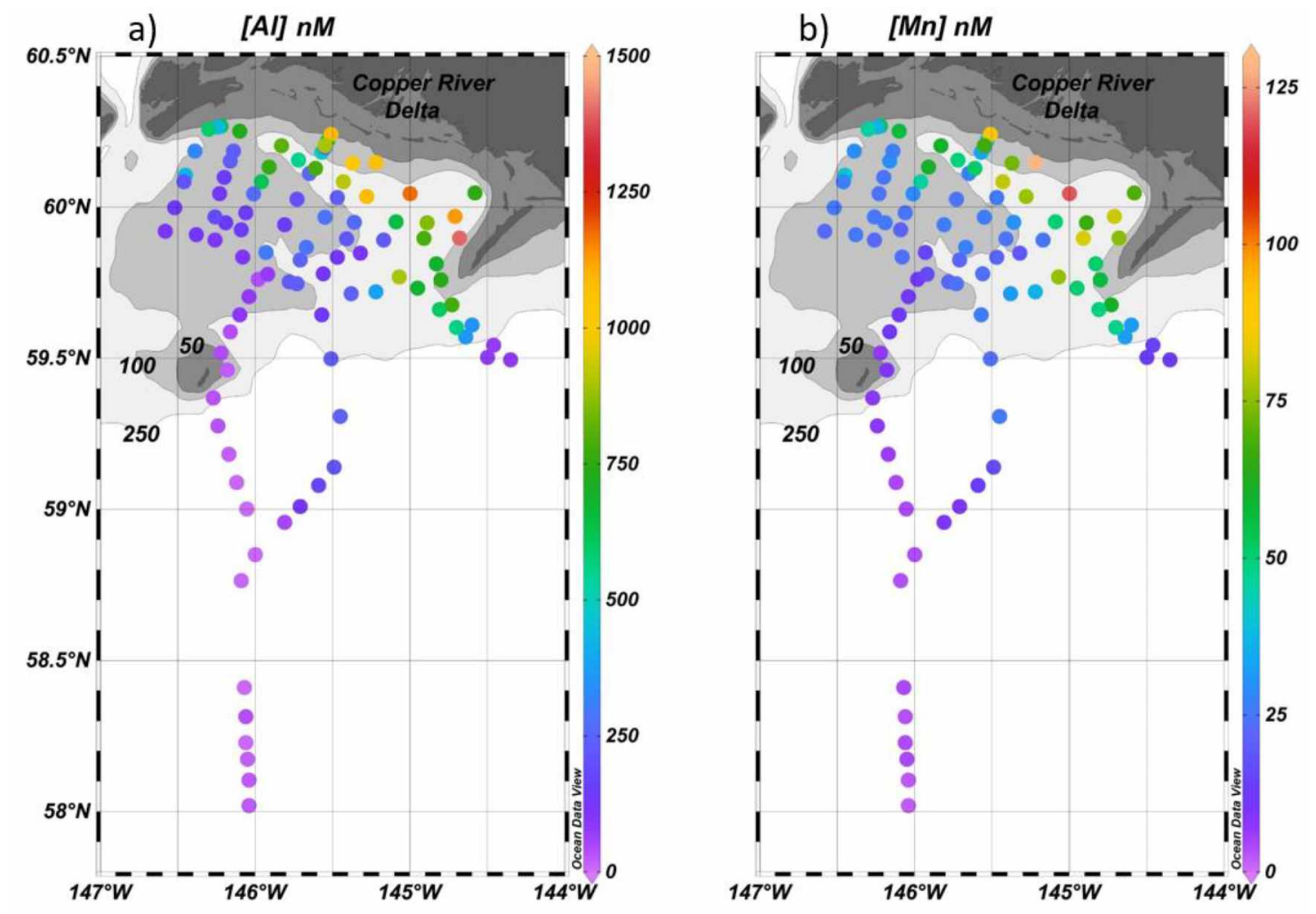

Figure 19: Maps of surface a) dAl and b) dMn for the 2019 plume study in the Northern Gulf of Alaska. Depth contours are marked in meters.

The relationships between salinity and dissolved metals tended to be conservative in regions further away from the Copper River delta, while in shallow regions of the shelf these 
relationships showed non-conservative mixing (Figs. 20 and 21) where other processes besides input of freshwater contributed to the elevated $\mathrm{dAl}$ and $\mathrm{dMn}$ values relative to salinity between about 18-30. The rapid decrease in concentration along the salinity gradient also demonstrates how efficiently $\mathrm{dAl}$ and $\mathrm{dMn}$ are removed from surface waters over the shelf and reflect some of the patchiness in the salinity/temperature fields.

Both metals showed statistically significant correlations with salinity within the plume study region ( $p<0.0001$, Figs. 20 and 21 ). While linear trends are apparent from salinity 21 to 32.5 , many samples between salinity $\sim 25-30$ showed elevated $\mathrm{dAl}$ and $\mathrm{dMn}$ relative to salinity. These elevated points at mid salinities are likely due to continued desorption from particles in the high sediment load carried by the glacially-fed Copper River.

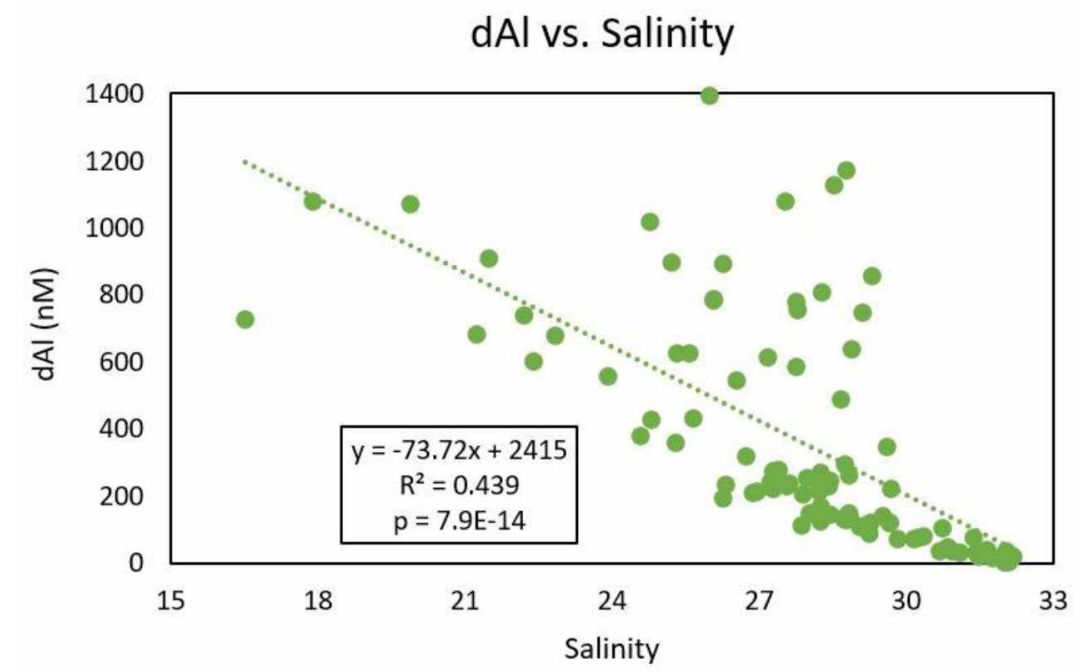

Figure 20: dAl vs. salinity for the Copper River plume study (summer 2019) in the Northern Gulf of Alaska. 
dMn vs. Salinity

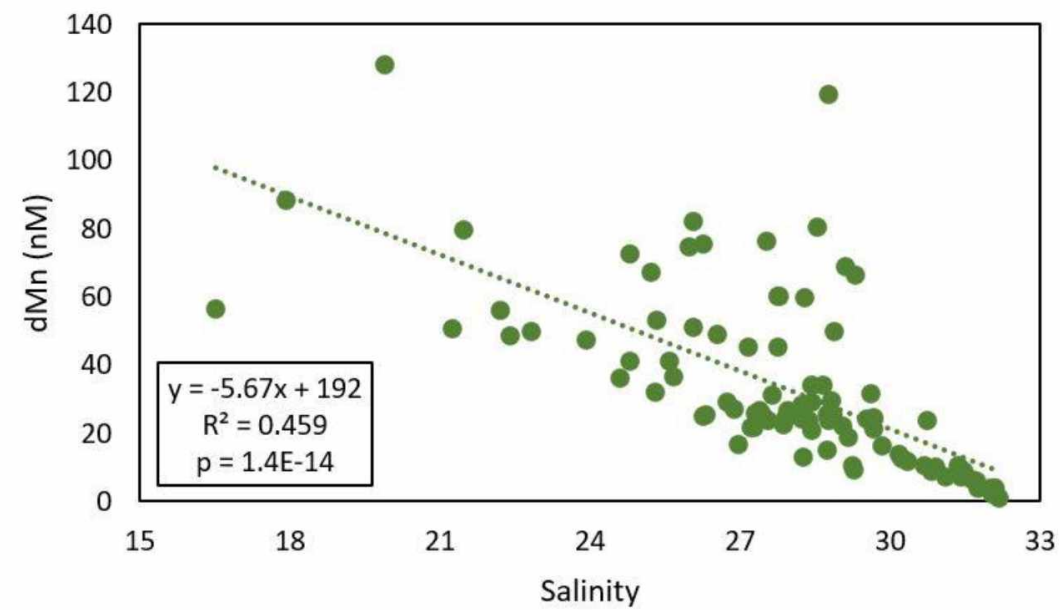

Figure 21: dMn vs. salinity for the Copper River plume study (summer 2019) in the Northern Gulf of Alaska.

\subsubsection{Residence Times}

Residence times were estimated for surface $\mathrm{dAl}$ and $\mathrm{dMn}$ over the shelf in the area around the inner MID Line and Copper River outflow (Table 4). In all seasons the estimated residence time for $\mathrm{dAl}$ was lower than that for $\mathrm{dMn}$ and in both years it was lower in summer than fall, yielding an overall average of 31 days for $\mathrm{dAl}$ and 42 days for $\mathrm{dMn}$. The residence times calculated for both metals in 2018 are more than double those calculated for the same seasons in 2019. For summer, this is mostly due to differences in Copper River outflow between the two years while in fall this difference is mostly due to much larger $\mathrm{dAl}$ and $\mathrm{dMn}$ reservoirs in 2018 (section 2.3.5) 
Table 4: Residence times for $\mathrm{dAl}$ and $\mathrm{dMn}$ in surface waters over the shelf in the Northern Gulf of Alaska from $\sim 144.4^{\circ} \mathrm{W}$ to $\sim 146.4^{\circ} \mathrm{W}$.

\begin{tabular}{|c|c|c|}
\hline & dAl & dMn \\
\hline Summer 2018 & $\sim 14$ days & $\sim 23$ days \\
\hline Summer 2019 & $\sim 5$ days & $\sim 10$ days \\
\hline Fall 2018 & $\sim 75$ days & $\sim 88$ days \\
\hline Fall 2019 & $\sim 30$ days & $\sim 46$ days \\
\hline Overall avg. & 31 days & 42 days \\
\hline
\end{tabular}

\subsubsection{Depth Profiles (Spring 2018 and Summer 2019)}

Vertical profiles were collected at six stations (Fig. 3). Temperature and salinity profiles for Station KOD5 indicate a relatively well-mixed water column in spring 2018 compared to summer 2019. The profiles for light transmission indicate a gradual increase in particles with depth during spring 2018. During summer 2019, temperature, salinity and beam transmission indicate a surface mixed layer down to $20 \mathrm{~m}$ that transitioned to a well-mixed deeper layer below $30 \mathrm{~m}$ (Fig. 21). Little vertical variability in dMn compared to dAl was observed at KOD5 during both seasons (Fig. 22). During spring 2018, both metals tended to increase with depth and had

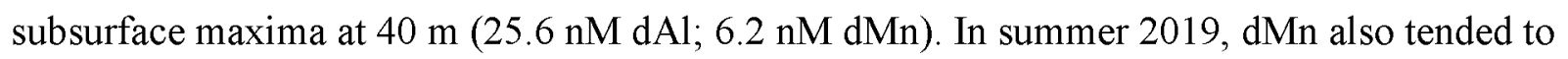
increase with depth, with a minimum $(4.4 \mathrm{nM})$ at the surface and a subsurface maximum at $50 \mathrm{~m}$ $(6.8 \mathrm{nM})$. In contrast, dAl appeared to decrease with depth in summer 2019. The surface and 50 $\mathrm{m}$ values (summer 2019) for $\mathrm{dAl}$ were lost during processing and could not be quantified. 
a) KOD5 Temperature

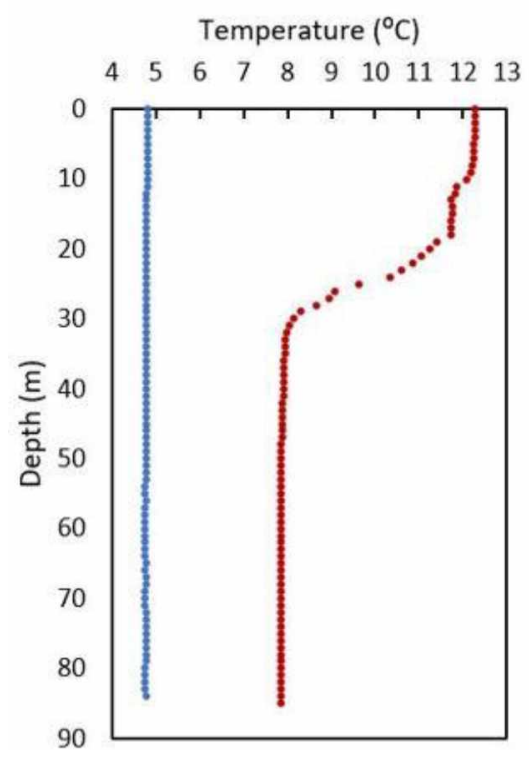

b) KOD5 Salinity

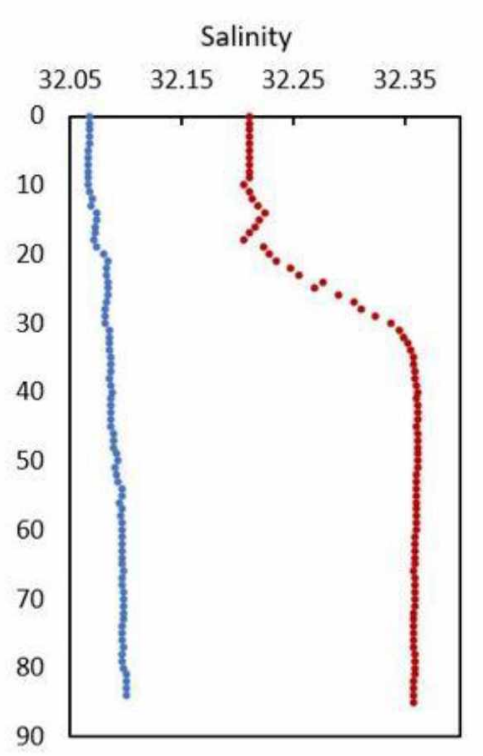

c) KOD5 Beam Transmission

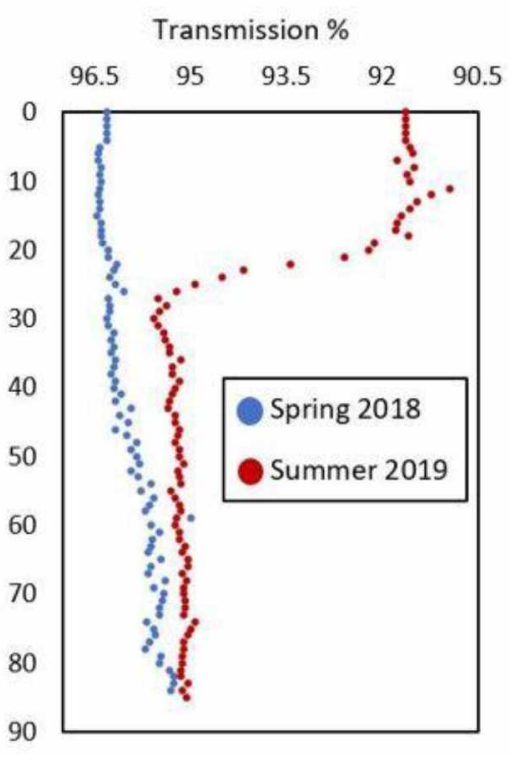

Figure 22: a) Temperature, b) salinity, and c) transmissivity for KOD5 from CTD casts on 4/19/18 and 7/15/19 in the Northern Gulf of Alaska. The bottom depth at KOD5 is $87 \mathrm{~m}$.

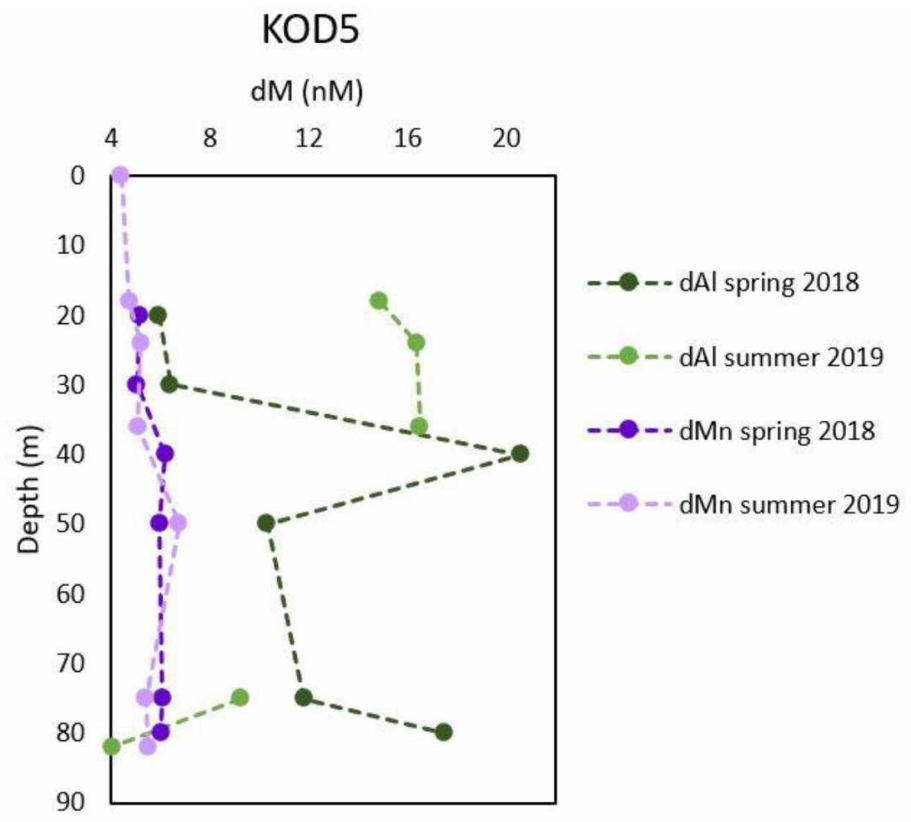

Figure 23: dAl and dMn profiles for KOD5 in the Northern Gulf of Alaska on 4/19/18 and 7/15/19. Dissolved $\mathrm{Al}$ are missing from $0 \mathrm{~m}$ and $50 \mathrm{~m}$ in the summer 2019 profile as these samples were preconcentrated on a different day, and sat too long prior to analysis, rendering the Al values unusable. 
Temperature and salinity at GAK1 indicated a colder water column in the upper $\sim 200 \mathrm{~m}$ in spring 2018 compared to summer 2019, and much fresher water in the upper $15 \mathrm{~m}$ during summer (Fig. 23). Deeper water (below $200 \mathrm{~m}$ ) at this station had similar T and S characteristics during both seasons. A lower particle load over the entire water column was observed in spring compared to summer, with summer 2019 exhibiting a near-surface particle maximum at $18 \mathrm{~m}$ from biological particles and a bottom particle maximum from resuspended sediment (Fig. 23). In contrast, spring 2018 exhibited a less pronounced particle maximum at depth and no observable maximum at the surface. In general $\mathrm{dAl}$ tended to be present in greater concentrations than dMn at GAK1. Surface inputs for $\mathrm{dAl}$ and dMn were particularly apparent in summer 2019 with surface maxima for both metals (as high as $214.5 \mathrm{nM}$ for $\mathrm{dAl}$ and $38.0 \mathrm{nM}$ for $\mathrm{dMn}$ ) that decreases rapidly with depth (Fig. 24). During spring 2018, a sedimentary source for both metals was apparent in enhanced metal concentrations ( $\sim 49 \mathrm{nM}$ for both) below $200 \mathrm{~m}$ that coincided with the decrease in transmissivity. This systematic increase in $\mathrm{dAl}$ and $\mathrm{dMn}$ with depth in the deeper layers of the water column was not apparent in summer 2019, although the decrease in light transmission was more pronounced and subsurface maximum concentrations were observed at $180 \mathrm{~m}$ for both $\mathrm{dAl}(81.3 \mathrm{nM})$ and $\mathrm{dMn}(27.7 \mathrm{nM})$. Vertical distributions at GAK1 at intermediate depths $(30-150 \mathrm{~m})$ ranged from 4.5-13 $\mathrm{nM}$ for $\mathrm{dAl}$ and 1.9-9.3 $\mathrm{nM}$ for $\mathrm{dMn}$ during both seasons.
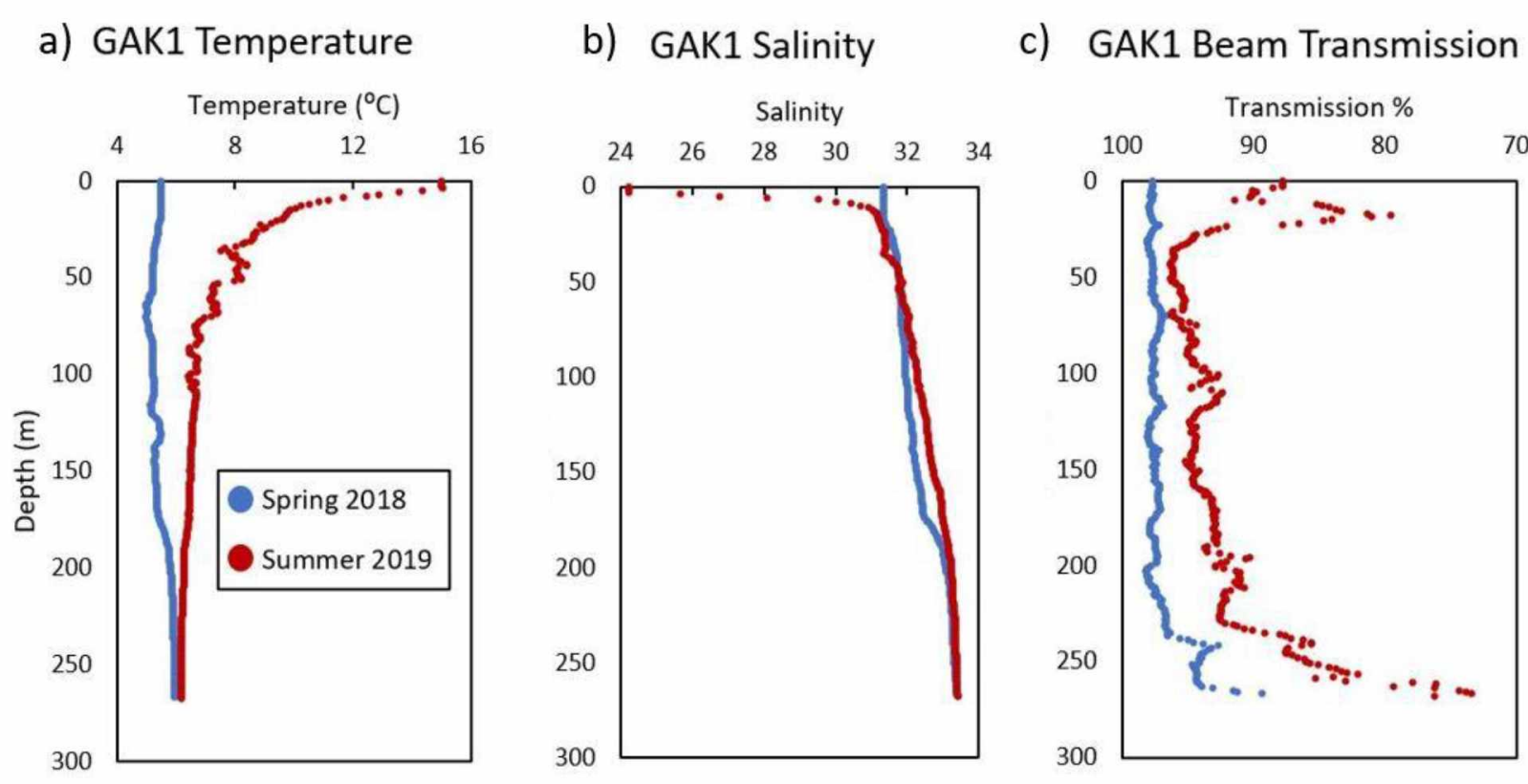

Figure 24: a) Temperature, b) salinity, and c) transmissivity at GAK1 from CTD casts on 5/4/18 and 6/29/19 in the Northern Gulf of Alaska. The bottom depth at GAK1 is $270 \mathrm{~m}$. 


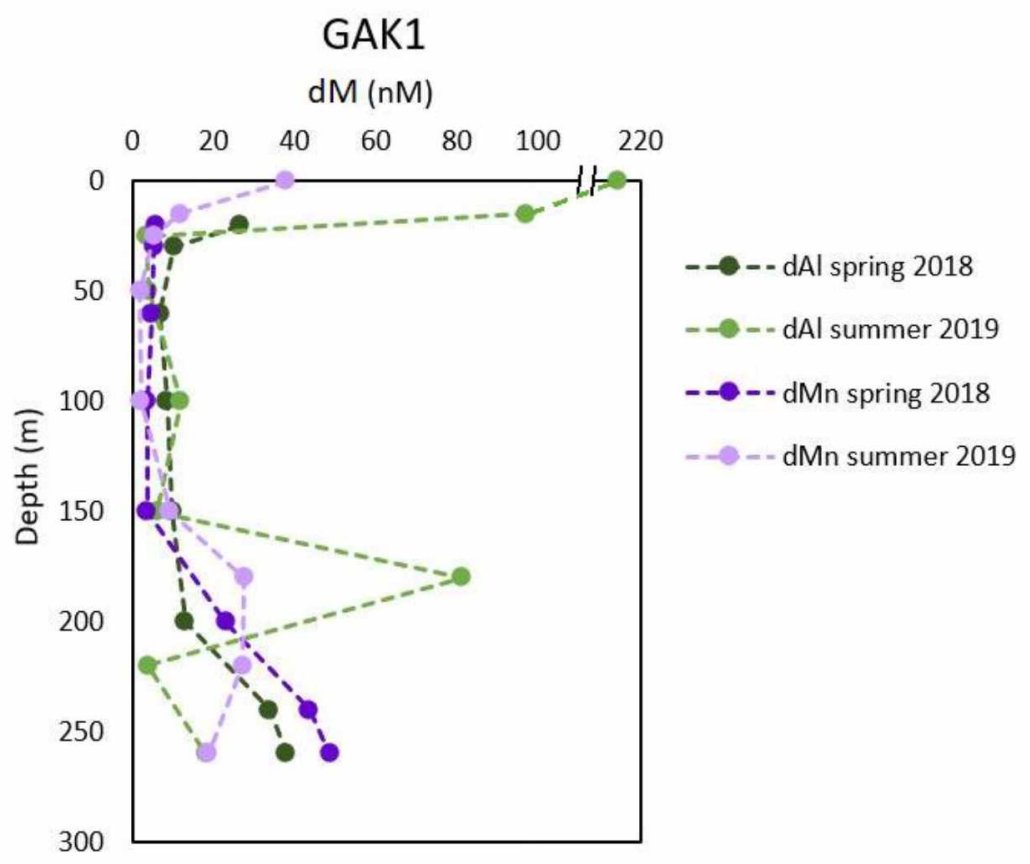

Figure 25: dAl and dMn profiles for GAK1 in the Northern Gulf of Alaska on 5/4/18 and $6 / 29 / 19$.

While the temperature profiles at GAK5 closely mirror those at GAK1 during both seasons, the decrease in surface salinity in summer 2019 at GAK 5 was much less pronounced (Fig. 25). This shallower station exhibited seasonal differences in its deeper waters with summer 2019 carrying saltier offshore waters below $100 \mathrm{~m}$. An increase in suspended particles was observed at $30 \mathrm{~m}$ during spring 2018 and at $15 \mathrm{~m}$ during summer 2019 at this station. Similar to GAK1, maxima in suspended particles in bottom waters were also observed at GAK5 during both seasons. At GAK5 dAl concentrations were greater than dMn concentrations during both seasons, and as expected surface maxima for both metals were lower than at GAK1. In general, the surface maxima were more pronounced for $\mathrm{dMn}$ in summer 2019 compared to spring 2018, while surface waters exhibited similar $\mathrm{dAl}(\sim 14 \mathrm{nM})$ during both seasons (Fig. 26). At intermediate depths (20 to $75 \mathrm{~m}$ ), lower concentrations of both metals were observed during summer 2019 as compared to 2018. In general, metal concentrations tended to increase below $100 \mathrm{~m}$ during both seasons and during summer 2019 subsurface changes in dAl mirrored changes the transmissivity data that showed two regions with increased suspended particles at $120 \mathrm{~m}$ and $167 \mathrm{~m}$ (Figs. 25 and 26). 


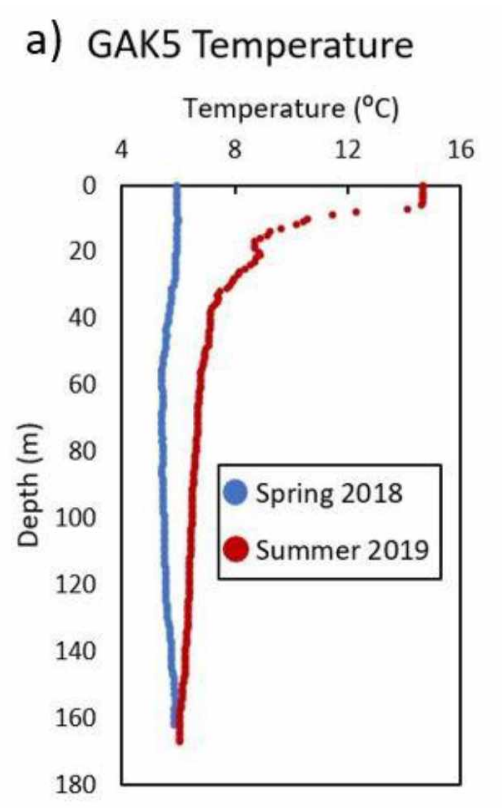

b) GAK5 Salinity

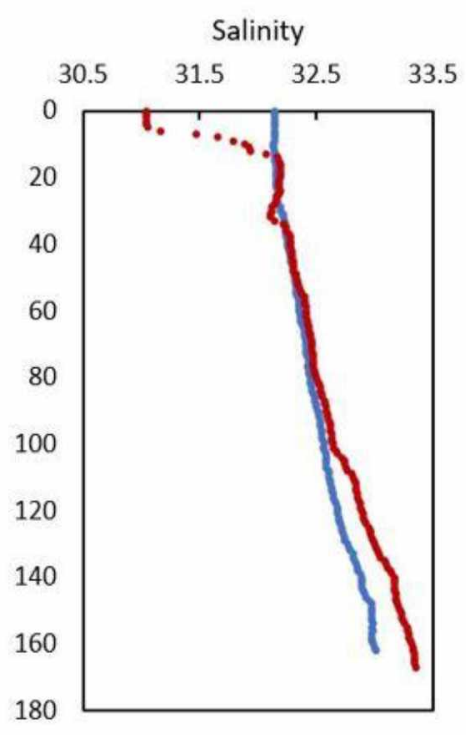

c) GAK5 Beam Transmission

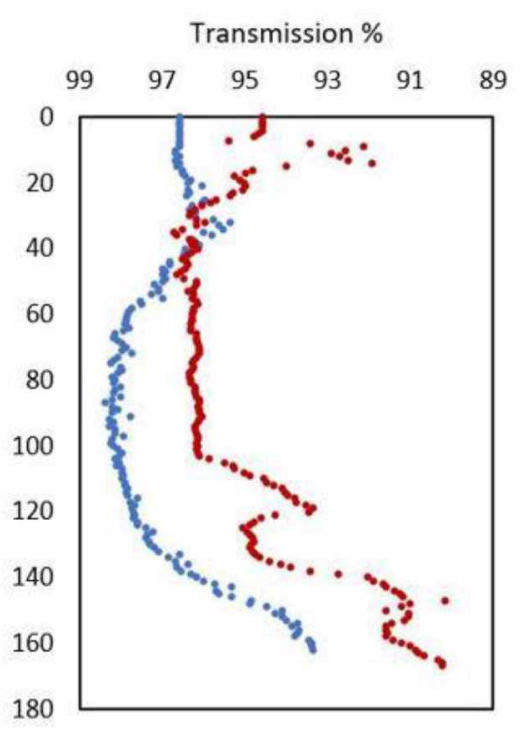

Figure 26: a) Temperature, b) salinity, and c) transmissivity at GAK5 from CTD casts in the Northern Gulf of Alaska on 5/3/18 and 7/13/19. The bottom depth at GAK5 is $167 \mathrm{~m}$.

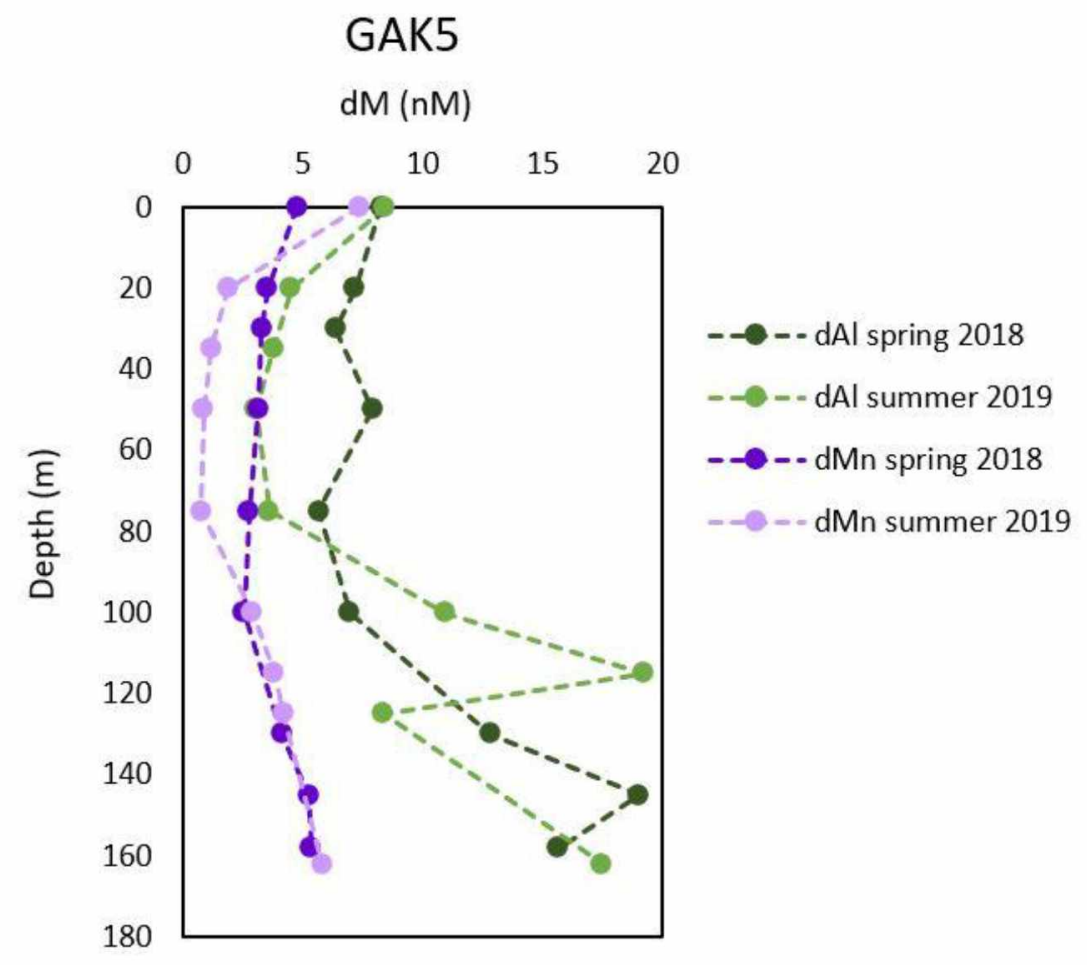

Figure 27: dAl and dMn profiles for GAK5 in the Northern Gulf of Alaska on 5/3/18 and $7 / 13 / 19$. 
Station MID2 is an inner-shelf station, and similar to GAK1 this location exhibited much lower surface salinity in summer 2019 (27.2) relative to spring 2018 (32.0). Here, warmer waters were observed in summer 2019 throughout the entire water column compared to spring 2018, and deeper waters (below $75 \mathrm{~m}$ ) were fresher in the spring profile (Fig. 27). Also similar to GAK1 beam transmission throughout the water column was reduced during summer 2019 compared to spring 2018. A signal from resuspended particles was apparent from the bottom up to $\sim 100 \mathrm{~m}$ depth during both seasons, and the upper water column (surface to $\sim 40 \mathrm{~m}$ depth) exhibited more structure in beam attenuation during summer 2019 than in spring 2018. During spring 2018 vertical dAl and dMn distributions were lower than in summer 2019 throughout the water column (Fig. 28). Also, dMn during both seasons and dAl during spring 2018 increased in the bottom two samples tracking the decrease in transmissivity at the bottom of the water column. However, dAl in summer 2019 exhibited greater concentrations at mid-depths (50 - 75 m) than at the bottom two samples.

a) MID2 Temperature

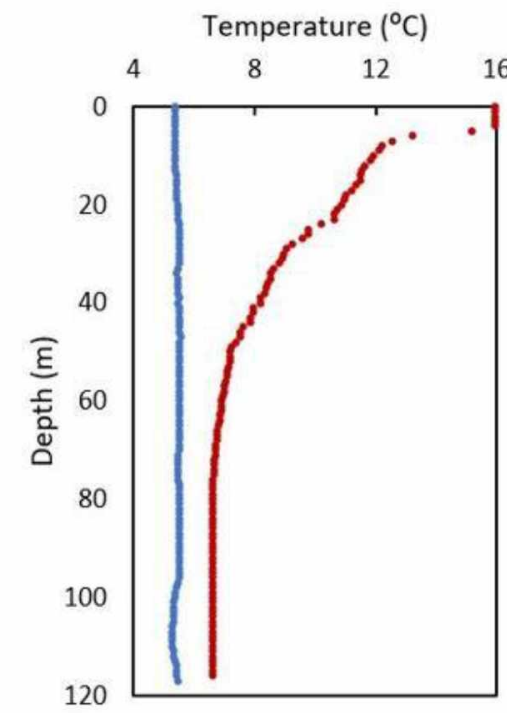

b) MID2 Salinity

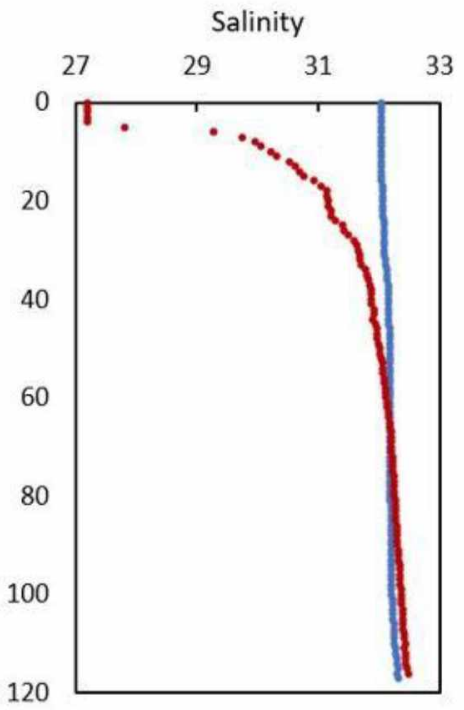

c) MID2 Beam Transmission

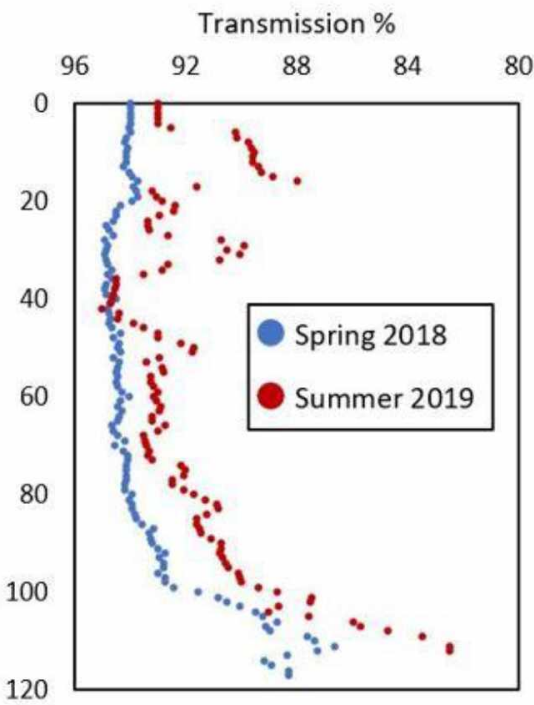

Figure 28: a) Temperature, b) salinity, and c) transmissivity at MID2 from CTD casts in the Northern Gulf of Alaska on 4/26/18 and 7/1/19. The bottom depth at MID2 is $118 \mathrm{~m}$. 


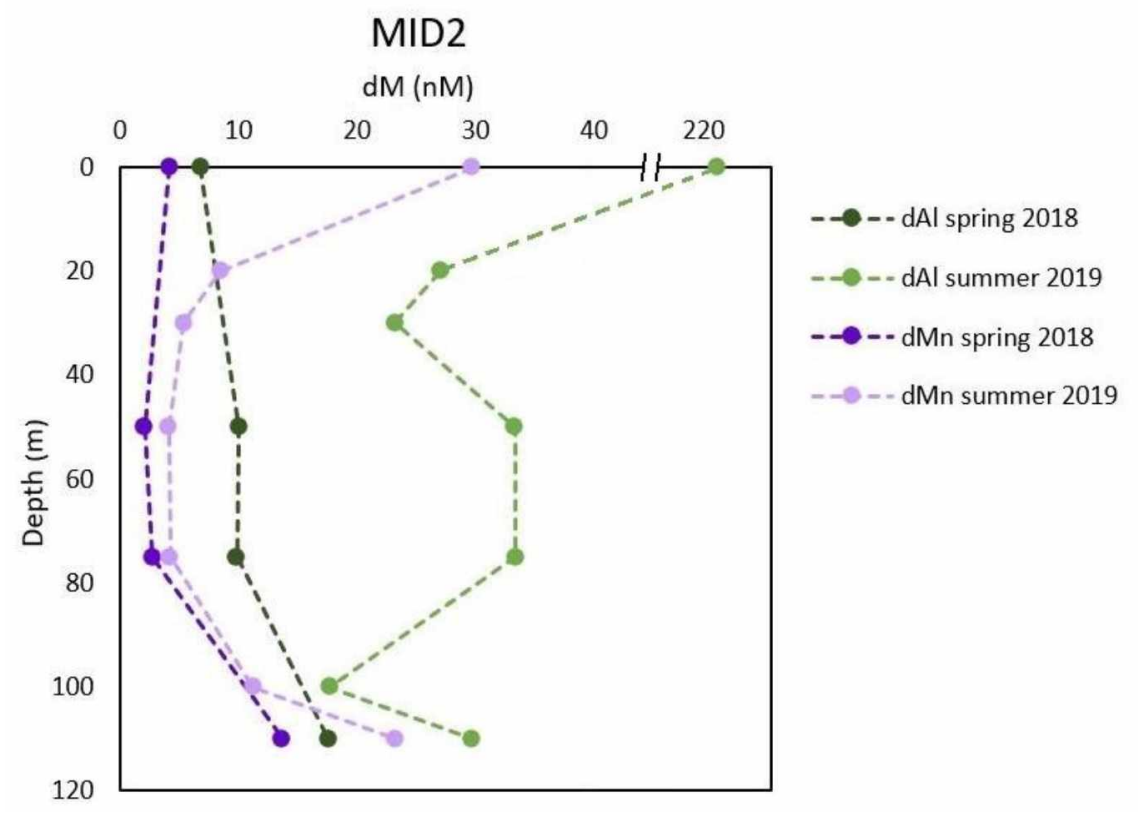

Figure 29: dAl and dMn profiles for MID2 in the Northern Gulf of Alaska on 4/26/18 and $7 / 1 / 19$.

The temperature profiles observed at MID5 followed the same broad pattern as other shelf stations, with colder waters and less variability in spring 2018 compared to summer 2019. Surface temperatures during summer 2019 were cooler than those at GAK5, but warmer than surface waters at KOD5. The observed salinity values at MID5 were fresher than those observed at GAK5 throughout the water column, and the salinity profile in spring 2018 indicated stratification in the upper $30 \mathrm{~m}$ which was not apparent in the temperature data (Fig. 29). At this station, lower beam transmission was also observed in summer 2019 compared to spring 2018, with the exception of the region between $\sim 25-50 \mathrm{~m}$. The difference in surface dAl between MID2 and MID5 in summer 2019 (221.0 nM vs. $57.8 \mathrm{nM}$ ) emphasizes the rapid loss of dA1 moving offshore. Similar to MID2 (and other shelf stations) the impact of fresh water on surface metal concentrations is less pronounced for $\mathrm{dMn}$, with MID5 exhibiting no enhancement in $\mathrm{dMn}$ at the surface between spring and summer. In both seasons $\mathrm{dMn}$ profiles exhibited lower concentrations at mid-depths $(20-50 \mathrm{~m})$, with surface and bottom inputs. A bottom input for dAl was not pronounced here. (Fig. 30). Samples for dAl for spring 2018 are not included as the samples sat too long between preconcentration and analysis and the $\mathrm{dAl}$ data were unusable. 
a) MID5 Temperature

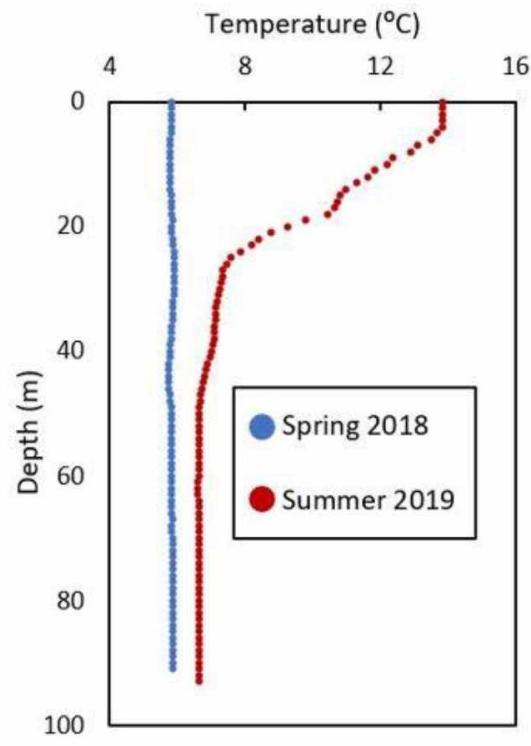

b) MID5 Salinity

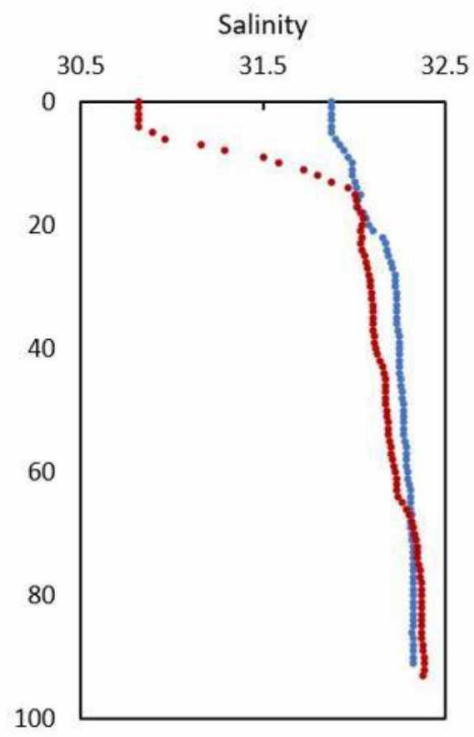

c) MID5 Beam Transmission

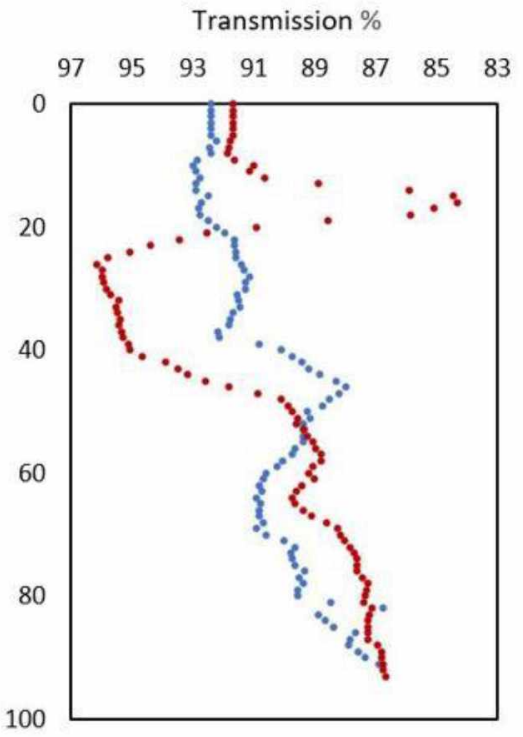

Figure 30: a) Temperature, b) salinity, and c) transmissivity at MID5 from CTD casts in the Northern Gulf of Alaska on 4/27/18 and 7/2/19. The bottom depth at MID5 is $95 \mathrm{~m}$.

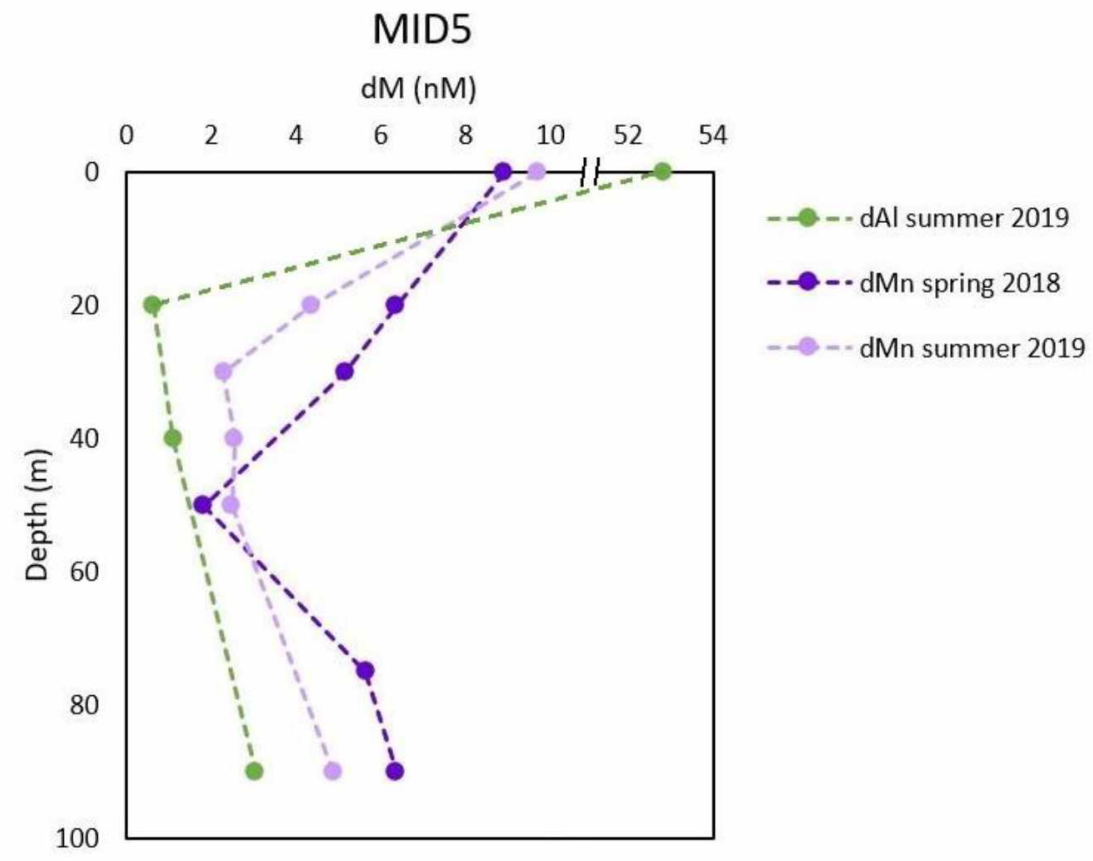

Figure 31: dAl and dMn profiles for MID5 in the Northern Gulf of Alaska on 4/27/18 and $7 / 2 / 19$.

Prince William Sound is impacted by several surrounding glaciers and includes regions with depths greater than those of the shelf. Evidence of a stratified water column was apparent at 
PWS2 from the temperature, salinity, and beam transmission in spring 2018 (Fig. 31). Surface temperatures at PWS2 during spring 2018 were comparable to those at GAK1, although surface salinity was fresher at GAK1. Similar to other stations, surface waters were warmer and fresher during summer 2019. More seasonal variability in temperature and salinity was observed between 100 to $500 \mathrm{~m}$ than below $500 \mathrm{~m}$. Reduction in beam transmission was more pronounced at the surface during summer 2019, but the reduction in beam transmission at the bottom was greater during spring 2018. Beam transmission was also reduced from $250-650 \mathrm{~m}$ during summer 2019 compared to spring 2018. Vertical distributions for dA1 and dMn at PWS2 generally exhibited greater concentrations during summer 2019 than during spring 2018 (Fig. 32), particularly below $100 \mathrm{~m}$. There was a surface input signal for both metals in both seasons but below $20 \mathrm{~m}$ dAl exhibited more variability than dMn. In spring $2018 \mathrm{dMn}$ gradually decreased from the surface to a minimum $(0.8 \mathrm{nM})$ at $100 \mathrm{~m}$, and then increased gradually to a maximum of $9.9 \mathrm{nM}$ at the bottom of the water column. This pattern mirrors changes in the transmissivity data (Fig. 31). In summer $2019 \mathrm{dMn}$ decreased with depth to subnanomolar concentrations below $200 \mathrm{~m}(0.06$ to $0.28 \mathrm{nM}$ ) with the lowest value at $500 \mathrm{~m}$, which could not be quantified with our methods. In spring $2018 \mathrm{dAl}$ had subsurface minima (14.3 and $14.5 \mathrm{nM}$ ) at $220 \mathrm{~m}$ and $650 \mathrm{~m}$, and subsurface maxima at $75 \mathrm{~m}(19.9 \mathrm{nM})$ and $500 \mathrm{~m}(31.0 \mathrm{nM})$. Similarly, in summer $2019 \mathrm{dAl}$ exhibited two subsurface maxima but at different depths; $30 \mathrm{~m}(17.4 \mathrm{nM})$ and $300 \mathrm{~m}(25.1 \mathrm{nM})$. In spring 2018 a decrease in $\mathrm{dAl}$ at $650 \mathrm{~m}$ coincided with the area of increased beam transmission. 
a) PWS2 Temperature

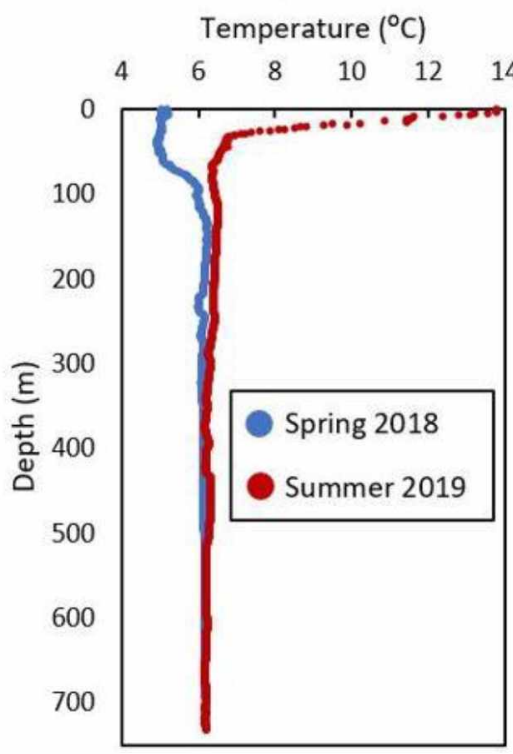

b) PWS2 Salinity

Salinity

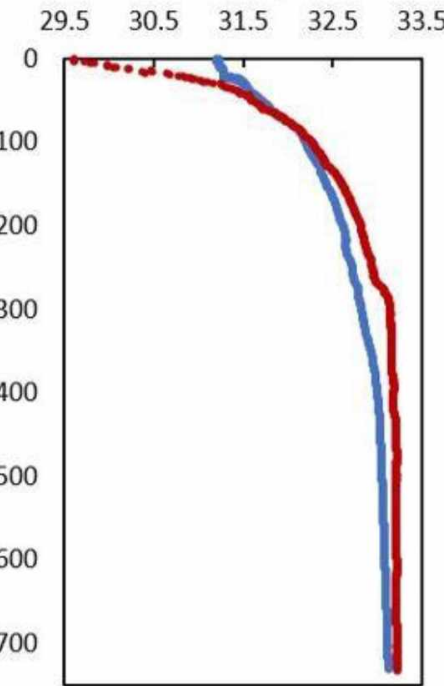

c) PWS2 Beam Transmission

Transmission \%

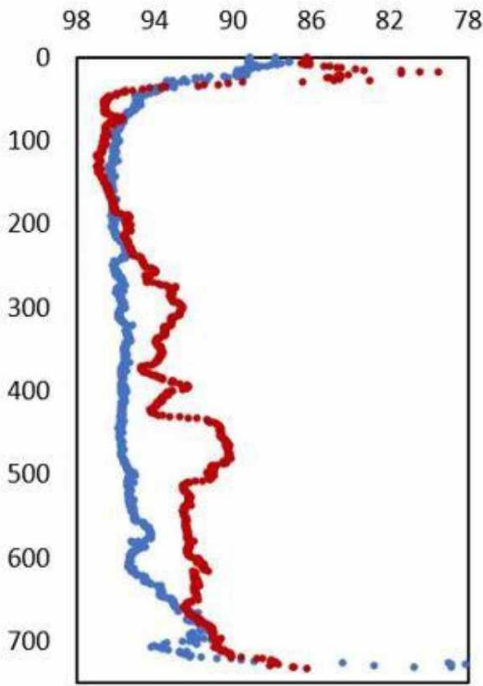

Figure 32: a) Temperature, b) salinity, and c) transmissivity at PWS2 from CTD casts in the Northern Gulf of Alaska on 4/23/18 and 6/30/19. The bottom depth at PWS2 is $728 \mathrm{~m}$.

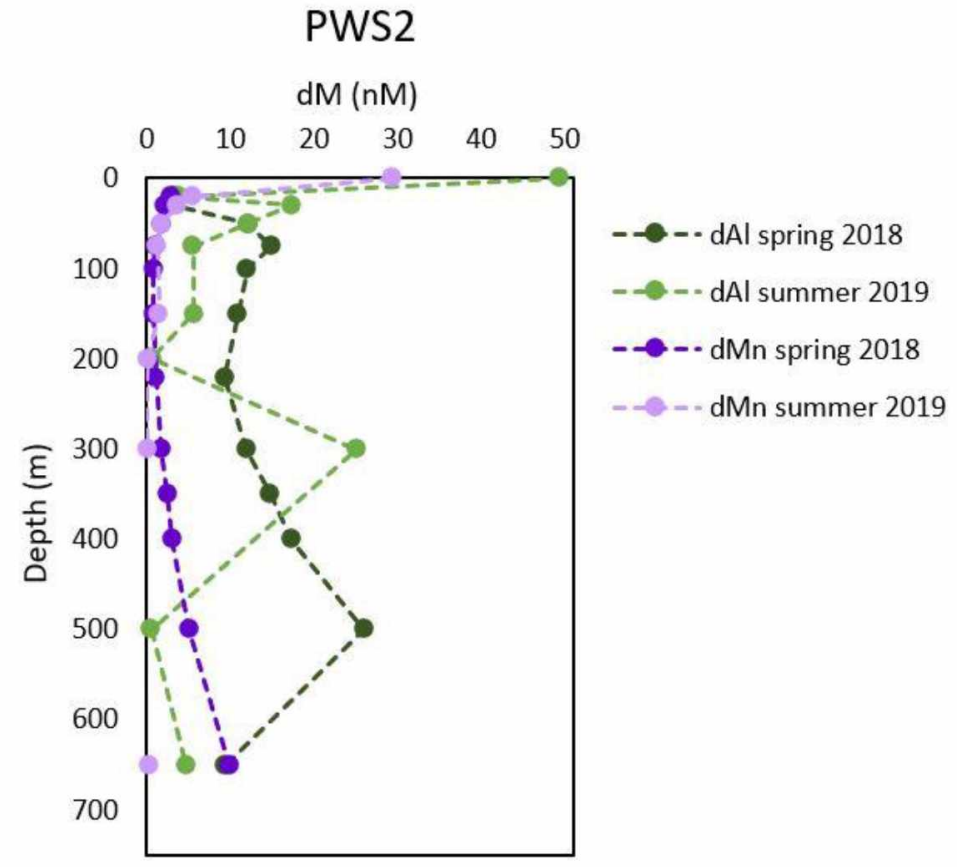

Figure 33: dAl and dMn profiles for PWS2 in the Northern Gulf of Alaska on 4/23/18 and 6/30/19. 


\subsection{Discussion}

\subsubsection{Freshwater influences on surface $\mathrm{dAl}$ and $\mathrm{dMn}$}

Surface waters on the Middleton, Seward, and Kodiak transects are impacted to various degrees by riverine/glacial inputs based on their proximity to large fresh water sources such as the Copper River. Due to its proximity to the Copper River, the largest single point source of fresh water in the NGA, the MID Line tended to be the freshest particularly in summer/fall (Fig. 13b) while the KOD Line was the most oceanic in character, particularly during spring (Fig. 4b). The Seward Line exhibited intermediate characteristics. The degree of freshwater entrainment was reflected in surface salinity values and was in general the main influence on concentrations of surface $\mathrm{dAl}$ and $\mathrm{dMn}$ along the shelf, with $\mathrm{dMn}$ exhibiting in general a more robust linear relationship with salinity than $\mathrm{dAl}$. The overall pronounced decrease in inner shelf $\mathrm{dAl}$ and $\mathrm{dMn}$ from the MID Line to the KOD Line emphasizes the importance of the Copper River as a point source for these metals. The lack of other large point sources west of the Copper River as well as the particle-reactive nature of both metals contributes to the observed decrease of $\mathrm{dAl}$ and $\mathrm{dMn}$ along the ACC. The efficiency of metal scavenging in these advective coastal waters, where biogenic and lithogenic particles tend to be the highest, is exemplified by the changing relationship of $\mathrm{dAl}$ and $\mathrm{dMn}$ with salinity along the path of the $\mathrm{ACC}$, with mixing lines becoming less steep to the west. Steep inshore/offshore gradients in both metals also highlight the key role of the ACC in keeping freshwater with higher dissolved metals closely constrained to the nearshore. Regardless of how high the $\mathrm{dAl}$ and $\mathrm{dMn}$ were inshore, their concentrations in the mid-to-outer shelf decreased to similar ranges in every season $(\sim 1-12 \mathrm{nM} \mathrm{dAl}$ and $<1-4 \mathrm{nM}$ $\mathrm{dMn}$ ) (Figs. 10 and 14) with the exception of fall MID transects when low-salinity, high dissolved metal waters extended further offshore (Figs. 13b and 14). The lowest dAl ( $0.9 \mathrm{nM}$, salinity $32.29 \mathrm{nM})$ and $\mathrm{dMn}(0.4 \mathrm{nM}$, salinity 32.54$)$ values determined during this study were in offshore waters. These do not reflect the low trace metal "oceanic" endmember with salinity in the range of 32.6, as the detection limit of our pre-concentration method was higher than the low $\mathrm{dAl}$ value measured previously in the NGA $(0.08 \mathrm{nM}$ at salinity 32.45 on the Seward Line) (Brown et al. 2010).

Given that freshwater is the main source of both metals in this region, a primary external factor affecting seasonal patterns in surface $\mathrm{dAl}$ and $\mathrm{dMn}$ is glacial melt. Glaciers encompass an area $>72,000 \mathrm{~km}^{2}$ in the GOA watershed (Beamer et al. 2016) and peak melt season tends to 
occur in late summer/early autumn, during which period runoff has been shown to double compared to the rest of the year (Royer 1981, Hill et al. 2015, Beamer et al. 2016) as was the case during our study years (Fig. 17). While seasonal patterns in surface $\mathrm{dAl}$ and $\mathrm{dMn}$ in our study region are mainly a result of glacial melt cycles, seasonality in trace metal distributions in areas without glacial influence may look different. In a study of the Mississippi River, dMn was lowest during summer, increasing rapidly in late fall (Oct-Nov) and then decreasing throughout spring (Shiller 1997). This pattern is thought to be due to reducing conditions within the river basin during winter that reduce Mn oxides to $\mathrm{dMn}$. In northern San Francisco Bay, dissolved Mn was observed to decrease in winter and spring due to adsorption, likely onto both inorganic and biogenic particles, while in southern waters $\mathrm{dMn}$ was highest in winter and summer due to reductive dissolution in the sediments (Roitz et al. 2002). A study of temporal Mn (and Cd) variability in the Hudson River estuary found a third type of seasonality, in which dMn actually decreased with higher river flow (Yang and Sañudo-Wilhelmy 1998).

The influence of seasonal patterns of riverine input to the surface trace metal distributions are clearest on the Seward and Middleton Lines that show the lowest $\mathrm{dAl}$ and $\mathrm{dMn}$ concentrations in spring when glacial melt was minimal. The KOD Line, which is the least influenced by freshwater input of the three transects, also contained higher surface dAl and dMn values during the fall, but had comparable dAl and dMn values in spring 2019 and summer 2018 with the lowest values observed for both metals in summer 2019. All three transects, however, generally had the highest metal concentrations in fall 2018. Interannual differences in Copper River discharge, as integrated outflow from May 30 - Sept 11 (the start date of the fall cruise both years) was comparable in 2018 and $2019\left(6.88 \times 10^{12} \mathrm{~m}^{3}\right.$ vs. $6.60 \times 10^{12} \mathrm{~m}^{3}$, respectively) (USGS). Given the advective nature of the GOA shelf system, it is difficult to determine a direct correlation between integrated river discharge values and surface $\mathrm{dAl}$ and $\mathrm{dMn}$ values at different locations along the ACC.

River discharge is likely not the only factor affecting interannual $\mathrm{dAl}$ and $\mathrm{dMn}$ fluctuations within a given season along the ACC waters. Storms prior to sampling could break surface stratification and dilute $\mathrm{dAl}$ and $\mathrm{dMn}$ concentrations by mixing surface waters with intermediate waters lower in dissolved metal values (Figs. 24 and 25). For example, the lower values (and shallower mixing lines) observed during fall 2019 compared to fall 2018 (Fig. 16) could be explained by storm mixing events, given that the fall 2019 field season was heavily 
impacted by storms, while the fall 2018 field season had calm conditions prior and during sampling.

Along the Seward Line, inner shelf (within the ACC) metal concentrations were highest in fall in both years followed by summer (Fig. 10), whereas along the MID Line inshore values for both metals were within the same range during summer and fall occupations (Fig. 14). This suggests that for inshore MID Line waters, which are located in close proximity to the Copper River outflow, the daily river discharge influences the concentration of $\mathrm{dAl}$ and $\mathrm{dMn}$ within fresh river plumes near the outflow. In contrast, on the Seward Line, high dAl and dMn values sampled within the ACC better reflect integrated freshwater discharge (including outflow from Prince William Sound). This difference in seasonal patterns between the two transects reflects the particle reactive nature of both $\mathrm{dAl}$ and $\mathrm{dMn}$, leading to overall loss of both metals as surface waters mix and age along the coast from the inshore MID Line to the inshore Seward Line.

Plots of dMn as a function of dAl (Figs. 34, 35, 36, and 38) highlight the tight correlation between these two metals within the Copper River plume, and more broadly in surface fresh waters of the inner shelf. This correlation became much less robust in regions least impacted by freshwater input. On the KOD Line the lack of correlation $(p>0.1)$ between $d A 1$ and $d M n$ during spring and summer suggests that at these times processes other than freshwater input determined surface $\mathrm{dAl}$ and $\mathrm{dMn}$ distributions. Similarly, along the Seward Line, there was low correlation ( $\mathrm{R}^{2}$ of 0.215 ) between $\mathrm{dMn}$ and $\mathrm{dAl}$ during spring, when the Seward Line was least impacted by freshwater. At a significance level of $\alpha=0.05$ this relationship was still statistically significant, although this p-value (0.0016) was still the highest observed on the Seward Line by 2 orders of magnitude. In general, decoupling in the surface concentrations of $\mathrm{dMn}$ to $\mathrm{dAl}$ could serve to pinpoint regions over the shelf where processes other than river input may be impacting surface waters at a given time. Differences in slope, both between the three cruise lines and between different seasons on each line, also indicate control on $\mathrm{dAl}$ and $\mathrm{dMn}$ distributions by other processes. For example, on the MID Line, slopes were steeper in spring 2019 than both summer occupations (Fig. 36) suggesting increased removal of dAl, increased input of $\mathrm{dMn}$ in summer, or perhaps some combination of these processes. Higher $\mathrm{dMn}$ relative to $\mathrm{dAl}$ in spring vs. summer was apparent throughout the water column in inshore waters based on the vertical profiles obtained at MID2, as the $\mathrm{dMn} / \mathrm{dAl}$ slope was $\sim 10 \mathrm{x}$ higher in spring 2018 than in summer 2019 (data not shown). Potential mechanisms for $\mathrm{dMn}$ input throughout the water column 
include photoreduction of particulate Mn (Sunda and Huntsman 1988) in surface waters or Mn respiration in sediments (Froelich et al. 1979). Winter mixing could carry either signal throughout the water column. Intense particle scavenging, which disproportionately affects dAl (Bruland and Lohan 2003) could also contribute to the observed $\mathrm{dMn} / \mathrm{dAl}$ ratios.

KOD dMn vs. dAI

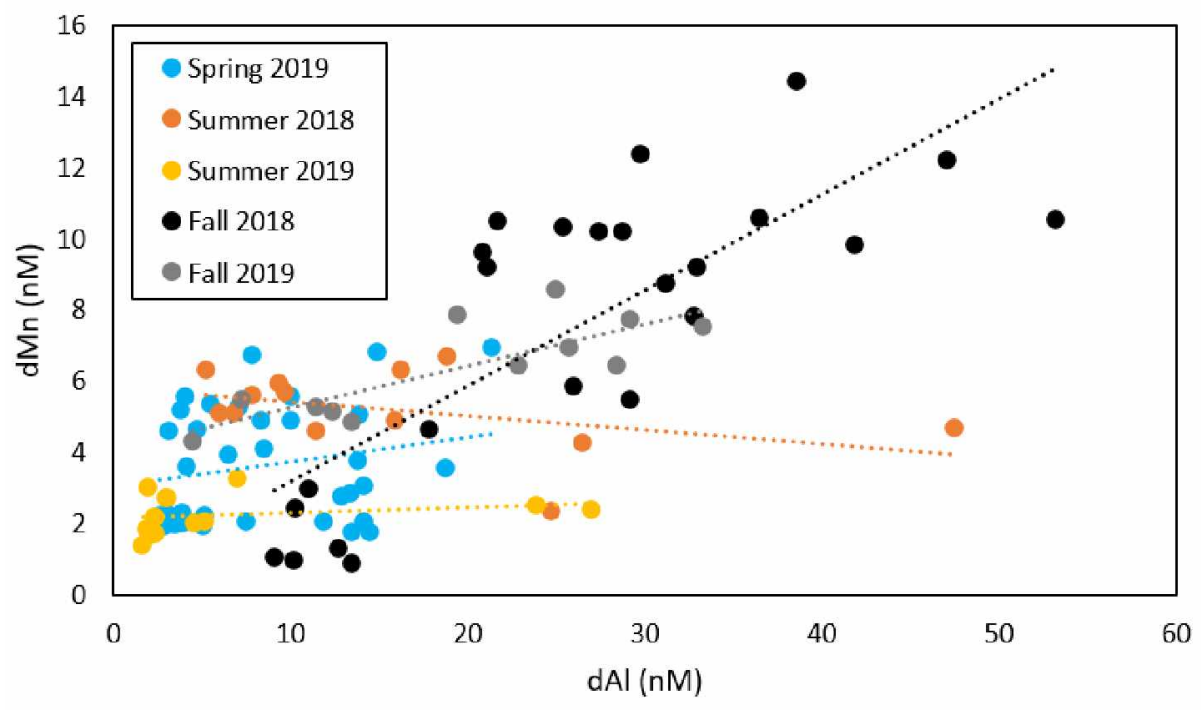

Figure 34: dMn vs. dAl along the KOD Line in the Northern Gulf of Alaska for all cruises except spring 2018 .

GAK dMn vs. dAl

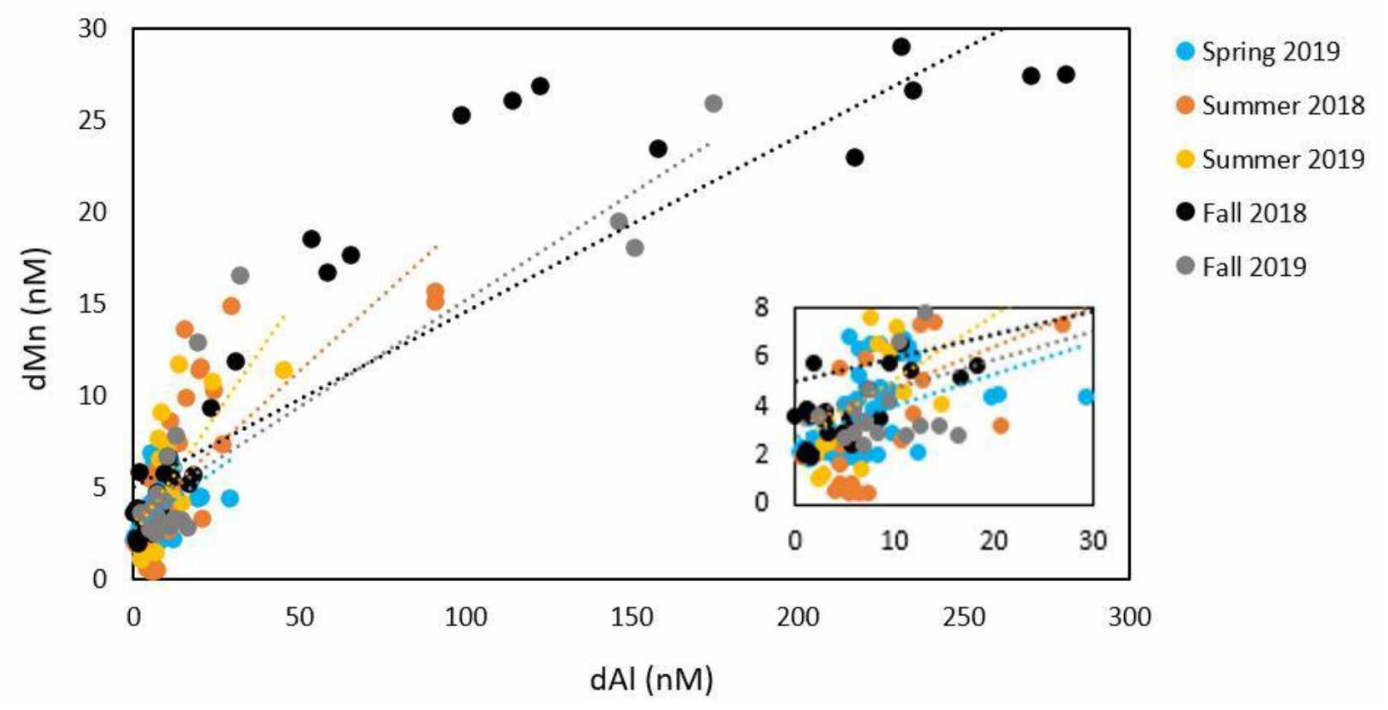

Figure 35: dMn vs. dAl along the Seward Line in the Northern Gulf of Alaska for all cruises except spring 2018. The insert shows points from $\mathrm{dAl}<30$ and $\mathrm{dMn}<8$ to highlight spring data. 
MID dMn vs. dAl

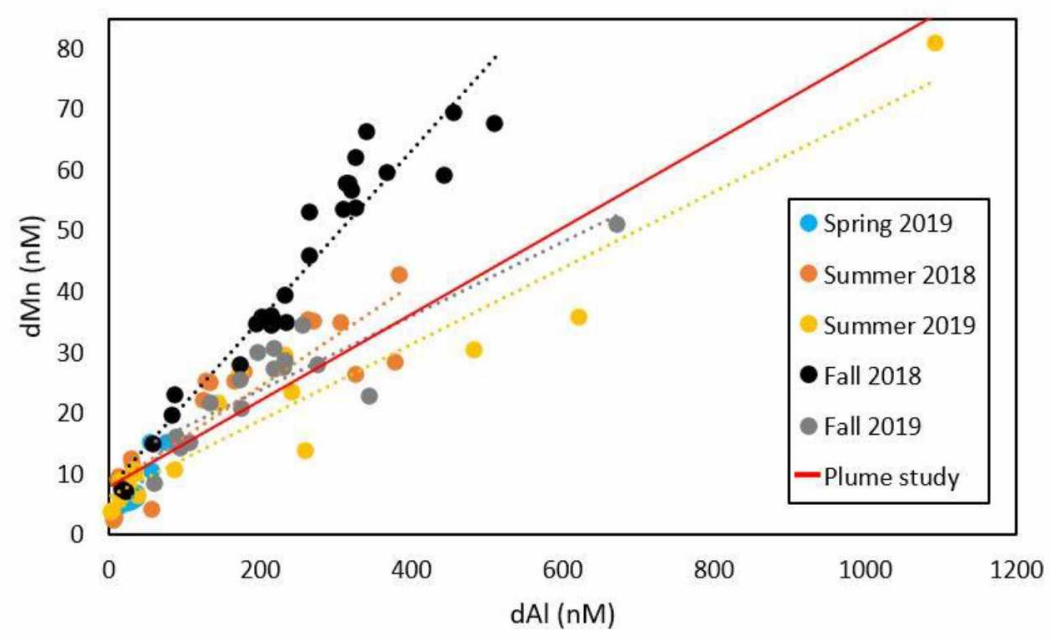

Figure 36: dMn vs. dAl along the MID Line in the Northern Gulf of Alaska for all cruises except spring 2018. The trendline from our summer 2019 Copper River plume study is shown in red.

2.5.2 The influence of bathymetric features on $\mathrm{dAl}$ and $\mathrm{dMn}$

Bathymetric features of the NGA shelf are highly irregular, and our study area is characterized by a series of banks and troughs (Gibson 1960, Zimmermann and Prescott 2015) that are unevenly distributed and contribute to the complexity of the NGA environment. The KOD Line crosses the northeast side of North Albatross Bank, which is separated from Portlock Bank by the Stevenson Trough (Fig. 37). The MID Line is also positioned across a large bank (Tar Bank) and the shoals surrounding Middleton Island before making a turn southeast across the slope. The plume study in summer 2019 also covered part of Kayak Trough and shallow regions near the Copper River outflow. The Seward Line bathymetry is yet more complex, crossing a relict moraine on its trajectory towards Amatuli Trough before reaching the slope. 


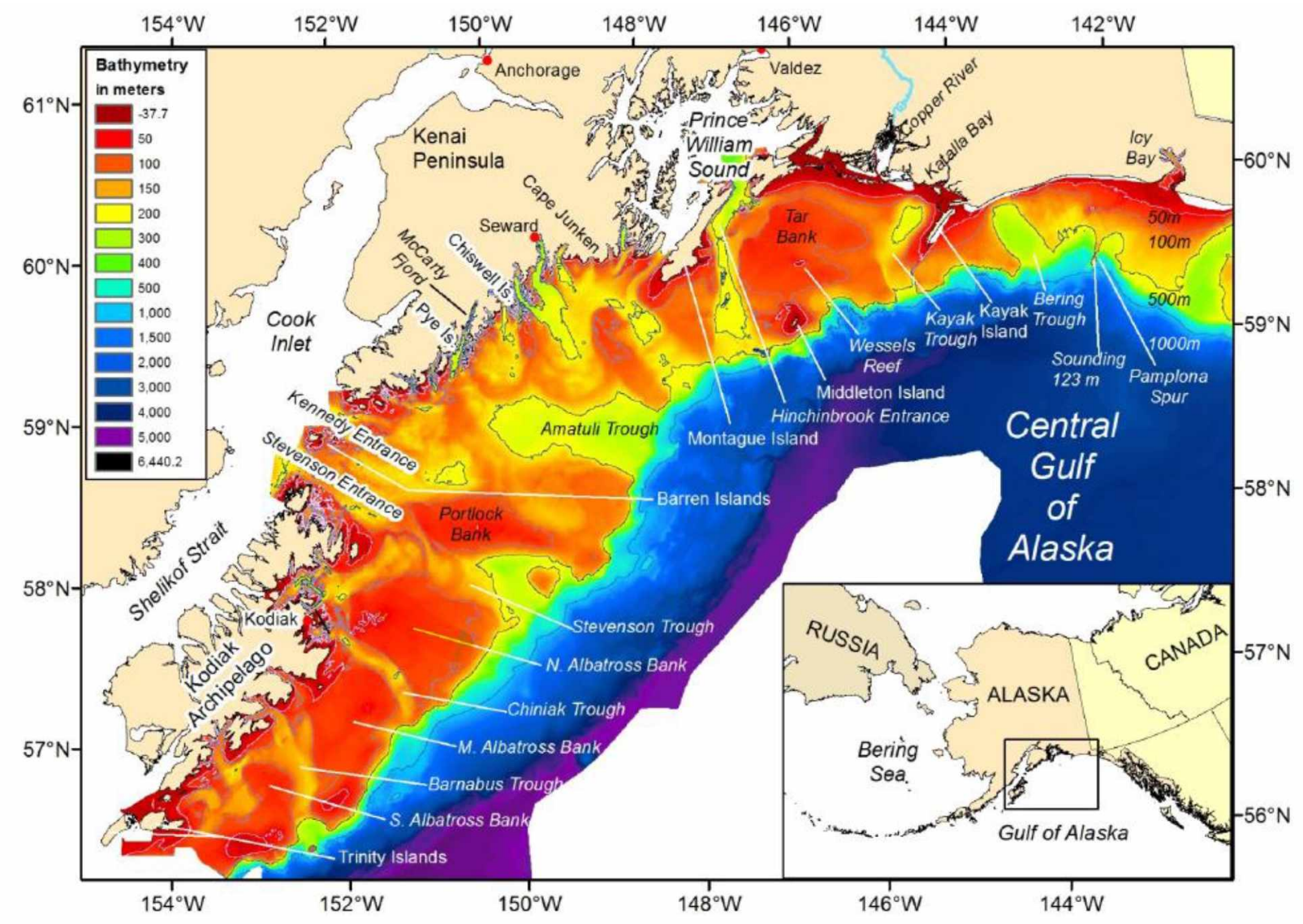

Figure 37: Major bathymetric features along the Northern Gulf of Alaska shelf, from Zimmermann and Prescott 2015.

Higher chlorophyll values relative to surrounding waters have been observed over shallow banks such as Albatross Bank due to enhanced vertical mixing that brings macronutrients from subsurface waters up to the surface (Cheng et al. 2012). Vertical mixing over the shallowest region of the bank could also provide elevated trace metals to surface waters. This process can help explain the enhanced values of dMn (Fig. 8) that we observed over the section of the KOD Line that crosses North Albatross Bank, which were more pronounced in spring 2019. Dissolved Al over the bank exhibited some elevated values, but the pattern was less distinct (data not shown). During spring 2019 dMn was almost twice as elevated over Albatross Bank (maximum of $6.9 \mathrm{nM}$ ) compared to its concentration in the furthest inshore sample (3.6 $\mathrm{nM}$ ). In general, hydrographic sections for the KOD Line (data not shown) indicate less stratification throughout the water column over Albatross Bank in spring compared to fall, which 
suggests that the signal of subsurface metals from winter mixing is still influencing surface waters. This is supported by the vertical profiles of dMn at Station KOD5 (Fig. 23).

It is reasonable that the enhancement in concentration in the productive waters over Albatross Bank is clearer for $\mathrm{dMn}$ than for $\mathrm{dAl}$ in spring given the biogeochemistry of $\mathrm{Mn}$ in seawater. Particulate Mn in the form of Mn oxides (Mn(III) and Mn(IV)) may be reduced in sediments to $\mathrm{dMn}\left(\mathrm{Mn}^{2+}\right)$ via anaerobic respiration, as Mn oxides are efficient oxidants utilized in suboxic/anoxic environments (Froelich et al. 1979). This reductive dissolution of Mn oxides in the sediment can provide an input of $\mathrm{dMn}$ to the water column that can then be mixed to the surface in shallow areas such as banks during mixing events, such as winter storms and tidal mixing. The enhanced production over Albatross Bank throughout the growing season (Waite and Mueter 2013) likely results in enhanced organic matter input to the sediment leading to enhanced respiration and oxygen utilization in surface sediment, and creating an environment where reductive dissolution of Mn oxides could take place (e.g., Rutgers Van Der Loeff et al. 1990). This process occurs for iron as well, so if these enhanced dMn values over North Albatross Bank in spring are indicative of winter anaerobic respiration in the sediments, $\mathrm{dFe}$ might also be enhanced. In addition, there would be implications for nitrogen cycling in this region as metals are less efficient electron acceptors than nitrate, so their utilization for respiration in a given area suggests denitrification has taken place and the available nitrate in pore waters has already been depleted (Froelich et al. 1979). Alternatively (or concomitantly), enhanced $\mathrm{dMn}$ (and $\mathrm{dFe}$ ) concentrations at the surface could result from photoreduction of suspended particulate Mn oxides (e.g., Sunda and Huntsman 1994) brought to the surface during mixing events, such as storms or enhanced tidal mixing. Photodissolution is also a process that affects particulate iron, and greater influence of tidal mixing is expected in spring compared to fall based on changes in water column stratification. In addition, tidal amplitude may play a role. In spring 2019 when the $\mathrm{dMn}$ increase over Albatross Bank was clearly observed (Fig. 8) the KOD Line was sampled during spring tide condition (NOAA tide data for Port of Kodiak), whereas in fall 2018 the KOD Line was sampled during neap tide conditions (NOAA tide data for Port of Kodiak).

Subsurface input from Tar Bank along the MID Line is harder to discern, given the influence of the Copper River on surface dMn concentrations. However, focusing on spring data, when river discharge is still low, surface dMn concentrations over Tar Bank ( $\sim 5.5-7 \mathrm{nM}$; salinity 
31.8-32.2) are similar to those over Albatross Bank ( $\sim 5-7 \mathrm{nM}$; salinity 32.3-32.4) at comparable salinities. The vertical profiles of dMn for MID2 and MID5 exhibited little variability below 20 $\mathrm{m}$ in spring and summer (Figs. 28 and 30), suggesting a potential input of $\mathrm{dMn}$ from the subsurface not just in spring. Similar to Albatross Bank, tidal mixing is likely an important mixing mechanism over Tar Bank supplying dissolved metals and nutrients to surface waters. Tides have also been shown to affect $\mathrm{dMn}$ values in river plumes. Aguilar-Islas and Bruland (2006) observed dMn in near-field Columbia River plumes varied widely with tidal amplitude. Much higher concentrations of $\mathrm{dMn}$ were found when plumes were sampled during a spring tides than when sampled during neap tides, and attributed the difference to enhanced suspended sediment loads during spring tides and photoreduction of Mn oxides.

\subsubsection{Residence times}

To determine the seasonal influence of Copper River outflow, residence times for surface $\mathrm{dAl}$ and $\mathrm{dMn}$ were estimated for the two seasons of greatest river discharge as described in section 2.3.5. The estimated residence times of both metals were on the order of days to tens of days for the two seasons when river discharge is pronounced, with fall having longer residence times for both metals, and $\mathrm{dMn}$ having longer residence times than $\mathrm{dAl}$ (Table 4). This is reasonable as Al is a highly particle reactive lithogenic metal (e.g., Hydes 1979), while Mn, although required by biology is less particle reactive, and concentrations of $\mathrm{dMn}$ in surface waters can be augmented via photoreduction (Sunda and Huntsman 1994). Our estimates for the residence times of $\mathrm{dAl}$ are in line with the value calculated by Brown et al. (2010) ( 10-days) for a broader region of the NGA surface waters from data obtained during August 2007.

\subsubsection{Plume study}

Our Copper River plume study showed dAl approximately an order of magnitude more concentrated than $\mathrm{dMn}$ in near-field plumes. The values of $\mathrm{dAl}$ we observed in this region are in line with those presented in Brown et al. 2010 (from August 2007). The range of dAl values they observed near the Copper River outflow (salinity 19.2-28) was 116 to $620 \mathrm{nM}$. Also, near the Alsek River outflow they reported dAl values as high as $1150 \mathrm{nM}$ in fresh (salinity 7.44) surface waters. Similarly, we observed extremely high dAl values ranging from 220.7 to $1395 \mathrm{nM}$ within 
low salinity waters (16.51 to 29.68) of the Copper River plume. While the relationship we observed between $\mathrm{dAl}$ and salinity during summer 2019 was statistically significant (Fig. 20, $\alpha=$ $0.05 ; \mathrm{p}=7.9 \mathrm{E}-14$ ) the linearity was much lower than that observed in 2007 (Fig. 38), due to the points between salinity 25-30 that show elevated dAl relative to salinity. This led to a steeper slope as well as a higher zero-salinity endmember in 2019, which likely contributed to our calculated dAl residence time being shorter than that reported in Brown et al. 2010 (5 days vs. 10 days; Table 4). Many of our samples with salinity $25-30$ and $\mathrm{dAl}<400 \mathrm{nM}$ match well with the values observed in 2007.

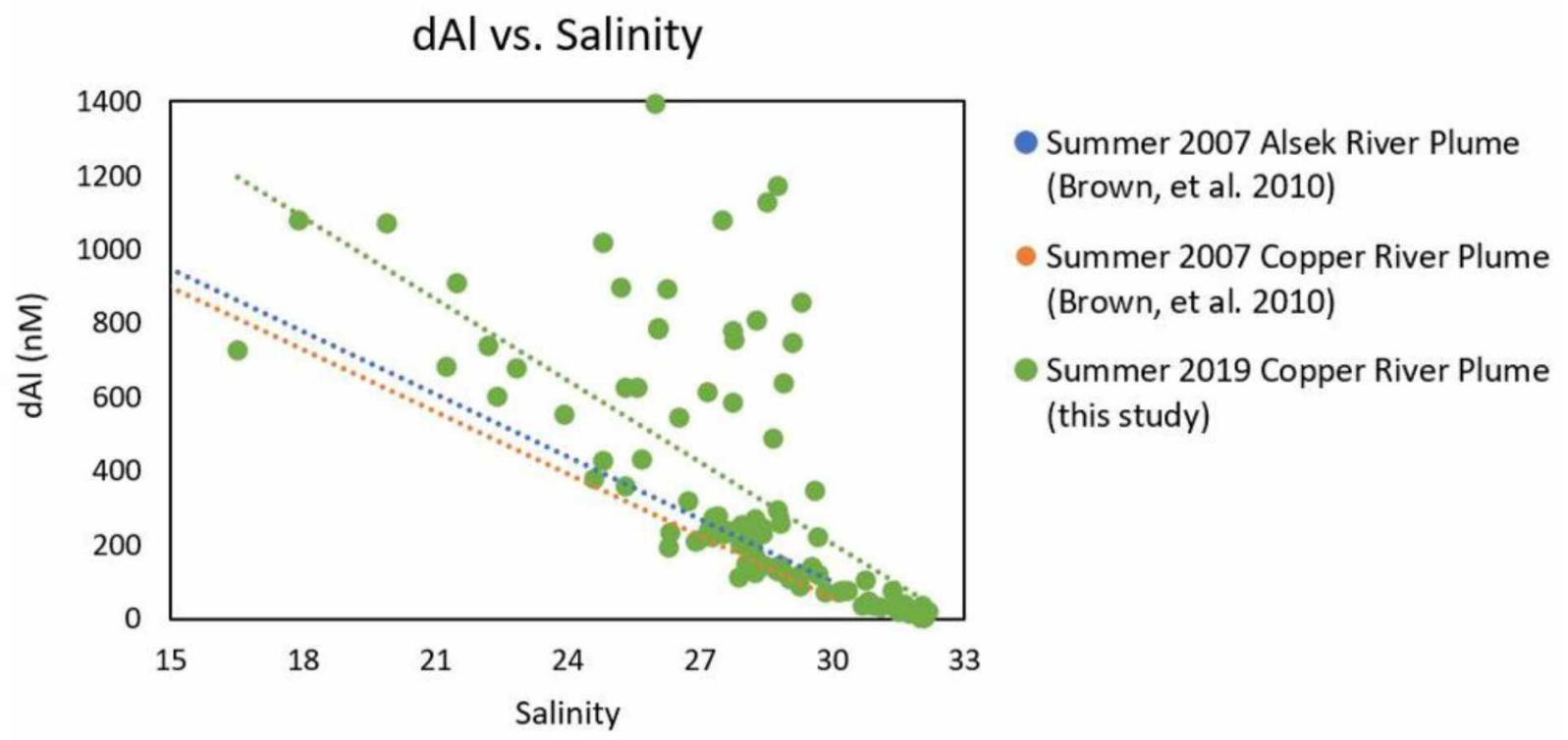

Figure 38: dAl vs. salinity in GOA freshwater plumes. Data shown are from this study (green), along with trendlines from summer 2007 data sets from a Copper River plume (orange, $\mathrm{y}=1740$ - 56.14x, $R^{2}=0.9629$ ) and an Alsek River plume (blue, $y=1792-56.42 x, R^{2}=0.9937$ ). Summer 2007 data are from Brown et al. (2010).

The overall higher dAl concentrations we observed in July 2019 could be explained by differences in Copper River outflow at the time of sampling - mean discharge was $3,945 \mathrm{~m}^{3} / \mathrm{s}$ from $8 / 25 / 07-8 / 27 / 07$ while from $7 / 4 / 19-7 / 6 / 19$ it was $8,467 \mathrm{~m}^{3} / \mathrm{s}$. The tight coupling observed between surface $\mathrm{dAl}$ and $\mathrm{dMn}$ in our plume study indicate that both metals generally came from the same source, i.e., river discharge (Fig. 39). 
dMn vs. dAl

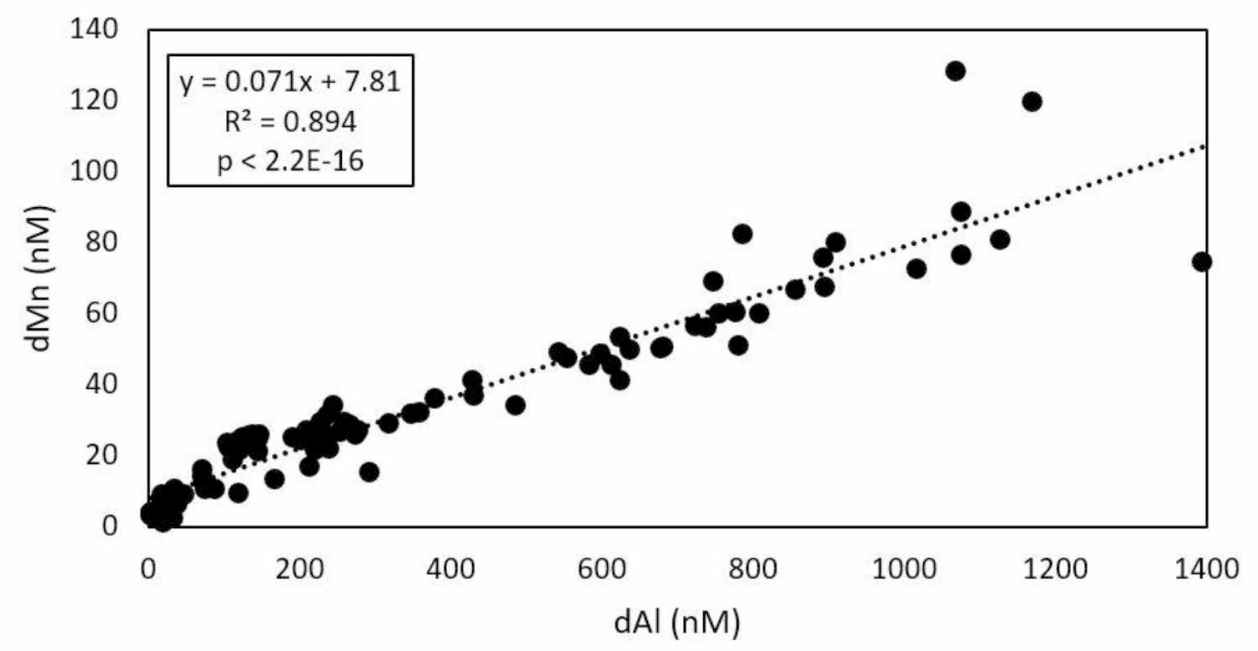

Figure 39: dMn vs. dAl for the Copper River plume study in the Northern Gulf of Alaska (summer 2019).

The higher river discharge is likely accompanied by greater suspended loads of glacial flour, and although we did not measure total suspended solids (TSS) in our samples Brown et al. (2010) found a weak correlation in dAl and TSS within Copper River plume waters. The very high $\mathrm{dAl}$ values we measured during summer and fall confirm the observation in Brown et al. (2010) that coastal GOA waters are generally higher in $\mathrm{dAl}$ (by one to two orders of magnitude) than other coastal shelf areas impacted by rivers such as the Columbia River region off the Oregon coast (Brown and Bruland 2009) and the Yangtze River region in the East China Sea (Ren et al. 2006). In contrast, high dMn values in the Copper River plume were approximately half as high ( $130 \mathrm{nM})$ as the highest concentrations measured in the Columbia River plume $(\sim 240 \mathrm{nM}$ ) at comparable salinities (Aguilar-Islas and Bruland 2006). The type of rock eroded along with the balance between competing dissolution/scavenging processes in waters with high suspended particulate loads allows for observed variations in the riverine delivery of dissolved metals to coastal waters.

For example, the zero-salinity endmember value $\mathrm{dAl}$ value calculated for the Copper River from our MID Line data ranges from $820 \mathrm{nM}$ in summer 2018 to $2520 \mathrm{nM}$ in summer 2019 (the value for summer 2018 may be an underestimate, resulting from generally low dA1 values associated with sampling during neap tide conditions). The $\mathrm{dAl}$ concentration calculated 
in Brown et al. (2010) for the Copper River, $1740 \mathrm{nM}$, falls within this range. This range of riverine $\mathrm{dAl}$ values is much higher than estimates from other studies of coastal regions highly impacted by freshwater inputs. Plots of dAl vs. salinity in the previously mentioned Columbia River and Yangtze River plume studies led to zero-salinity endmember values of $\sim 85 \mathrm{nM}$ and $220 \mathrm{nM} \mathrm{dAl}$, respectively (Brown and Bruland 2009, Ren et al. 2006). This suggests that the lower $\mathrm{dAl}$ values observed in these regions at comparable (or lower) salinities to our plume study directly resulted from lower $\mathrm{dAl}$ in the rivers themselves. The apparently high $\mathrm{dAl}$ content in the Copper River is likely due to the high load of glacial flour carried in this river (Fig. 40), which consists of aluminosilicate materials and results from intense physical weathering of nearby glaciers (Spotila et al. 2004). This is supported by a similar zero-salinity endmember dAl estimate (1792 nM) for the Alsek River, another glacially-fed river in Alaska (Brown et al. 2010). Figure 39 shows a satellite image of the Copper River plume taken on 6/28/19, less than a week before our study began, with surface dAl values overlaid. The color of the river water reflects the high amount of silt entering the system, and many of the high dAl samples $(>500$ $\mathrm{nM})$ are located in or near the lightly colored waters indicative of high suspended particulate loads (Fig. 40). 


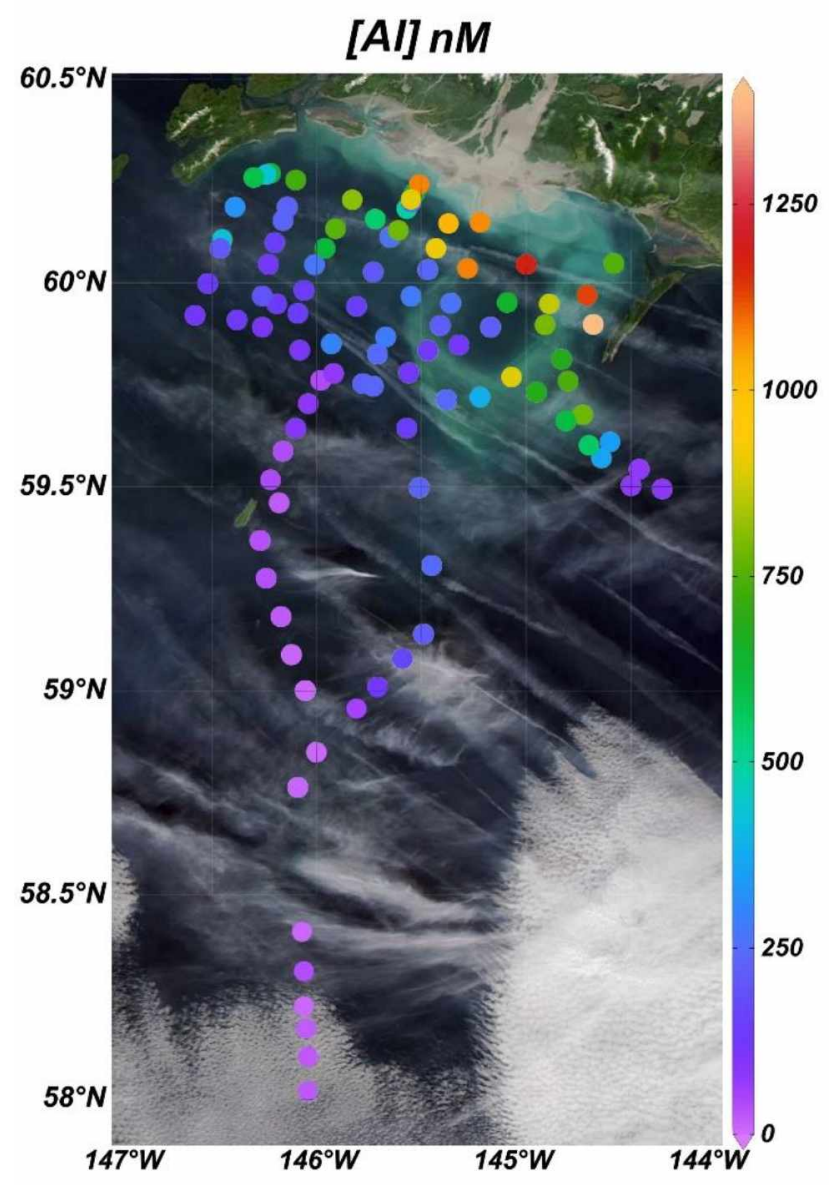

Figure 40: Satellite image of the Copper River plume in the Northern Gulf of Alaska taken on $6 / 29 / 19$ overlaid with surface dAl values from our plume study (7/4/19-7/8/19). Figure courtesy of Rachel Potter.

\subsubsection{Dissolved $\mathrm{Al}$ and $\mathrm{Mn}$ as tracer of the dFe input into the NGA}

Dissolved $\mathrm{Al}$ and $\mathrm{Mn}$ are good candidates as proxies for $\mathrm{dFe}$ input from the Copper River, as the Copper River is also a major source of dFe to the NGA shelf (Lippiatt et al. 2010), but the quasi-conservative behavior of $\mathrm{dAl}$ and $\mathrm{dMn}$ in plume waters might serve to shed light on the input of $\mathrm{dFe}$ from this source. All three metals are lithogenic elements (Al constitutes $8.23 \%$, Fe $5.63 \%$ of continental crust, and $\mathrm{Mn}$ is found at $716 \mathrm{ppm}$ by weight (Taylor, 1964)) and are particle reactive to differing degrees, with $\mathrm{dAl}$ and $\mathrm{dFe}$ being more easily scavenged by particles than dMn (Landing and Bruland 1987, Bruland and Lohan 2003). Compared to Al, the biogeochemistry of $\mathrm{Mn}$ has more similarities to that of Fe as they are both micronutrients that can also undergo reductive dissolution, via anaerobic respiration in sediments (Froelich et al. 
1979) or photoreduction of particles in surface waters (Sunda and Huntsman 1994). However, cellular requirements for $\mathrm{Fe}$ are higher than those for Mn (Twining and Baines 2013). Yet, unlike $\mathrm{dFe}$, which is $>99 \%$ bound by organic ligands in seawater (e.g., Rue and Bruland 1995), neither $\mathrm{dAl}$ nor $\mathrm{dMn}$ is bound by organic ligands to a significant extent (Jones et al. 2020, Orians and Bruland 1985).

Iron is an essential micronutrient used by phytoplankton for processes such as photosynthesis and nitrate acquisition, and is regarded as the limiting nutrient in HNLC waters such as those in the offshore NGA. Fe-binding organic ligands control dFe concentrations (e.g., Buck et al. 2007) in seawater by forming complexes with $\mathrm{Fe}$, these naturally-occurring ligands increase the amount of Fe that can exist in the dissolved form in seawater. Thus, ligand concentration sets an upper limit on dFe concentrations, although inorganic colloidal Fe can also contribute to enhanced dFe concentrations in coastal waters (Wu and Luther 1994).

Consequently, due to high biological uptake coupled with dependence on ligand availability, ambient $\mathrm{dFe}$ concentrations cannot be used to directly assess $\mathrm{dFe}$ inputs into a given system.

Plots of $\mathrm{dFe}$ as a function of $\mathrm{dAl}$ and $\mathrm{dMn}$ from our Copper River plume study illustrate the control that organic Fe-binding ligands exerts over dFe concentrations (Fig. 41). While dAl and $\mathrm{dMn}$ were tightly coupled to salinity and each other in surface waters collected during the plume study (Fig. 39), dFe is decoupled from these metals, particularly at higher dAl $(>\sim 200$ $\mathrm{nM})$ and $\mathrm{dMn}(>\sim 20 \mathrm{nM})$ concentrations, where $\mathrm{dFe}$ values do not continue to increase. This decoupling suggests either intense removal of $\mathrm{dFe}$ in fresher plume waters, or low concentrations of available Fe-binding organic ligands that cap $\mathrm{dFe}$ concentrations in these surface waters. Lippiatt et al. (2010) also found dFe did not surpass concentrations of $\sim 2.5 \mathrm{nM}$ in coastal waters near the Copper River plume at comparable salinity values as those sampled during our plume study (minimum salinity of 16.5 in 2019 vs. 19 in 2007). 
a)

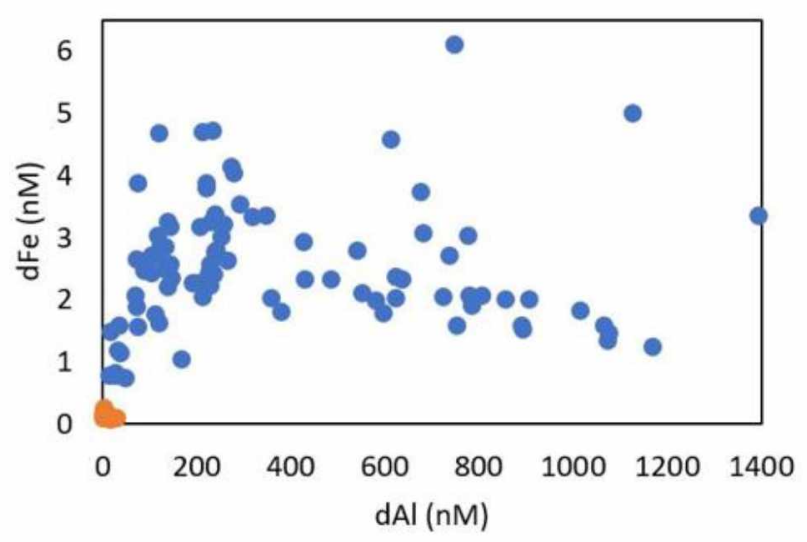

b) dFe vs. dMn

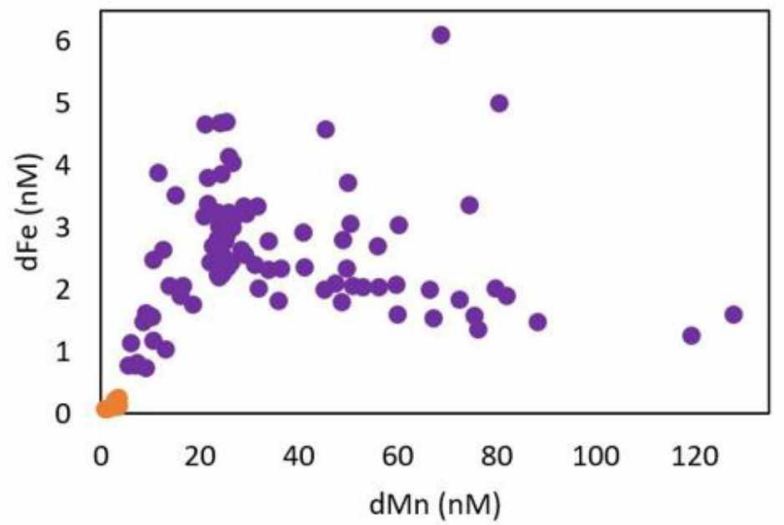

Figure 41: dFe vs. a) dAl and b) dMn in the Copper River plume study (summer 2019) in the Northern Gulf of Alaska. Orange points indicate offshore waters with salinity $>31.75$.

To further visualize how $\mathrm{dFe}$ varied relative to $\mathrm{dMn}$, the ratio of $\mathrm{dFe}: \mathrm{dMn}$ was plotted as a function of dMn (Fig. 42), separating offshore waters (salinity >31.75) from plume waters (Fig. 42). This plot highlights where $\mathrm{dFe}$ tended to be more (or less) abundant relative to $\mathrm{dMn}$. In higher salinity ( $>31.75)$ offshore waters, the ratio of $\mathrm{dFe}$ to $\mathrm{dMn}$ is low and less variable $(0.03$ to 0.06) providing an endmember where exceedingly low $\mathrm{dFe}$ concentrations (due to biological uptake and lack of additional input) drive the ratio down. The low ratios at high dMn values provide an endmember for a fresh Copper River plume (under high riverine input and spring tide conditions), where the low $\mathrm{dFe}: \mathrm{dMn}$ ratios ( 0.01 to 0.02 ) are driven by the high input of $\mathrm{dMn}$ by the Copper River together with the capping of dFe concentrations by Fe-binding organic ligand availability. A third endmember is mid-salinity shelf waters ( $\sim 28$ to 31$)$, where the ratio of dFe to $\mathrm{dMn}$ reaches its maximum, suggesting high concentrations of Fe-binding organic ligands that help stabilize dFe, and an Fe source (such as suspended particles; e.g. Lippiatt et al. 2010) that can serve as a ready source of additional $\mathrm{Fe}$ as $\mathrm{dFe}$ is removed by biological uptake. A schematic diagram of these processes (Fig. 43) that likely drive dFe:dMn ratios among endmembers helps clarify this continuum. 
$\mathrm{dFe} / \mathrm{dMn}$ vs. $\mathrm{dMn}$

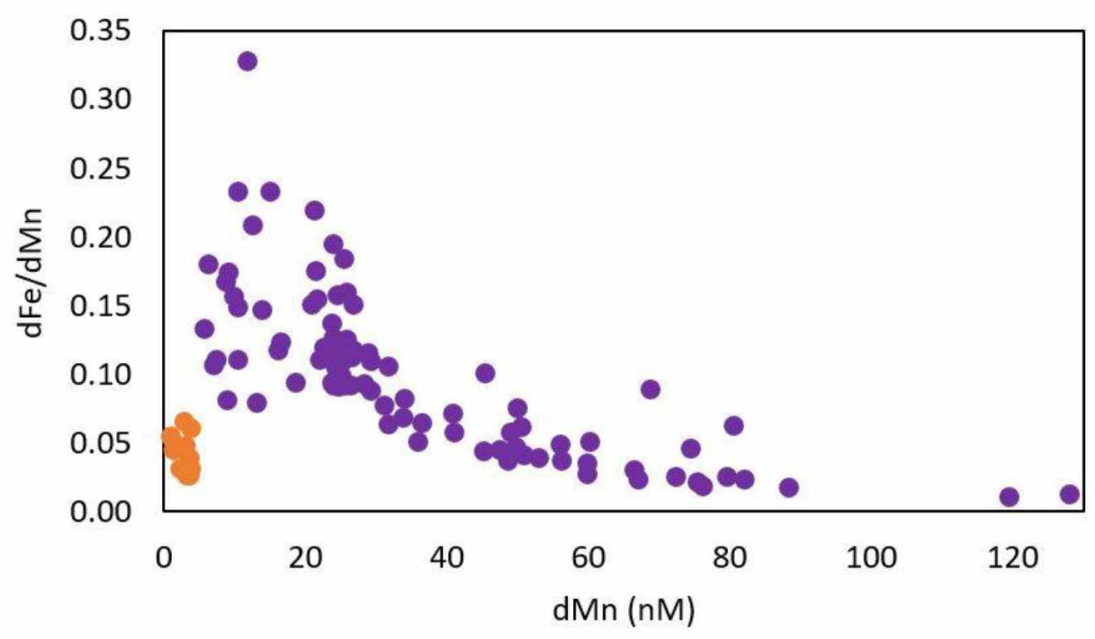

Figure 42: $\mathrm{dFe} / \mathrm{dMn}$ ratio plotted as a function of dMn for the Copper River plume study (summer 2019) in the Northern Gulf of Alaska. Orange points indicate offshore waters with salinity $>31.75$.

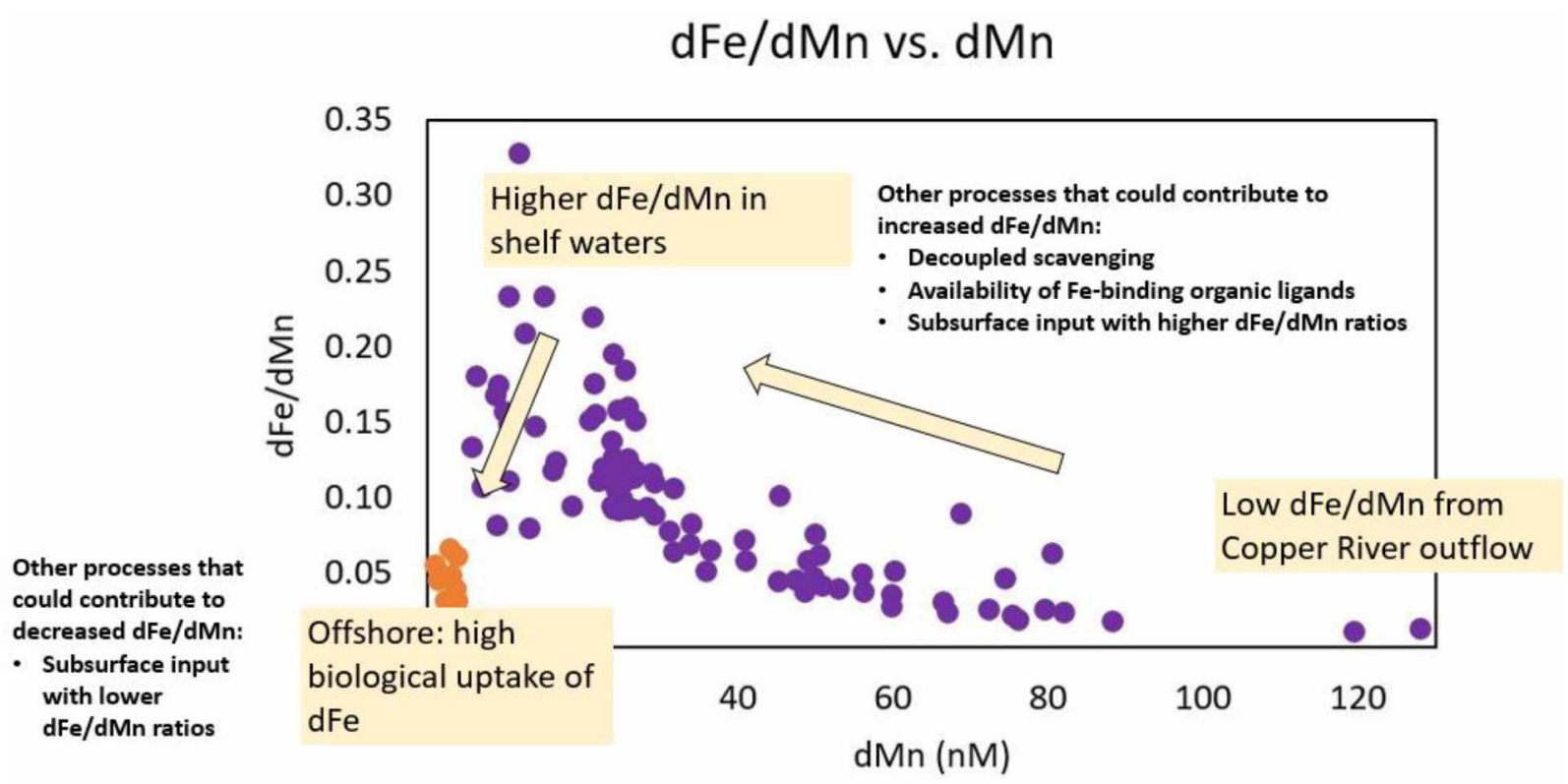

Figure 43: Schematic describing how to interpret data plotted as dMn vs. dFe/dMn (Fig. 42).

\subsection{Conclusions}

Freshwater input from rivers appears to be the main source of dissolved $\mathrm{Al}$ and $\mathrm{Mn}$ to the surface waters of the NGA. The NGA also receives large amounts of freshwater input from small discharges, but little is known about the concentrations of these metals in smaller streams, or the 
degree of flocculation and removal processes that occur at the freshwater/seawater interface. Riverine input varies seasonally with cycles of precipitation and glacial melt, reaching peak runoff observed in late summer/early autumn when discharge rates may be up to two times higher compared to rates observed in other seasons. Surface distributions of $\mathrm{dAl}$ and $\mathrm{dMn}$ reflected these seasonal patterns throughout the study region (Kodiak, Seward, and Middleton Lines) exhibiting concentrations that were higher on average during fall (high glacial melt) than spring (very low melt), and that were less pronounced with distance from the Copper River outflow, the major point source of fresh water in this region. Inshore/offshore gradients were commonly observed on all transects throughout the 2018-2019 field seasons, with higher dAl and $\mathrm{dMn}$ concentrations inshore (within ACC waters) that decreased off the shelf to consistently low values ( $\sim 1-12 \mathrm{nM} \mathrm{dAl}$ and $<1-4 \mathrm{nM} \mathrm{dMn}$ ). Coastal circulation (the ACC) keeps freshwater input constrained to the inner shelf, and advects surface water from the northwest region of the study area (MID Line) to the southeast (KOD Line). Along the ACC path, linear correlations between salinity and dissolved Al and Mn exhibited diminishing slopes with distance from the Copper River outflow. This decrease reflects removal of both metals via particle scavenging as well as input of freshwater into the ACC from small rivers and streams, likely providing lower input of $\mathrm{dAl}$ and $\mathrm{dMn}$ than the Copper River and diluting its signal. The $\mathrm{dAl}$ and $\mathrm{dMn}$ surface data from the Copper River plume study (summer 2019) underscored the patchiness in the distribution of dissolved constituents within NGA surface shelf waters, which arises from the various processes that lead to the mixing of shelf waters and HNLC offshore waters.

Seasonal sampling near the Copper River outflow allowed us to estimate the residence time of $\mathrm{dAl}$ and $\mathrm{dMn}$ on a seasonal basis relative to input of fresh water by the Copper River plume. Residence times for both metals were on the order of days to months, which are reasonable given this region is particle rich and both metals are particle reactive.

Vertical profiles from stations across the shelf provided some data suggesting sedimentary input to subsurface waters, and to surface waters over banks. Sedimentary inputs were more clearly observed for dMn over Albatross bank in spring and summer, and over Tar Bank during spring when surface waters in the NGA were less impacted by freshwater input.

One of the goals of the NGA LTER site is to investigate how intense environmental variability can lead to ecosystem resilience. Overall, the wide ranges of concentrations observed 
for $\mathrm{dAl}$ and $\mathrm{dMn}$ suggest that inputs of $\mathrm{dFe}$ are highly spatially and temporally variable, contributing to the notion that the NGA naturally experiences intense environmental variability.

\subsection{References}

Aguilar-Islas, A. M., and Bruland, K. W., 2006. Dissolved manganese and silicic acid in the Columbia River plume: a major source to the California current and coastal waters off Washington and Oregon. Marine Chemistry 101, 233-247.

Beamer, J. P., Hill, D. F., Arendt, A., and Liston, G. E., 2016. High-resolution modeling of coastal freshwater discharge and glacier mass balance in the Gulf of Alaska watershed. Ware Resources Research 52, 3888-3909.

Brown, M. T., and Bruland, K. W., 2008. An improved flow-injection analysis method for the determination of dissolved aluminum in seawater. Limnology and Oceanography: Methods 6, 87-95.

Brown, M. T., and Bruland, K. W., 2009. Dissolved and particulate aluminum in the Columbia River and coastal waters of Oregon and Washington: Behavior in near-field and far-field plumes. Estuarine, Coastal and Shelf Science 84, 171-185.

Brown, M. T., Lippiatt, S. M., and Bruland, K. W., 2010. Dissolved aluminum, particulate aluminum, and silicic acid in the northern Gulf of Alaska coastal waters: glacial/riverine inputs and extreme reactivity. Marine Chemistry 122, 160-175.

Cheng, W., Hermann, A. J., Coyle, K. O., Dobbins. E. L., Kachel, N. B., and Stabeno, P. J., 2012. Macro- and micro-nutrient flux to a highly productive submarine bank in the Gulf of Alaska: A model-based analysis of daily and interannual variability. Progress in Oceanography 101, 63-77.

Froelich, P. N., Klinkhammer, G. P., Bender, M. L., Luedtke, N. A., Heath, G. R., Cullen, D., and Dauphin, P., 1979. Early oxidation of organic matter in pelagic sediments of the eastern equatorial Atlantic: suboxic diagenesis. Geochimica et Cosmochimica Acta 43, 1075-1090.

Gibson, W. M., 1960. Submarine topography in the Gulf of Alaska. Bulletin of the Geological Society of America 71, 1087-1108.

Hill, D. F., Bruhis, N., Calos, S. E., Arendt, A., and Beamer, J., 2015. Spatial and temporal variability of freshwater discharge into the Gulf of Alaska. Journal of Geophysical Research: Oceans 120, 634-646.

Hydes, D. J. and Liss, P. S., 1977. The behaviour of dissolved aluminium in estuarine and coastal waters. Estuarine and Coastal Marine Science 5, 755-769. 
Hydes, D. J., 1979. Aluminum in seawater: control by inorganic processes. Science 205, 12601262.

Jones, M. R., Luther III, G. W., and Tebo, B. M., 2020. Distribution and concentration of soluble manganese(II), soluble reactive $\mathrm{Mn}(\mathrm{III})-\mathrm{L}$, and particulate $\mathrm{MnO}_{2}$ in the Northwest Atlantic Ocean. Marine Chemistry 226, 103858.

Lagerloef, G. S. E., 1995. Interdecadal Variations in the Alaska Gyre. Journal of Physical Oceanography $25,2242-2258$.

Lippiatt, S. M., Lohan, M. C., and Bruland, K. W., 2010. The distribution of reactive iron in northern Gulf of Alaska coastal waters. Marine Chemistry 121, 187-199.

Maring, H. B. and Duce, R. A., 1987. The impact of atmospheric aerosols on trace metal chemistry in open ocean surface seawater, 1. Aluminum. Earth and Planetary Science Letters 84, 381-392.

Minami, T., Konagaya, W., Zheng, L., Takano, S., Sasaki, M., Murata, R., Nakaguchi, Y., and Sohrin, Y., 2015. An off-line preconcentration system with ethylenediaminetriacetate chelating resin for the determination of trace metals in seawater by high-resolution inductively coupled plasma mass spectrometry. Analytica Chimica Acta 854, 183-190.

Moore, R. M. and Millward, G. E., 1984. Dissolved-particulate interactions of aluminium in ocean waters. Geochimica et Cosmochimica Acta 48, 235-241.

Orians, K. J. and Bruland, K. W., 1986. The biogeochemistry of aluminum in the Pacific Ocean. Earth and Planetary Science Letters 78, 397-410.

Peers, G. and Price, N. M., 2004. A role for manganese in superoxide dismutases and growth of Iron-deficient diatoms. Limnology and Oceanography 49, 1774-1783.

Rember, R., Aguilar-Islas, A. M., and Domena, V., 2016. Distribution and abundance of select trace metals in Chukchi and Beaufort Sea ice. OCS Study BOEM 2016-079.

Ren, J. L., Zhang, J., Li, J. B., Yu, X. Y., Liu, S. M., and Zhang, E. R., 2006. Dissolved aluminum in the Yellow Sea and East China Sea - $\mathrm{Al}$ as a tracer of Changjiang (Yangtze River) discharge and Kuroshio incursion. Estuarine, Coastal and Shelf Science 68, 165174.

Roitz, J. S., Flegal, A. R., and Bruland, K. W., 2002. The biogeochemical cycling of manganese in San Francisco Bay: Temporal and spatial variations in surface water concentrations. Estuarine, Coastal and Shelf Science 54, 227-239.

Royer, T. C., 1975. Seasonal variations of waters in the northern Gulf of Alaska. Deep-Sea Research 22, 403-416.

Royer, T. C., 1981. Baroclinic transport in the Gulf of Alaska Part II. A fresh water driven coastal current. Journal of Marine Research 39, 251-266. 
Royer, T. C. and Emery, W. J., 1987. Circulation in the Gulf of Alaska, 1981. Deep-Sea Research Part A. Oceanographic Research Papers 34, 1361-1377.

Rutgers Van Def Loeff, M. M., Meadows, P. S., and Allen, J. A., 1990. Oxygen in pore waters of deep-sea sediments. Philosophical Transactions of the Royal Society of London. Series A, Mathematical and Physical Sciences 331, 69-84.

Sakamoto, H., Yamamoto, K., Shirasaki, T., and Inoue, Y., 2006. Pretreatment method for determination of trace elements in seawater using solid phase extraction column packed with polyamino-polycarboxylic acid type chelating resin. Bunseki Kagaku 55, 133-139.

Schumacher, J. D., Stabeno, P. J., and Roach, A. T., 1989. Volume transport in the Alaska Coastal Current. Continental Shelf Research 9, 1071-1083.

Shiller, A. M., 1997. Dissolved trace elements in the Mississippi River: Seasonal, interannual, and decadal variability. Geochimica et Cosmochimica Acta 61, 4321-4330.

Spotila, J. A., Buscher, J. T., Meigs, A. J., and Reiners, P. W., 2004. Long-term glacial erosion of active mountain belts: Example of the Chugach-St. Elias Range, Alaska. Geology 32, 501-504.

Stabeno, P. J., Bond, N. A., Hermann, A. J., Kachel, N. B., Mordy, C. W., and Overland, J. E., 2004. Meteorology and oceanography of the Northern Gulf of Alaska. Continental Shelf Research 24, 859-897.

Strom, S. L., Olson, M. B., Macri, E. L., and Mordy, C. W., 2006. Cross-shelf gradients in phytoplankton community structure, nutrient utilization, and growth rate in the coastal Gulf of Alaska. Marine Ecology Progress Series 328, 75-92.

Sunda, W. G. and Huntsman, S. A., 1988. Effect of sunlight on redox cycles of manganese in the southwestern Sargasso Sea. Deep-Sea Research 35, 1297-1317.

Sunda, W. G. and Huntsman, S. A., 1994. Photoreduction of manganese oxides in seawater. Marine Chemistry 46, 133-152.

Twining, B. S., and Baines, S. B., 2013. The trace metal composition of marine phytoplankton. Annual Review of Marine Science 5, 191-215.

Waite, J. N., and Mueter, F. J., 2013. Spatial and temporal variability of chlorophyll-a concentrations in the coastal Gulf of Alaska, 1998-2011, using cloud-free reconstructions of SeaWiFS and MODIS-Aqua data. Progress in Oceanography 116, 179-192.

Weingartner, T. J., Danielson, S. L., and Royer, T. C., 2005. Freshwater variability and predictability in the Alaska Coastal Current. Deep-Sea Research II: Topical Studies in Oceanography 52, 169-191. 
Yang, S., and Sañudo-Wilhelmy, S. A., 1998. Cadmium and manganese distributions in the Hudson River estuary: interannual and seasonal variability. Earth and Planetary Science Letters 160, 403-418.

Yang, L., Nadeau, K., Meija, J., Grinberg, P., Pagliano, E., Ardini, F., Grotti, M., Schlosser, C., Streu, P., Achterberg, E. P., Sohrin, Y., Minami, T., Zheng, L., Wu, J., Chen, G., Ellwood, M. J., Turetta, C., Aguilar-Islas, A., Rember, R., Sarthou, G., Tonnard, M., Planquette, H., Matousek, T., Crum, S., and Mester, Z, 2018. Inter-laboratory study for the certification of trace elements in seawater certified reference materials NASS-7 and CASS-6. Analytical and Bioanalytical Chemistry 410, 4469-4479.

Zimmermann, M. and Prescott, M. M., 2015. Smooth Sheet Bathymetry of the Central Gulf of Alaska. NOAA Technical Memorandum NMFS-AFSC-287. 


\section{Chapter 3: Conclusions}

The purpose of this study was to investigate the distribution of $\mathrm{dAl}$ and $\mathrm{dMn}$ in the NGA and determine their use as quasi-conservative tracers of freshwater input, given the large amount of freshwater discharge into this region and the high input of these metals from riverine systems (e.g., Brown et al. 2010, Aguilar-Islas and Bruland 2006). This study contributes to the larger goals of the NGA LTER site which aims to investigate the impact of freshwater input on shelf circulation, nutrient availability, and primary production. Rivers are a major source of nutrients such as dFe and silicate (Martin and Whitfield 1983, DeMaster 2001), and these influence the phytoplankton community composition and thus the overall NGA ecosystem.

Large gradients in $\mathrm{dAl}$ and $\mathrm{dMn}$ concentrations were expected given the contrasting ecosystems of the inner shore (highly impacted by freshwater runoff) and offshore waters (very low impact from rivers and atmospheric deposition). To address the expected gradients in the concentrations of these metals, two sample processing methods were used prior to analytical determination. Analysis of certified reference materials (CASS-6 and NASS-7) confirmed the accuracy of the dilution (used for $\mathrm{dAl}>70 \mathrm{nM}$ and $\mathrm{dMn}>20 \mathrm{nM}$ ) and preconcentration (used for $\mathrm{dAl}<70 \mathrm{nM}$ and $\mathrm{dMn}<20 \mathrm{nM}$ ) methods for $\mathrm{dMn}$ (Table 3). Dissolved Al values are not published for these materials, so the accuracy of our $\mathrm{dAl}$ values is somewhat uncertain. However, our dAl values fell within the ranges observed in the NGA by Brown et al. (2010), and the overall seasonal and spatial patterns were oceanographically consistent. Measurements of dAl were less precise (median RSD 11.4\%) than dMn (median RSD 2.2\%) with the preconcentration method due to interactions of $\mathrm{dAl}$ with the resin. On the other hand, measurements for $\mathrm{dAl}$ were more precise $(6.1 \%)$ than $\mathrm{dMn}(9.2 \%)$ when using the dilution method. This is likely due to the lower values of $\mathrm{dMn}$ ( $\sim 10$ fold lower than $\mathrm{dAl}$ values) being assessed using the dilution method. The dilution method was faster and simpler than the preconcentration method, and was appropriate for the exceedingly high concentrations of these metals present within ACC waters, especially in summer and fall along the Seward and Middleton Lines. Although the preconcentration method was more labor-intensive and time consuming, it was essential for the determination of low trace metal values found over much of the study region. Greater preconcentration times will be needed to determine truly oceanic concentrations of $\mathrm{dAl}$ and $\mathrm{dMn}$ in the North Pacific. 
Having two analytical methods allowed for the determination of seasonal and spatial patterns of surface $\mathrm{dAl}$ and $\mathrm{dMn}$ distributions across the NGA LTER site. Seasonal sampling allowed us to determine that the distribution of these metals mirror glacial melt cycles in inshore waters, with the highest values in late summer/early fall and the lowest values in spring. Both metals showed clear seasonal patterns along all transects, but most significantly along the Seward and Middleton Lines, which are more heavily impacted by freshwater discharge. On these transects, seasonal concentrations could vary by 1-2 orders of magnitude whereas along the KOD Line, which is the least impacted by freshwater input, the seasonal signal in nearshore waters was less intense, with concentrations doubling between spring/summer and fall. Inshoreoffshore gradients were observed on all seasons and in all regions, with concentrations varying by 1-3 orders of magnitude between nearshore and offshore waters, depending on the metal and the season. This is the first seasonal study of these two metals in the NGA and our results, specifically the correlations with salinity, indicate that $\mathrm{dAl}$ and $\mathrm{dMn}$ are good tracers of freshwater discharge in this region.

Our Copper River plume study carried out in summer 2019 allowed us to investigate an area of the shelf near the river outflow that was much larger than just the inshore section of the MID Line, and the five-day study was concurrent with the highest river discharge observed in 2019 (Fig. 17). While dAl and dMn were tightly coupled throughout the plume study (Fig. 38), many mid-salinity (25-29) samples showed elevated dAl and dMn relative to salinity (Figs. 20 and 21). These elevated values are likely due to continued desorption from the high particle load carried in Copper River water as plume waters enter the NGA, spread, and begin to age. They may also be a result of enhanced vertical mixing over Tar Bank and the shoals around Kayak and Middleton Islands. If we had only sampled the MID Line, these trends may not have been apparent. Comparison to past plume studies in the GOA (Brown et al. 2010) as well as plume studies in temperate regions, such as the Pacific Northwest (Aguilar-Islas and Bruland 2006) and the East China Sea (Ren et al. 2006) also emphasize the high dAl content in glacial Alaskan rivers. This is a result of intense physical weathering of aluminosilicate materials within the GOA watershed (Spotila et al. 2004).

While large rivers such as the Copper River and the Alsek River are considered major sources of trace metals due to high amounts of glacial flour and low amounts of organic materials that can lead to removal processes such as flocculation, we recommend future work to 
look at smaller creeks in the region whose impact has yet to be quantified to the same degree. Future studies could investigate their freshwater signatures, potential tracers for their signatures, and their contribution to trace metals in the NGA.

In addition to surface transects, six vertical profiles from shelf stations were analyzed in this study. Many profiles showed typical $\mathrm{dAl}$ and $\mathrm{dMn}$ distributions throughout the water column, with a surface maximum due to external (freshwater) inputs, rapid decreases with depth due to particle scavenging, and occasionally an increase at the bottom, potentially due to sediment resuspension (Orians and Bruland 1985). However, most notably at Station KOD5, both spring 2018 and summer 2019 dMn profiles indicated vertical mixing (Fig. 23). This station is located over North Albatross Bank, a shallow area where enhanced vertical mixing has been observed (Cheng et al. 2012). This also led to enhanced trace metal values over Albatross Bank (Fig. 8), in contrast to the general inshore-offshore gradient observed in other seasons and in other areas. Subsurface inputs of $\mathrm{dAl}$ and $\mathrm{dMn}$ also indicate areas where subsurface inputs of $\mathrm{dFe}$ might be relevant, especially as $\mathrm{dMn}$ and $\mathrm{dFe}$ can both be produced in sub/anoxic sediments via reductive dissolution (Froelich et al. 1979). Future studies in the NGA could also investigate these alternative sources of trace metals, and their spatial and seasonal patterns.

This study allows us to conceptualize the important processes that determine distributions of $\mathrm{dAl}, \mathrm{dMn}$, and $\mathrm{dFe}$ throughout the water column (Fig. 44). In the NGA, major rivers such as the Copper River are a source of both particulate and dissolved phases. Dust (aeolian) input can also act as a source of particles to surface waters. These terrigenous particles, as well as biogenic particles produced by phytoplankton, can be solubilized to produce dissolved $\mathrm{Al}, \mathrm{Mn}$, and/or Fe. Particles can also act as a sink for the dissolved phase by scavenging them, and these solubilization/scavenging processes can occur throughout the water column as the particles settle. Remineralization can also occur as particles settle, acting as a deeper source of dissolved trace metals. At the bottom of the water column, sediment resuspension (nepheloid layers) can provide a deep source of particles and thus dissolved trace metals. Processes that impact only $\mathrm{dMn}$ and $\mathrm{dFe}$ include reductive dissolution both at the ocean surface (photoreduction of particles) and at depth (anaerobic respiration in sub/anoxic sediments, producing $\mathrm{dMn}$ and $\mathrm{dFe}$ that can flux back into the water column), and biological uptake by phytoplankton. Finally, vertical mixing can re-distribute $\mathrm{dAl}, \mathrm{dMn}$, and $\mathrm{dFe}$ throughout the water column. 


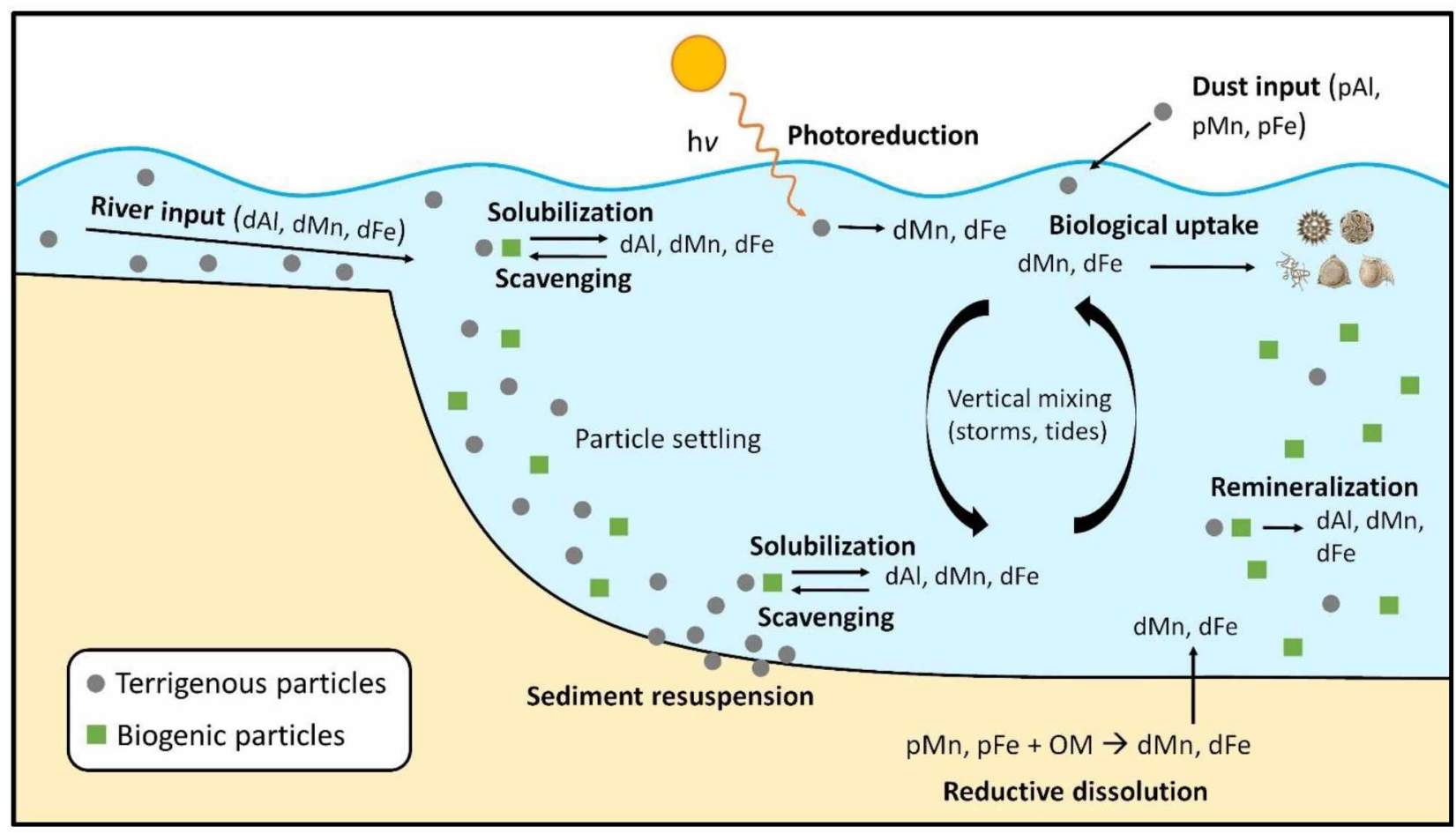

Figure 44: Diagram illustrating processes affecting $\mathrm{dAl}, \mathrm{dMn}$, and $\mathrm{dFe}$ distributions throughout the water column. 
References

Aguilar-Islas, A. M., and Bruland, K. W., 2006. Dissolved manganese and silicic acid in the Columbia River plume: a major source to the California current and coastal waters off Washington and Oregon. Marine Chemistry 101, 233-247.

Ahlnas, K., Royer, T. C., and George, T. H., 1987. Multiple Dipole Eddies in the Alaska Coastal Current Detected With Landsat Thematic Mapper Data. Journal of Geophysical Research 92(C12), 13041-13047.

Beamer, J. P., Hill, D. F., Arendt, A., and Liston, G. E., 2016. High-resolution modeling of coastal freshwater discharge and glacier mass balance in the Gulf of Alaska watershed. Ware Resources Research 52, 3888-3909.

Boyle, E. A., Sclater, F. R., and Edmond, J. M., 1977. The distribution of dissolved copper in the Pacific. Earth and Planetary Science Letters 37, 38-54.

Brabets, T. P., 1996. Geomorphology of the Lower Copper River, Alaska. U.S. Geological Survey Open-File Report 96-500.

Brown, M. T., Lippiatt, S. M., and Bruland, K. W., 2010. Dissolved aluminum, particulate aluminum, and silicic acid in the northern Gulf of Alaska coastal waters: glacial/riverine inputs and extreme reactivity. Marine Chemistry 122, 160-175.

Byrne, R.H., Kump, L. R., and Cantrell, K. J., 1988. The influence of temperature and pH on trace metal speciation in seawater. Marine Chemistry 25, 163-181.

Cain, A. N., 2014. Dissolved Aluminum in the Northeast Pacific and the Western Arctic Ocean. Master's thesis, University of British Columbia.

Coale, K. H., and Bruland, K. W., 1985. ${ }^{234}$ Th: ${ }^{238} \mathrm{U}$ disequilibria within the California Current. Limnology and Oceanography 30, 22-33.

De Jong, J. T. M., Boye, M., Gelado-Caballero, M. D., Timmermans, K. R., Veldhuis, M. J. W., Nolting, R. F., van den Berg, C. M. G., and de Baar, H. J. W., 2007. Inputs of iron, manganese and aluminium to surface waters of the Northeast Atlantic Ocean and the European continental shelf. Marine Chemistry 107, 120-142.

DeMaster, D. J., 2001. Marine silica cycle. In: Encyclopedia of Ocean Sciences, Vol. 3 (Steele, J. H., Turekian, K. K., and Thorpe, S. A., eds.), 1659-1667, Academic Press, London.

Gehlen, M., Beck, L., Calas, G., Flank, A. M., Van Bennekom, A. J., and Van Beusekom J. E. E., 2002. Unraveling the atomic structure of biogenic silica: evidence of the structural association of $\mathrm{Al}$ and $\mathrm{Si}$ in diatom frustules. Geochimica et Cosmochimica Acta 66, 1601-1609. 
Han, Q., Moore, J. K., Zender, C., Measures, C., and Hydes, D., 2008. Constraining oceanic dust deposition using surface ocean dissolved Al. Global Biogeochemical Cycles 22, GB2003.

Hatta, M., Measures, C. I., Wu, J., Roshan, S., Fitzsimmons, J. N., Sedwick, P., and Morton, P., 2015. An overview of dissolved $\mathrm{Fe}$ and Mn distributions during the 2010-2011 U.S. GEOTRACES north Atlantic cruises: GEOTRACES GA03. Deep-Sea Research II 116, $117-129$.

Hill, D. F., Bruhis, N., Calos, S. E., Arendt, A., and Beamer, J., 2015. Spatial and temporal variability of freshwater discharge into the Gulf of Alaska. Journal of Geophysical Research: Oceans 120, 634-646.

Hopcroft, R. R., Aguilar-Islas, A. M., Danielson, S. L., Fiechter, J., and Strom, S. L., 2016. LTER: Resilience in the Environmental Mosaic of the Northern Gulf of Alaska (NGA) Shelf Ecosystem. NSF Proposal.

Hydes, D. J. and Liss, P. S., 1977. The behaviour of dissolved aluminium in estuarine and coastal waters. Estuarine and Coastal Marine Science 5, 755-769.

Hydes, D. J., 1979. Aluminum in seawater: control by inorganic processes. Science 205, 12601262.

Jahn, R., Herrmann, L., and Stahr, K., 1996. Die Bedeutung äolischer Einträge für Bodenbildung und Standorteigenschaften im circumsaharischen Raum. Zentralblatt für Geologie und Paläontologie, Teil I, 421-432.

Jones, M. R., Luther III, G. W., and Tebo, B. M., 2020. Distribution and concentration of soluble manganese(II), soluble reactive $\mathrm{Mn}(\mathrm{III})-\mathrm{L}$, and particulate $\mathrm{MnO}_{2}$ in the Northwest Atlantic Ocean. Marine Chemistry 226, 103858.

Koning, E., Gehlen, M., Flank, A. M., Calas, G., and Epping, E., 2007. Rapid post-mortem incorporation of aluminum in diatom frustules: evidence from chemical and structural analyses. Marine Chemistry 106, 208-222.

Lagerloef, G. S. E., 1995. Interdecadal Variations in the Alaska Gyre. Journal of Physical Oceanography $25,2242-2258$.

Landing, W. M., and Bruland, K. W., 1980. Manganese in the North Pacific. Earth and Planetary Science Letters 49, 45-56.

Maring, H. B. and Duce, R. A., 1987. The impact of atmospheric aerosols on trace metal chemistry in open ocean surface seawater, 1. Aluminum. Earth and Planetary Science Letters 84, 381-392.

Martin, J. H. and Knauer, G. A., 1984. VERTEX: manganese transport through oxygen minima. Earth and Planetary Science Letters 67, 35-47. 
Martin, J. H., Gordon, R. M., and Fitzwater, S. E., 1991. The case for iron. Limnology and Oceanography 36, 1793-1802.

Martin, J. M. and Whitfield, M., 1983. River input of trace elements to the ocean. In Trace Metals in Sea Water (ed. Wong, C. S.), pp. 265-296. Plenum Press, New York.

Measures, C. I. and Brown, E. T., 1996. Estimating dust input to the Atlantic Ocean using surface water aluminium concentrations. In: Guerzoni, S., Chester R. (eds) The Impact of Desert Dust Across the Mediterranean. Environmental Science and Technology Library, vol 11. Springer, Dordrecht.

Measures, C. I. and Vink, S., 2000. On the use of dissolved aluminum in surface waters to estimate dust deposition to the ocean. Global Biogeochemical Cycles 14, 317-327.

Middag, R., de Baar, H. J. W., Laan, P., and Bakker, K., 2009. Dissolved aluminium and the silicon cycle in the Arctic Ocean. Marine Chemistry 115, 176-195.

Moore, R. M. and Millward, G. E., 1984. Dissolved-particulate interactions of aluminium in ocean waters. Geochimica et Cosmochimica Acta 48, 235-241.

Nash, J. D., and Mourn, J. N., 2005. River plumes as a source of large-amplitude internal waves in the coastal ocean. Nature 437, 400-403.

Neal, E. G., Hood, E., and Smikrud, K., 2010. Contribution of glacier runoff to freshwater discharge into the Gulf of Alaska. Geophysical Research Letters 37, L06404.

Orians, K. J. and Bruland, K. W., 1985. Dissolved aluminium in the central North Pacific. Nature $316,427-429$.

Orians, K. J. and Bruland, K. W., 1986. The biogeochemistry of aluminum in the Pacific Ocean. Earth and Planetary Science Letters 78, 397-410.

Peers, G. and Price, N. M., 2004. A role for manganese in superoxide dismutases and growth of Iron-deficient diatoms. Limnology and Oceanography 49, 1774-1783.

Raven, J. A., 1990. Predictions of Mn and Fe use efficiencies of phototrophic growth as a function of light availability for growth and of $\mathrm{C}$ assimilation pathway. New Phytologist $116,1-18$.

Ren, J. L., Zhang, J., Li, J. B., Yu, X. Y., Liu, S. M., and Zhang, E. R., 2006. Dissolved aluminum in the Yellow Sea and East China Sea - Al as a tracer of Changjiang (Yangtze River) discharge and Kuroshio incursion. Estuarine, Coastal and Shelf Science 68, 165 174.

Ren, H., Brunelle, B. G., Sigman, D. M., and Robinson, R. S., 2013. Diagenetic aluminum uptake into diatom frustules and the preservation of diatom-bound organic nitrogen. Marine Chemistry 155, 92-101. 
Royer, T. C., 1975. Seasonal variations of waters in the northern Gulf of Alaska. Deep-Sea Research 22, 403-416.

Royer, T. C., 1981. Baroclinic transport in the Gulf of Alaska Part II. A fresh water driven coastal current. Journal of Marine Research 39, 251-266.

Royer, T. C. and Emery, W. J., 1987. Circulation in the Gulf of Alaska, 1981. Deep-Sea Research Part A. Oceanographic Research Papers 34, 1361-1377.

Rutgers Van Def Loeff, M. M., Meadows, P. S., and Allen, J. A., 1990. Oxygen in pore waters of deep-sea sediments. Philosophical Transactions of the Royal Society of London. Series A, Mathematical and Physical Sciences 331, 69-84.

Schumacher, J. D., Stabeno, P. J., and Roach, A. T., 1989. Volume transport in the Alaska Coastal Current. Continental Shelf Research 9, 1071-1083.

Stabeno, P. J., Bond, N. A., Hermann, A. J., Kachel, N. B., Mordy, C. W., and Overland, J. E., 2004. Meteorology and oceanography of the Northern Gulf of Alaska. Continental Shelf Research 24, 859-897.

Stabeno, P. J., Bond, N. A., Kachel, N. B., Ladd, C., Mordy, C. W., and Strom, S. L., 2016. Southeast Alaskan shelf from southern tip of Baranof Island to Kayak Island: currents, mixing, and chlorophyll-a. Deep-Sea Research II 132, 6-23.

Strom, S. L., Olson, M. B., Macri, E. L., and Mordy, C. W., 2006. Cross-shelf gradients in phytoplankton community structure, nutrient utilization, and growth rate in the coastal Gulf of Alaska. Marine Ecology Progress Series 328, 75-92.

Sunda, W. G. and Huntsman, S. A., 1988. Effect of sunlight on redox cycles of manganese in the southwestern Sargasso Sea. Deep-Sea Research 35, 1297-1317.

Sunda, W. G. and Huntsman, S. A., 1994. Photoreduction of manganese oxides in seawater. Marine Chemistry 46, 133-152.

Taylor, S. R., 1964. Abundance of chemical elements in the crust: a new table. Geochimica et Cosmochimica Acta 28, 1273-1285.

Twining, B. S., and Baines, S. B., 2013. The trace metal composition of marine phytoplankton. Annual Review of Marine Science 5, 191-215.

Wedepohl, K. H., 1995. The composition of the continental crust. Geochimica et Cosmochimica Acta 59, 1217-1232.

Weingartner, T. J., Danielson, S. L., and Royer, T. C., 2005. Freshwater variability and predictability in the Alaska Coastal Current. Deep Sea Research II: Topical Studies in Oceanography 52, 169-191. 
Williams, W. J., Weingartner, T. J., and Hermann, A. J., 2007. Idealized three-dimensional modeling of seasonal variation in the Alaska Coastal Current. Journal of Geophysical Research 112, C07001.

Wolfe-Simon, F., Starovoytov, V., Reinfelder, J. R., Schofield, O., and Falkowski, P. G., 2006. Localization and role of manganese superoxide dismutase in a marine diatom. Plant Physiology 142, 1701-1709. 